\title{
Cobra-SFS Predictions of Single Assembly Spent Fuel Heat Transfer Data
}
N. J. Lombardo
T. E. Michener
C. L. Wheeler
D. R. Rector

April 1986

Prepared for the U.S. Department of Energy under Contract DE-AC06-76RLO 1830

Pacific Northwest Laboratory Operated for the U.S. Department of Energy by Battelle Memorial Institute 


\title{
DISCLAIMER
}

This report was prepared as an account of work sponsored by an agency of the United States Government. Neither the United States Government nor any agency thereof, nor any of their employees, makes any warranty, express or implied, or assumes any legal liability or responsibility for the accuracy, completeness, or usefulness of any information, apparatus, product, or process disclosed, or represents that its use would not infringe privately owned rights. Reference herein to any specific commercial product, process, or service by trade name, trademark, manufacturer, or otherwise, does not necessarily constitute or imply its endorsement, recommendation, or favoring by the United States Government or any agency thereof. The views and opinions of authors expressed herein do not necessarily state or reflect those of the United States Government or any agency thereof.

\author{
PACIFIC NORTHWEST LABORATORY \\ operated by \\ BATTELLE \\ for the \\ UNITED STATES DEPARTMENT OF ENERGY \\ under Contract DE-AC06-76RLO 1830
}

\begin{tabular}{|c|c|}
\hline \multirow{2}{*}{\multicolumn{2}{|c|}{ Printed in the United States of America }} \\
\hline & \\
\hline \multicolumn{2}{|c|}{$\begin{array}{l}\text { Available from } \\
\text { National Technical Information Service }\end{array}$} \\
\hline \multicolumn{2}{|c|}{ United States Department of Commerce } \\
\hline \multicolumn{2}{|c|}{5285 Port Royal Road } \\
\hline \multicolumn{2}{|c|}{ Springfield, Virginia 22161} \\
\hline \multirow{2}{*}{\multicolumn{2}{|c|}{$\begin{array}{l}\text { NTIS Price Codes } \\
\text { Microfiche A01 }\end{array}$}} \\
\hline & \\
\hline \multicolumn{2}{|c|}{ Printed Copy } \\
\hline & Price \\
\hline Pages & Codes \\
\hline 001-025 & $\wedge 02$ \\
\hline 026-050 & $\mathrm{A} 03$ \\
\hline $051-075$ & A04 \\
\hline $076-100$ & A05 \\
\hline $101-125$ & A06 \\
\hline $126-150$ & A07 \\
\hline $151-175$ & $A 06$ \\
\hline $176-200$ & $\mathrm{~A} 09$ \\
\hline $201-225$ & A010 \\
\hline $226-250$ & A011 \\
\hline $251-275$ & A012 \\
\hline $276-300$ & $A 013$ \\
\hline
\end{tabular}




\section{9}

PNL-5781

UC -85

COBRA-SFS PREDICTIONS OF SINGLE

ASSEMBLY SPENT FUEL HEAT

TRANSFER DATA

N. J. Lombardo

T. E. Michener

C. L. Wheeler

D. R. Rector

Apri] 1986

Prepared for

the U.S. Department of Energy

under Contract DE-AC06-76RLO 1830

Pacific Northwest Laboratory

Richland, Washington 99352 


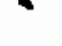




\section{ACKNOWLEDGMENTS}

The authors would like to thank the U. S. Department of Energy and the Monitored Retrievable Storage Program Office for the opportunity to perform this work. Additional thanks are extended to Dr. Dennis Kreid of the Monitored Retrievable Storage Program office and Mr. Jim Creer of the Commercial Spent Fuel Management Program/Dry Storage System Performance Evaluation Project for their support and insight. Special thanks also goes to Mr. Jim Bates for his dedication and hard work in performing and reporting the tests described in this document. Finally, thanks to E. D. Barajas for assistance in the data reduction, and to E. C. Darby for preparation of the manuscript. 


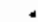

$$
\text { - }
$$

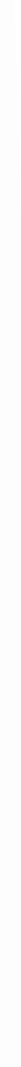


CONTENTS

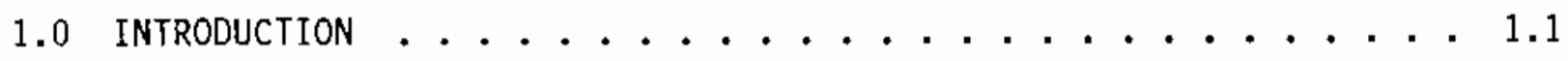

2.0 CDNCLUSIONS AND RECOMMENDATIONS .................... 2.1

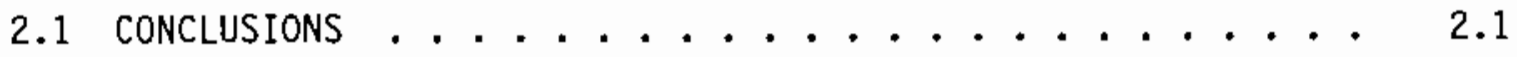

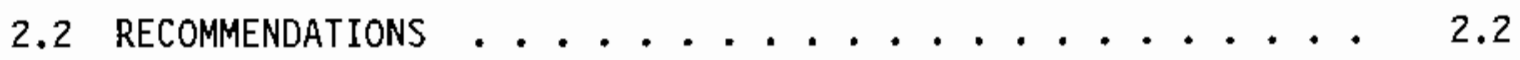

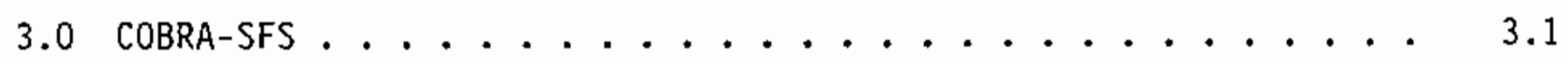

3.1 COBRA-SFS DESCRIPTIDN $\ldots \ldots \ldots \ldots \ldots . \ldots . \ldots . \ldots . \ldots$

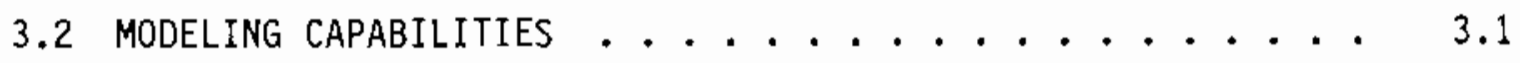

3.3 COMPUTATIONAL PHILOSOPHY . . . . . . . . . 3.2

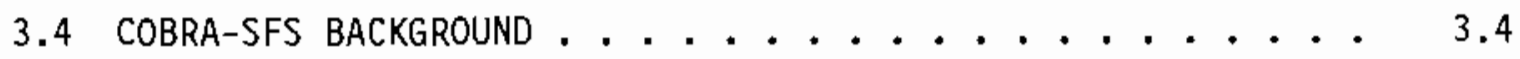

4.0 PWR SINGLE ASSEMBLY SPENT FUEL TESTS . . . . . . . . . . 4.1

4.1 TEST DESCRIPTION .......................... 4.1

4.2 COMPUTATIONAL MODEL DESCRIPTION $\ldots \ldots \ldots . \ldots . \ldots . \ldots$

4.2 .1 Nodal Representation .............. 4.8

4.2.2 Modeling Parameters and Correlations ...... 4.10

4.2 .3 Modeling Uncertainties .............. 4.11

4.3 COMPARISONS OF PREDICTIONS TO DATA . . . . . . . . 4.13

4.3.1 Prelook Predictions............. 4. 4.13

4.3.1.1 Helium Backfill Results ......... . 4.17

4.3.1.2 Air Backfill Results ........... 4.21

4.3.1.3 Vacuum Results............ 4.22

4.3.2 Post-Test Refinements ............ 4.23

4.3 .3 Post-Test Predictions ........... 4.23 
5.0 ELECTRICALLY HEATED PWR SINGLE ASSEMBLY SPENT FUEL TEST $\ldots \ldots$.

5.1 TEST DESCRIPTION . . . . . . . . . . . . 5.1

5.2 COMPUTATIONAL MODEL DESCRIPTION ............ 5.7

5.2.1 Nodal Representation ........... 5.7

5.2.2 Modeling Parameterș and Correlations ...... 5.10

5.2.3 Modeling Uncertainties .......... 5.12

5.3 COMPARISONS OF PREDICTIONS TO DATA . . . . . . . 5.15

5.3.1 Prelook Predictions ............ 5.15

5.3.1.1 Vertical Orientation Results........ 5.21

5.3.1.2 Horizontal Orientation Results...... 5.24

5.3.1.3 Inclined Orientation Results . . . . . 5.25

5.3.2 Post-Test Refinements ........... 5. 5.26

5.3.3 Post-Test Predictions ............ 5. . 5.26

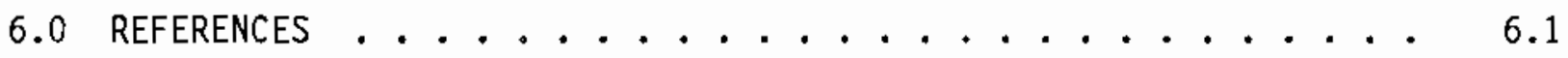

APPENDIX A - SAMPLE COBRA-SFS INPUT FOR THE PWR SINGLE ASSEMBLY SPENT

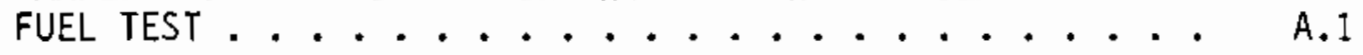

APPENDIX B - PWR SINGLE ASSEMBLY SPENT FUEL TEST PREDICTED AND

EXPERIMENTAL AXIAL PROFILES ........... B. 1

APPENDIX C - SAMPLE COBRA-SFS INPUT FOR THE ELECTRICALLY HEATEO PWR

SINGLE ASSEMBLY SPENT FUEL TEST . ............... c.

APPENDIX D - ELECTRICALLY HEATED PWR SINGLE ASSEMBLY SPENT FUEL TEST

PREDICTED AND EXPERIMENTAL AXIAL PROFILES ....... .1 


\section{FIGURES}

1.1 Post-Test Predicted and Experimental Axial Profiles: Rod No. 1, PWR Single Assembly Test ... . . . . . . . . . . . . . . . xV

1.2 Post-Test Predicted and Experimental Results: Rod 9H, $1.0 \mathrm{~kW}$, Vertical Orientation, Electrically Heated PWR Single Assembly Test xvii

3.1 Relation of Subchannel Control Volume to a Storage System . . . 3.4

4.1 PWR Single Assembly Spent Fuel Test Apparatus . . . . . . . . 4.2

4.2 Assumed Axial Power Profile for a PWR Spent Fuel Assembly . . . 4.5

4.3 Test Assembly Axial Profile and Thermocouple Locations . . . . 4.6

4.4 Cross Sectional View of Fuel Assembly and Canister. . . . . 4.7

4.5 Cross Section of COBRA-SFS Prelook Computational Model for the PWR Single Assembly Test . . . . . . . . . . . . . 4.9

4.6 Predicted and Experimental Axial Profiles: Helium Case, Rod No. 1, PWR Single Assembly Test . . . . . . . . . 4.14

4.7 Predicted and Experimental Axial Profiles: Air Case, Rod No. 1, PWR Single Assembly Test ................ . . 4.15

4.8 Predicted and Experimental Axial Profiles: Vacuum Case, Rod No. 1, PWR Single Assembly Test ........... . 4.16

4.9 Predicted and Experimental Radial Profiles at Elevation $185 \mathrm{~cm}$ : Helium Backfill, PWR Single Assembly Test . . . . . . . . 4 4.18

4.10 Predicted and Experimental Radial Profiles at Elevation $185 \mathrm{~cm}$ : Air Backfill, PWR Single Assembly Test .......... 4.19

4.11 Predicted and Experimental Radial Profiles at Elevation $185 \mathrm{~cm}$ : Vacuum Backfill, PWR Single Assembly Test . . . . . . . 4.20

4.12 Cross Section of COBRA-SFS Post-Test Computational Model for the PWR Single Assembly Test . . . . . . . . . . . . 4.24

5.1 Electrically Heated PWR Single Assembly Test Apparatus . . . . 5.2

5.2 Cross Sectional View of Electrically Heated Single Assembly Test Section . . . . . . . . . . . . . . . . . . . . 
5.3 Fuel-Tube Transition Piece . . . . . . . . . 5.6

5.4 Cross Section of COBRA-SFS Prelook Computational Model for Electrically Heated PWR Single Assembly Test . . . . . . . 5.8

5.5 Prelook Predicted and Experimental Axial Profiles: $1.0 \mathrm{~kW}$, Vertica1, Helium Run, Electrically Heated PWR Single Assembly

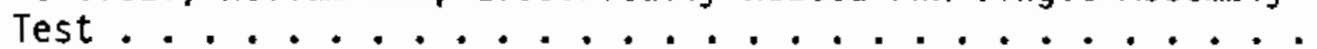

5.6 Prelook Predicted and Experimental Axial Profiles: $1.0 \mathrm{~kW}$, Vertical, Air Run, Electrically Heated PWR Single Assembly Test 5.17

5.7 Prelook Predicted and Experimental Axial Profiles: $1.0 \mathrm{~kW}$, Vertical, Vacuum Run, Electrically Heated PWR Single Assembly

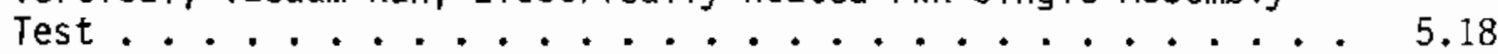

5.8 Prelook Predicted and Experimental Axial Profiles: $1.0 \mathrm{~kW}$, Horizontal, Air Run, Electrically Heated PWR Single

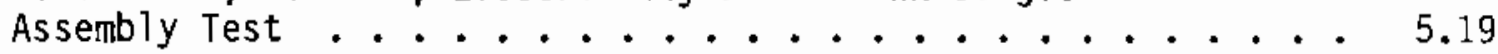

5.9 Prelook Predicted and Experimental Axial Profiles: $1.0 \mathrm{~kW}$, Inclined, Air Run, Electrically Heated PWR Single Assembly Test ................ 5.20

5.10 Post-Test Predicted and Experimental Axial Profiles: $0.5 \mathrm{~kW}$, Vertical, Vacuum Run, Electrically Heated PWR Single Assembly

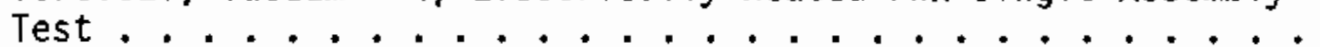

5.11 Post-Test Predicted and Experimental Axial Profiles: $1.0 \mathrm{~kW}$, Vertical, Vacuum Run, Electrically Heated PWR Single Assembly Test ....................

5.12 Post-Test Predicted and Experimental Axial Profiles: $1.0 \mathrm{~kW}$, Vertical, Helium Run, Electrically Heated PWR Single Assembly Test.................. 5.30

5.13 Post-Test Predicted and Experimental Axial Profiles: $1.0 \mathrm{~kW}$, Vertical, Air Run, Electrically Heated PWR Single Assembly

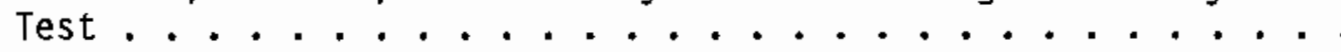

5.14 Predicted and Experimental Radial Profiles at Elevation $275 \mathrm{~cm}$ : $1.0 \mathrm{~kW}$, Vertical, Helium Case, Electrically Heated PWR Single

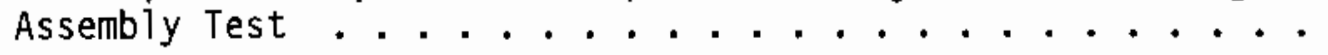

5.15 Predicted and Experimental Radial Profiles at Elevation $275 \mathrm{~cm}$ : $1.0 \mathrm{~kW}$, Vertical, Air Case, Electrically Heated PWR Singie Assembily Test 
5.16 Predicted and Experimental Radial Profiles at Elevation $275 \mathrm{~cm}$ : $1.0 \mathrm{~kW}$, Vertical, Vacuum Case, Electrically Heated PWR Single Assembly Test ........................... 54 
TABLES

3.1 COBRA-SFS Capabilities and Limitations . . . . . . . . 3.3

4.1 Turkey Point No. 3 PWR Fuel Assembly Parameters . . . . . . . 4.3

5.1 Electrically Heated PWR Single Assembly Test Matrix . . . . . . 5.6 


\section{EXECUTIVE SUMMARY}

The study reported here is one of several efforts to evaluate and qualify the COBRA-SFS computer code for use in spent fuel storage system thermal analysis. The ability of COBRA-SFS to predict the thermal response of two single assembly spent fuel heat transfer tests was investigated through comparisons of predictions with experimental test data. From these comparisons, conclusions regarding the computational treatment of the physical phenomena occurring within a storage system can be made. This objective was successfully accomplished as reasonable agreement between predictions and data were obtained for the 21 individual test cases of the two experiments.

\section{THE COBRA-SFS CODE}

The COBRA-SFS (Spent Fuel Storage) computer code is a steady-state, lumpedparameter, finite-difference code which predicts flow and temperature distributions in spent fuel storage systems. COBRA-SFS provides solutions to the equations governing mass, momentum, and energy conservation for singlephase incompressible flows. Analyses are conducted using a subchannel approach which allows effective simulation of a wide variety of complex geometries. Most importantly, COBRA-SFS predicts recirculating flows, and includes models for conduction and radiation heat transfer.

COBRA-SFS allows for simulation of a wide range of storage systems via input instructions. In addition to the single assembly analyses described in this report, applications have included analyses of multiple spent fuel storage systems under a variety of fill media and cask orientations, and analyses of both single- and multiassembly consolidated storage systems. A summary of COBRA-SFS-computed results for the two single assembly spent fuel heat transfer tests is presented below. 


\section{ANALYSIS OF THE SINGLE ASSEMBLY HEAT TRANSFER TEST}

The initial test that was modeled was the PWR Single Assembly Spent Fuel Heat Transfer Test. In this first test, an actual PWR spent fuel assembly was placed within a simulated storage cask. This allowed for testing with different types of fill media (air, helium, and a vacuum). To simulate thermal conditions similar to a multiassembly storage cask, the outer surface of the test cask was trace-heated to maintain a fixed, elevated wall temperature. Axial temperature gradients at several radial positions were obtained in the three different fill media to determine the fuel assembly thermal response. Al1 tests were performed in the vertical orientation.

Pre-Test Analyses

Using information obtained from the test designers, a one-eighth sector COBRA-SFS model of the test apparatus was created. Boundary temperature data and the fuel assembly decay heat rate data were made available as input for the COBRA-SFS model. Without prior knowledge of the data, "prelook predictions" were made for each of the three fill media. The term prelook simply means that predictions were made without prior knowledge of the experimental results. Comparisons of the prelook predictions with the data were then made to identify deficiencies in the simulated cask or code thermal hydraulic models.

Several areas of code model improvements were identified from these comparisons. The vacuum case, which was dominated by radiation heat transfer identified a deficiency in the rod-to-rod radiation heat transfer model. In creating the initial rod-to-rod radiation exchange factors, uniform radiosity over the entire fuel surface was assumed. This approach tended to produce calculated peak surface temperatures consistently lower than measured. To remove the assumption of uniform radiosity, the fuel rod surface was divided into four discrete surfaces when computing rod-rod radiation exchange factors for the post-test simulations. This substantially improved the agreement with data.

Comparisons of predicted rod-to-rod temperature differences for the three fill media did not show the reduction in rod temperature difference expected 
for the high conductivity helium gas. This result was attributed to the symmetric rod heat flux model used in the prelook version of the code. The rod-to-coolant heat transfer model was therefore reformulated so that an asymetric rod-to-fluid heat transfer model was used in the post-test simulations. The effect of this code modification was to flatten the predicted temperature gradient throughout the fuel assembly, thereby providing better agreement with the data trend.

Prelook comparisons of computed and experimental results for the air backfill case showed somewhat different axial temperature profiles. These differences were attributed to inadequate modeling of convection within the cask. Since the major differences were observed in the lower elevations, it was concluded that the calculated circulating flow rate is larger than that in the test assembly. A larger than real flow rate tends to transfer more energy to the downcomer near the top of the assemblies. This increases the overall efficiency of energy transport to the environment, so the average temperature of the model assembly is less than that of the test assembly. A new friction factor for the fuel was adopted for the post-test simulations which better accounts for the effect of the neighboring fuel rods on the flow field. The new correlation increased the wall friction by $50 \%$ resulting in lower overall convection within the cask.

\section{Post-Test Analysis}

In the post-test analysis, the separate effects of refinements in the fuel rod radiosity, asymmetric rod-to-fluid heat transfer, and system friction were combined and the computed results again compared to data. The change in the rod-to-fluid heat transfer model required changes to the code; all other modifications were made via changes in input. Representative post-test predicted axial temperature profiles for the center rod are plotted with the experimental test data in Figure 1.1 as a function of elevation from the cask bottom for the three fill media cases. For all media excellent agreement between peak temperature predictions was observed, with an estimated difference of $\pm 3^{\circ} \mathrm{C}$. The good agreement supports the post-test modifications made to the 
input and code models. Some disagreement in the post-test data comparisons was still observed in the upper elevations of the test assembly. The remaining differences in temperatures were attributed to the unmodeled effects of a tubular heater located on the test canister upper lid. Although not shown in the center rod temperature profiles displayed in Figure 1.1, some differences also remain in the outer rod post-test vacuum results. The unmodeled radiation shielding effects of the fuel assembly support cage is thought to be responsible for the disagreement in the radiation heat transfer dominated vacuum run.

\section{ANALYSIS OF THE ELECTRICALLY HEATED ASSEMBLY TEST}

The second test utilized from the spent fuel heat transfer data base for qualification of COBRA-SFS was the Electrically Heated PWR Single Assembly Test. In this extensive series of tests (18 total) the effects of fill media (air, helium, and vacuum), test assembly power level (0.5 and $1.0 \mathrm{~kW}$ ), and cask orientation (vertical, horizontal, and inclined) were examined for an electrically heated mode? PWR fuel assembly. Again, the cask outer surface was trace-heated to simulate thermal conditions similar to a multiassembly storage cask. To determine the. model fuel assembly thermal response, axial temperature data were obtained at several radial positions.

A full three-dimensional COBRA-SFS model of the test apparatus was produced from existing design information. Measured power level and boundary temperature data for each test were provided as input to the model. "Prelook" predictions for the 18 test cases were then performed. Comparisons of predictions with data were made to identify refinements in the input or code models as was done for the first test case discussed above.

\section{Prelook Comparisons}

A review of the data and code predictions for the 18 cases showed that the code consistently overpredicted the temperature data at the inner radial locations in the cask, with better agreement observed in the low power cases. For all runs, the temperature drop from the fuel tube-to-cask wall was overpredicted. The overprediction of temperature at the other radial locations 


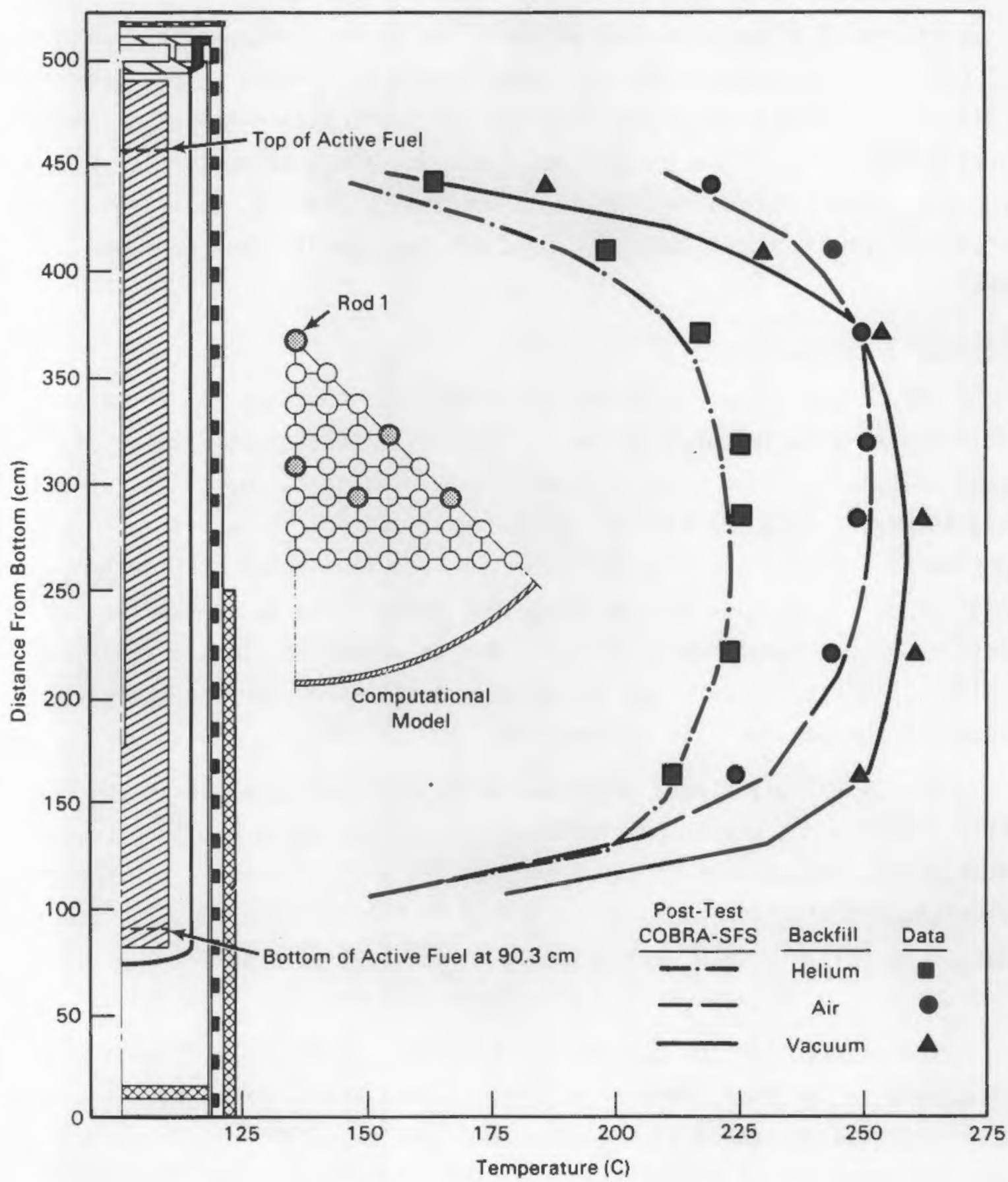

EIGURE 1.1. Post-Test Predicted and Experimental Axial Profiles: Rod No. 1, PWR Single Assembly Test 
was attributed to this overpredicted temperature difference. The largest overprediction was in the horizontal cases, which results from the simplifying assumptions of a centered fuel assembly (no contact with walls) and the elimination of buoyancy effects. Very little difference in peak temperature data was observed between the vertical and horizontal orientations because fuel assembly/fuel tube contact was 1 imited. (Fuel assembly/fuel tube contact has been shown to provide significant thermal benefit.) This trend was correctly predicted by COBRA-SFS, and was observed for the inclined runs as well.

\section{Post-Test Comparisons}

The consistent overprediction of fuel tube to cask wall temperature difference was attributed to the uncertainty in the assumed value of the fuel tube emissivity. The fuel tube emissivity used in the post-test simulations was increased from 0.2 to 0.25 , a value well within the uncertainty of this parameter. Modification to an asymmetric rod-fluid heat transfer model was again made in the code for the post-test predictions as it was for the first test case discussed above. The need for this modification is evidenced by the uniform predicted rod-to-rod temperature differences for the three fill media shown in the prelook data comparisons.

Four simulations were repeated in the post-test analyses: the three fill media in the vertical orientation at $1.0 \mathrm{~kW}$, and a vertical vacuum case at $0.5 \mathrm{~kW}$. The center rod axial temperature profile results for the $1.0 \mathrm{~kW}$ vertical orientation cases are presented in Figure 1.2 along with the test data. No reliable data were obtained on the lower end of the fuel in this test because of experimental difficulties that were not resolved.

The results for the two post-test vacuum cases displayed much improved agreement in the fuel tube-to-cask wall temperature difference. The fact that improved agreement in the predicted fuel tube temperature was observed for the two distinct assembly power levels suggests the validity of the posttest fuel tube emissivity change from 0.2 to 0.25 . As expected, correction of the predicted fuel tube temperature resulted in an improved agreement in 


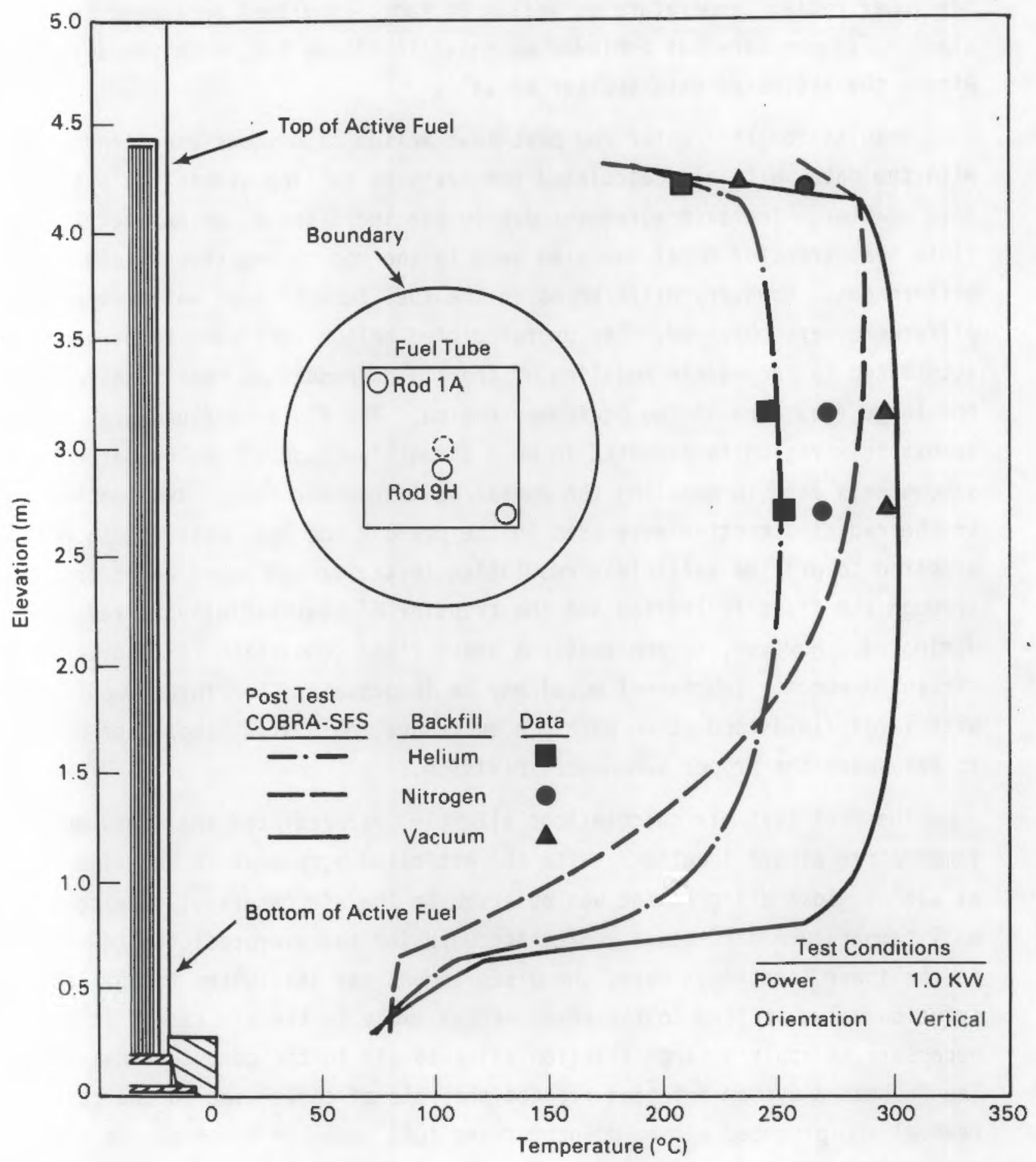

EIGURE 1.2. Post-Test Predicted and Experimental Results: Rod $9 \mathrm{H}_{1} 1.0 \mathrm{~kW}$, Vertical Orientation, Electrically Heated PWR Single Assembly Test 
the inner radial temperature as we11. In fact, excellent agreement in peak cladding temperature was achieved as shown in Figure 1.2, with the agreement within the estimated data scatter of $=3^{\circ} \mathrm{C}$.

Results for the center rod post-test helium case shows excellent agreement with the data, with all calculated temperatures falling within the estimated data scatter. Improved agreement due to the inclusion of an asymmetric rodfluid heat transfer model was also seen in the rod-to-rod temperature differences. However, differences in the fuel tube to cask wall temperature difference were observed. The overpredicted helium fuel tube temperature was attributed to incomplete modeling of the fluid conduction heat transfer across the large flow area of the downcomer region. The fluid-to-fluid heat transfer across this region is expected to be a direct function of the number of subchannels used in modeling the radial heat transfer path. Two subchannels in the radial direction were used in the prelook and post-test models. This appeared to provide sufficient resolution in the vacuum cases where conduction through the fluid is limited and the transfer of heat radially is radiation dominated. However, in applications where fluid conduction is important, the current downcomer subchannel model may be inadequate. For future applications with large fluid conduction paths, a subchannel mesh study should be performed to determine the proper subchannel division.

The post-test air calculations slightly overpredicted the measured temperature at all locations, with the estimated agreement in peak temperature at $\pm 15^{\circ} \mathrm{C}$. Some disagreement was observed in the air case fuel tube-to-cask wall temperature difference, which accounts for the overpredicted temperatures in the inner location. Here, the disagreement was attributed to the large friction value applied to the downcomer assembly in the air case. It was necessary to apply a large friction value to aid in the computational stability. The increased system friction reduced the role of convection in the cask heat removal and produced warmer downcomer and fuel assembly temperatures than observed in the data. 


\section{Conclusions}

In summary, COBRA-SFS was successfully used in modeling two single assembly spent fuel heat transfer tests. Applications included a variety of fill media, cask orientations, and assembly power levels. It is concluded from the results of the 21 individual test predictions that the conduction, convection, and radiation models incorporated into the COBRA-SFS code are adequate for modeling spent fuel heat transfer.

The single assembly spent fuel data base used in this study for evaluation of qualified thermal analysis tools provided valuable insight into the performance of the code and input models via comparisons of predictions with data. As a result of this exercise, the code's usefulness has been expanded and its predictive capabilities enhanced. The results of these data comparisons clearly demonstrate the applicability of COBRA-SFS for spent fuel storage system thermal analysis. To further extend the range of applicability and provide a more complete qualification of the codes capabilities, it is suggested that COBRA-SFS be evaluated with multiassembly spent fuel storage system data. 
COBRA-SFS PREDICTIONS OF SINGLE ASSEMBLY SPENT

FUEL HEAT TRANSFER OATA

\subsection{INTRODUCTION}

The Nuclear Waste Policy Act of 1982 required the preparation of a proposal for the development of Monitored Retrievable Storage (MRS) facilities for spent nuclear fuel and high-level waste from commercial nuclear power operations. One important consideration in the design of the MRS facility is temperature control of the stored materials. Thus, the ability of the storage system to dissipate the decay heat is of interest.

The capability to accurately predict the thermal performance of storage systems is an essential element of the MRS design process. The COBRA-SFS computer code is currently being used at PNL to analyze the thermal performance of spent fuel storage systems including the MRS cask design. Before such a tool can be generically applied, however, the code must be qualified or validated against existing relevant experimental results through extensive comparison of code predictions with data. The ability of a predictive tool to provide accurate results over many and widely ranging tests extends the level of qualification and increases confidence in the reported results. The study reported here is the first of a number of such comparisons that are planned to qualify COBRA-SFS for use in spent fuel storage thermal analyses.

This report describes the results of comparison of analytical predictions and experimental data for two separately conducted tests in which the thermal response of a typical PWR spent fuel assembly and a model electrically heated PWR fuel assembly were investigated. In combination, the two separately conducted tests examined the effects of orientation, backfill media, and power level on the test assembly thermal response. 
A general description of the COBRA-SFS code, its modeling capabilities, and computational philosophy is first provided. For each test, the computational model used in the simulations is presented along with discussions of the modeling parameters and correlations employed. An overview of the modeling uncertainties is then presented to better interpret the predicted and measured results. Prelook predictions, made prior to the availability of experimental data, are compared against the measured test data. Following the prelook data comparison, refinements in the computational model are made and their effects verified in post-test simulations. 


\subsection{CONCLUSIONS AND RECOMMENDATIONS}

The ability of the COBRA-SFS computer code to predict the thermal response of two single assembly spent fuel tests was investigated through comparisons of predictions with experimental test data. From these comparisons, conclusions regarding the computational treatment of the physical phenomena and input models are made. The principal conclusions and recommendations identified from this validation study are presented in this section.

\subsection{CONCLUSIONS}

The principal conclusions resulting from the comparison of measured and predicted temperature distributions of the two single assembly heat transfer tests are:

- The prelook analyses predicted peak rod temperatures for the three PWR Single Assembly Spent Fuel Test runs, and the eighteen Electrically Heated PWR Single Assembly Test runs were within $\pm 10^{\circ} \mathrm{C}$ and $\pm 27^{\circ} \mathrm{C}$, respectively, of the measured data. The results of the prelook simulations are in reasonable agreement with the data and the data trends observed.

- Observed prediction inaccuracies were deduced to be results of deficiencies in code models and uncertainties in the input specification of as-tested geometry (i.e. extent of surface-to-surface contact) and surface conditions (material emissivities and roughness). The improved code models used in the post-test analyses include the radiation exchange model (modified to more closely adhere to the assumption of uniform radiosity by increasing the number of nodes in the modeled surface areas), and the rod-to-fluid heat transfer model (modified to include asymmetric rod heat flux effects). Refinements made in the input parameters included changes to the assumed surface conditions (material emissivity and form friction).

- The relatively good agreement of the two prelook analyses with the experimental results demonstrates the fundamental validity and generality of the COBRA-SFS computational tool. Changes made as a consequence of 
the prelook analyses represent only refinements in the basic methodology that are physically defensible and do not constitute mere "tuning" or "force fitting" of the code to the data.

- In its current, refined state of development COBRA-SFS has been shown to be capable of predicting complex heat transfer in two realistic spent fuel storage system applications to good accuracy $\left( \pm 3^{\circ} \mathrm{C}, \pm 15^{\circ} \mathrm{C}\right)$ providing support for its broader use including multiassembly applications.

- Although the agreement of the predictions with data was considerably improved in the post-test analysis, some suspected deficiencies still remain. Additional refinements in the modeling of fluid-to-fluid heat transfer and in the modeling of the heat transfer and fluid flow in the plenum regions would be expected to further improve the post-test predictions.

- To further extend the credibility of the code's predictive capabilities, additional, broader qualification is still needed. Continued evaluation of the code with single assembly test data should be performed when additional test data is made available. The existing models in COBRA-SFS which were successful in performing single assembly spent fuel storage system themal analysis should also be evaluated against multiassembly data. Finally, qualification of the code against test data for singleand multiassembly consolidated spent fuel storage systems is also needed.

\subsection{RECOMMENDATIONS}

As a result of the evaluation of the code predictions and the test data, the following analytical and experimental efforts are recommended:

- Future analyses should include modeling of an eccentrically located fuel assembly to better demonstrate the code's capability to predict fuel assembly temperatures in the horizontal or inclined orientations where convection is diminished and wall contact is enhanced. The fluid momentum equations should also be modified to include buoyancy effects in the transverse direction. 
- The thermal benefit resulting from fuel assembly-fuel tube contact should be better defined for modeling purposes.

- With high-conductivity backfills, the potential benefits of more extensive (finer) dimensioning of radial fluid subchannel meshing should be investigated to provide more accurate predictions of fluid-fluid conduction heat transfer across large flow areas.

- COBRA-SFS predictions should be compared with additional single- and multiassembly spent fuel dry storage test data. Further evaluation of the code against different and more complex applications will provide increased confidence and support for its general use in the thermal analysis of spent fuel storage.

- To reduce the overall modeling uncertainty and improve the prelook prediction performance, experimentally determined emissivity values are needed for all cask components which participate in radiation heat exchange. 


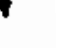




\subsection{COBRA-SFS}

The COBRA-SFS (ㅁpent Fuel Storage) computer code was used to predict temperature and velocity distributions in model single assembly spent fuel storage casks. Results were obtained for the operation of the casks with backfills of nitrogen, helium, and a vacuum for the vertical, horizontal, and inclined orientations. In the following sections, a description of the COBRA-SFS code, its modeling capabilities, and computational philosophy are presented, along with a discussion of the code versions used in the analyses.

\subsection{COBRA-SFS DESCRIPTION}

The COBRA-SFS code is a steady-state, lumped-parameter, finite-difference computer code which predicts flow and temperature distributions in spent fuel storage systems and fuel assemblies under mixed and/or natural convection conditions. Derived from the COBRA family of codes which have been extensively evaluated against in-pile and out-of-pile data (Stewart et a1. 1977, Khan et al. 1981), COBRA-SFS retains all the important features of the parent COBRA codes and extends the range of application to problems with two-dimensional radiation and conduction heat transfer. This capability permits analyses of single- and multiassembly spent fuel storage systems with unconsolidated or consolidated fuel, using a variety of fill media.

In the following sections, the COBRA-SFS modeling capabilities are outlined, along with a brief discussion of the modeling philosophy.

\subsection{MODELING CAPABILITIES}

A wide range of dry storage systems can be simulated by COBRA-SFS via input instructions. In addition to the single assembly cask heat transfer analyses described in this report, applications have included analyses of multiassembly spent fuel storage systems under various orientations and fill media (Wiles et al., 1986), and analyses of both single- and multiassembly consolidated storage systems (Cuta, Rector and Creer 1984; Rector and wheeler 
1986). The code contains thermal-hydraulic models for pressure drop, turbulent mixing, subchannel diversion crossflow, buoyancy-induced flow recirculation, conduction and radiation heat transfer, and boundary and plenum heat losses. A summary of the characteristics of the code used to perform the post-test analyses is given in Table 3.1 .

\subsection{COMPUTATIONAL PHILOSOPHY}

COBRA-SFS is based upon the subchannel modeling philosophy. This method has been used extensively in the nuclear industry in past years because it allows quite complex three-dimensional geometries to be simulated easily and accurately. In the subchannel approach, the storage system, fuel bundle, or waste form being simulated is divided into a number of quasi-one-dimensional flow paths or channels. These channels are characterized mathematically by a flow area and wetted perimeter--the exact shape of the channel is unimportant. the relation of a subchannel control volume to a storage system is depicted in Figure 3.1.

Mass, momentum, and energy can be exchanged between neighboring channels by diversion crossflow and turbulent mixing. A lateral connection between channels is defined mathematically by a gap width and the distance between channel centroids. Since a crossflow exists only between adjacent channels that are connected and since there is no momentum coupling from one crossflow to another, discrete lateral coordinate directions or lateral boundary conditions are not needed.

Subchannels can be used in a variety of ways to describe fluid flow regions. The channel shapes may be quite regular, as in a square array of a fuel bundle, or quite irregular, where large areas of flow are lumped into a single flow channel. In either case, the channels may be connected to an arbitrary number of adjacent channels. Additionally, subchannels may be thermally connected to an arbitrary number of wall or slab nodes; wall nodes 
TABLE 3.1. COBRA-SFS Capabilities and Limitations

- Modeling Capabilities

- Quasi-three dimensional

- Steady state

- Triangular, square, or consolidated rod arrays

- Multiple flow regions

- Recirculating flows

- Interassembly and intra-assembly heat transfer

- Mixed coordinate systems

- Variable axial grid spacing

- Fiuid conduction and turbulent mixing

- Pressure drop mode1 (network and subchannel)

- Variable rod property

- Variable boundary heat transfer

- Prescribed surface heat flux

- Plenum heat transfer

- User-prescribed flow

- Variable fluid properties.

- Program and I/0 Control

- Constant prescribed flow

- Zero-net flow solution

- Restart and post-processing dump

- Decoupled hydrodynamics (no buoyancy)

- Fully coupled hydrodynamics

- Echoed input

- Result execution and time monitoring

- Pressure drop initialization scheme

- Data "roll" option for large problems.

- Limitations and Assumptions

- Steady state

- Single phase

- Incompressible flow

- Lumped parameter approach

- Quasi-three dimensional

- No free-field capability

- One-dimensional boundary heat transfer

- Nonparticipating radiation (planar). 


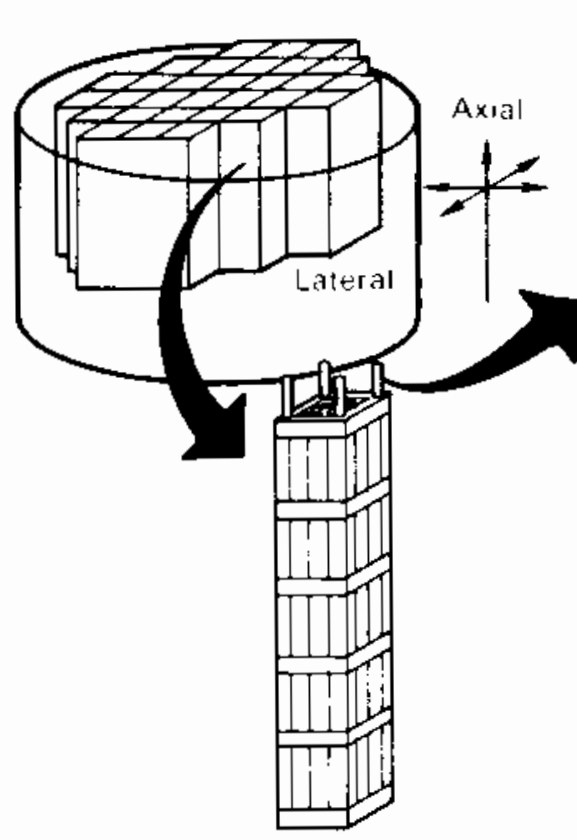

Fuel Assembly
Subchannel

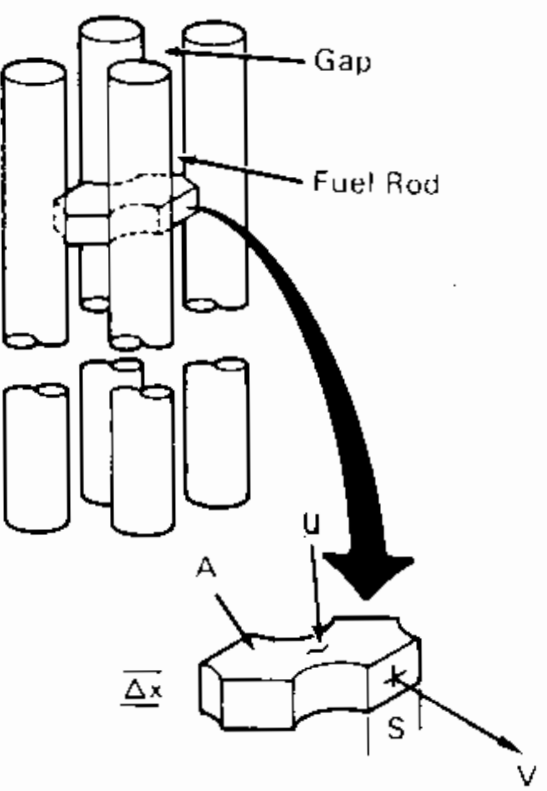

Control Volume

EIGURE 3.1. Relation of Subchanne1 Control Volume to a Storage System

can then be thermally connected to any number of other walls via conduction or radiation heat transfer. The overall flexibility of the subchannel approach makes it a very powerful tool in effectively simulating complex geometries.

\subsection{COBRA-SFS BACKGROUND}

COBRA-SFS was developed on the strengths of the COBRA code series. COBRA-IIIC (Rowe 1973), COBRA-IV-I (Wheeler et al. 1973) and COBRA-WC (George et al. 1977) were developed at Battelle under sponsorship of the Atomic Energy Commission, the Nuclear Regulatory Commission, and the Department of Energy as part of the reactor safety research effort. The basic computational philosophy of COBRA-SFS comes from COBRA-WC, which included the capability of predicting recirculating (natural convective) flows. 
To extend the range of applicability of COBRA-WC to handle the expected radiation and conduction heat transfer components in a storage system, a wal 1 conduction model and fuel rod and wall radiation heat transfer models were incorporated into COBRA-WC to form the earliest stages of COBRA-SFS. This somewhat crude version of SFS was used to make prelook predictions for the PWR Single Assembly Spent Fuel Test described in Section 4.0 of this report. The success of these predictions suggested that further comparisons of the code with data be performed to fully evaluate the models contained in COBRA-SFS. As new data were being made available, COBRA-SFS was modified to provide additional heat transfer and fluid modeling capabilities to facilitate the modeling of different storage systems.

Specifically, an interim version was created which contained:

- addition of a numerical procedure to internally iterate to a zero-net flow solution

- addition of upper and lower plenum heat transfer models

- addition of a structural member axial conduction mode]

- modifications of the existing boundary heat transfer model to be more flexible

- generalization of the input for the radiation exchange model

- modification of input to reflect the above.

This interim version was then used to perform prelook predictions for the Electrically Heated PWR Single Assembly test which is described in Section 5.0 of this report. Comparisons of the prelook predictions for both of the above experiments with their respective data suggested a common revision in the code's rod-to-fluid heat transfer model. In the prelook prediction version of the code, the energy transferred between the rod and coolant in an adjacent subchannel was assumed proportional to the difference between the fuel rod surface temperature and the average temperature of its surrounding subchannels. In the revised model the heat transfer to a subchannel is proportional to the difference between the surface temperature and the local temperature of the 
individual subchannel. The modeling change was made and the revised code was used to produce the post-test predictions presented in this report. Although the prelook data comparisons used different versions of COBRA-SFS, both posttest data set predictions were made with the identical version of the code. 


\subsection{PWR SINGLE ASSEMBLY SPENT FUEL TESTS}

In this series of tests, the temperature response of a single, instrumented, vertical, PWR spent fuel assembly was investigated in atmospheres of air, helium, and a partial vacuum. Experimental axial temperature data were obtained at several radial positions for fixed boundary conditions. In this section descriptions of the test apparatus, computational model, and modeling uncertainties are provided. The prelook predictions are then compared with the data and, finally, post-test predictions are provided to demonstrate the effectiveness of the modifications made to the code and to the model input. An evaluation of the code's predictive capabilities is also presented.

\subsection{TEST DESCRIPTION}

The test apparatus is shown in Figure 4.1. The test section consisted of a PWR spent fuel assembly sealed in an instrumented stainless steel canister, which is enclosed by a carbon steel cylindrical liner. The test assembly was maintained in a vertical position by a seismic restraint fixture. The test facility and procedures are fully described by Bates (1986), so only a summary of the components is given below.

The PWR spent fuel assembly used in these tests was discharged from the Florida Power and Light Turkey Point Unit Number 3 reactor with a burnup of approximately 28,000 MWD/MTU. The fuel assembly consisted of a $15 \times 15$ array with 204 fuel rods, 20 control rod guide tubes, and 1 instrumentation tube. The active fuel length after exposure was assumed to be $3658 \mathrm{~mm}$; the overall fuel assembly length $4097 \mathrm{~mm}$. A total of seven spacer grids were located axially over the length of the fuel. A list of relevant fuel assembly parameters is presented in Table 4.1 .

Decay heat measurements of the spent fuel assembly were obtained from boiling water calorimetry measurements. Decay heat levels of $1.17 \mathrm{~kW}$ for the air and vacuum runs and $1.16 \mathrm{~kW}$ for the helium run were reported subject to a $\pm 5 \%$ accuracy. The axial power distribution was inferred from gamma flux 


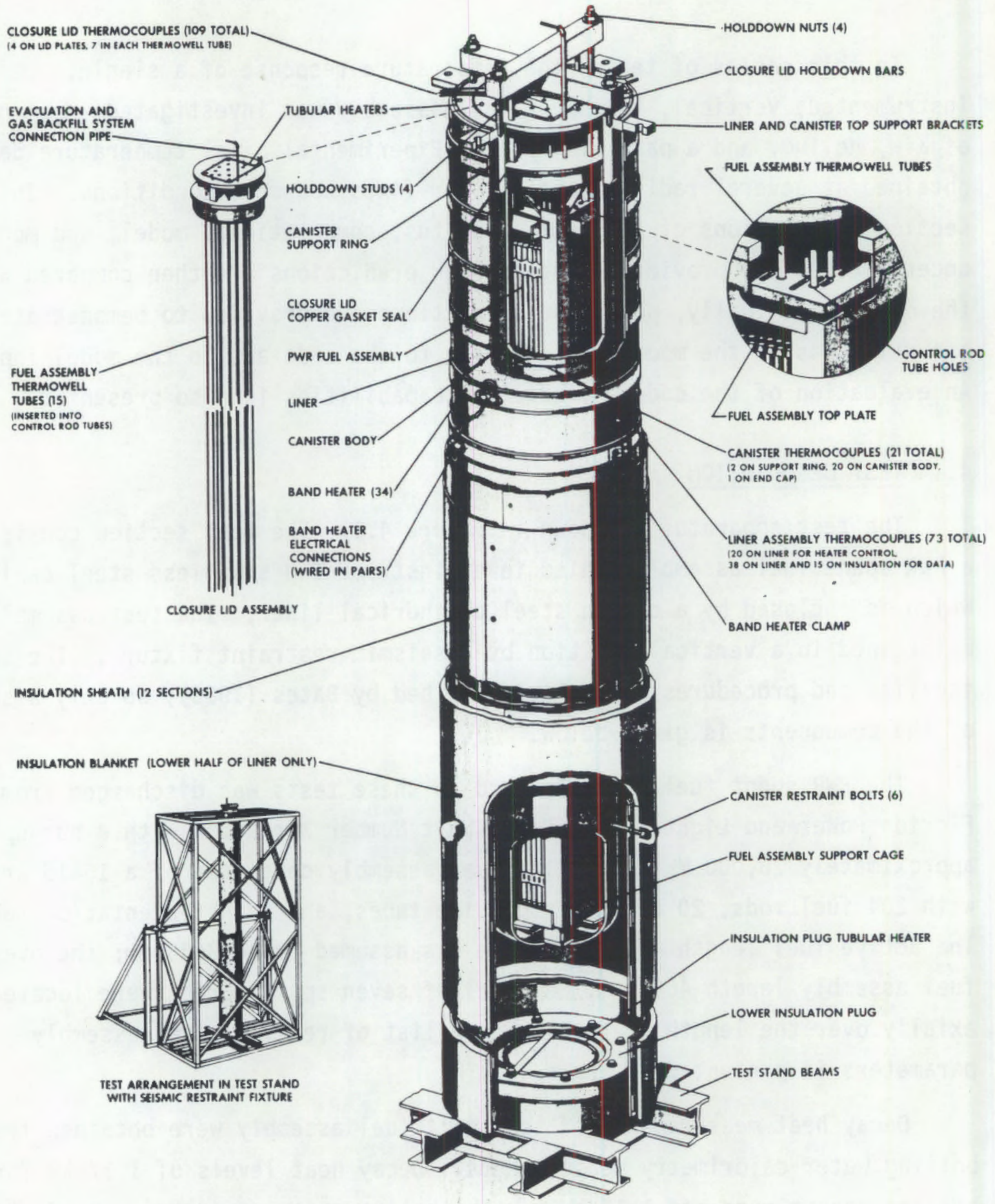

EIGURE 4.1. PWR Single Assembly Spent Fuel Test Apparatus 
TABLE 4.1. Turkey Point No. 3 PWR Fuel Assembly Parameters

Vendor

Type (Rod Array)

Assembly Parameters

Transverse Dimension

Assembly Weight

Assembly Length

Control Rod Guide Thimble Tubes

Number

Upper OD

Wall Thickness

Material

Instrument Tubes

Number

$O D$

Wall Thickness

Material

Spacer Grids

Number

Material

Spring Material

Fuel Rods

Number

Length

00

Wall Thickness

Material

Fuel Length

Plenum Springs

Working Length

Material

Fuel Pellet Material

Enrichment

Density
Westinghouse Electric Corp

$15 \times 15$

$21.4 \mathrm{~cm}$ (8.426 in.)

$652.73 \mathrm{~kg}(1439 \mathrm{lb})$

$409.7 \mathrm{~cm}$ (161.3 in.)

20

$1.39 \mathrm{~cm}(0.546$ in.)

$0.43 \mathrm{~mm}(0.017 \mathrm{in.})$

$\mathrm{Zr}-4$

1

$1.39 \mathrm{~cm}$ (0.546 in.)

$0.43 \mathrm{~mm}$ (0.18 in.)

$\mathrm{Zr}-4$

7

Inconel 718

Inconel 718

204

$386.08 \mathrm{~cm}$ (152.0 in.)

$1.07 \mathrm{~cm}(0.422 \mathrm{in.})$

$0.62 \mathrm{~mm}(0.0243 \mathrm{in.})$

$\mathrm{Zr}-4$

$365.76 \mathrm{~cm}$ (144.0 in.)

$17.27 \mathrm{~cm}$ (6.80 in.)

Inconel 718

$\mathrm{U}^{\mathrm{U}}{ }^{2} .59$ Weight $\% \mathrm{U}^{235}$

$92 \%$ Theoretical 
measurements of a selected sample of individual fuel pins. It was assumed that the decay heat flux is directly proportional to the gamma flux; a plot of the axial power distribution inferred from the measured gamma flux is displayed in Figure 4.2 .

During testing, the spent fuel assembly was placed inside the cylindrical, stainless steel test canister. The canister was surrounded by an externally heated, carbon steel cylindrical pipe which elevated the temperature of the canister wall to values typical of what might be expected in a multiassembly storage system. Welded to the inside of the canister was the fuel assembly vertical support cage, which provided lateral restraint and centered the assembly within the canister. The fuel assembly support cage was fabricated from four $50.8 \mathrm{~mm}$ angle-iron pieces, with each member set upright and positioned adjacent to the assembly corners. Rectangular metal plates were used to join the vertical members of the support cage at six axial levels.

Instrumentation of the canister consisted of 20 thermocouples placed at 5 different axial locations on the outer wall to provide boundary temperature data and heater control. Attached to the canister upper end cap was a tubular heater, also used to maintain elevated boundary temperatures. An axial profile of the test assembly and canister thermocouple locations is shown in Figure 4.3. Note that the canister was suspended from the liner to minimize the axial heat transfer.

The test assembly was sealed by the canister closure lid assembly. The closure lid assembly is penetrated by 15 instrumentation tubes. The tubes were positioned such that they could be inserted into the existing, hollow PWR fuel assembly control rod guide tubes and center instrumentation tube. Each instrumentation tube contained seven thermocouples and provided fuel assembly temperature data over the length of the bundle. A cross sectional view of the fuel assembly and canister presented in Figure 4.4 illustrates the thermocouple position within the canister. In addition to the instrument tubes, a penetration for gas evacuation and backfill was provided to allow the canister to be filled with various gaseous media for fuel temperature response testing. 


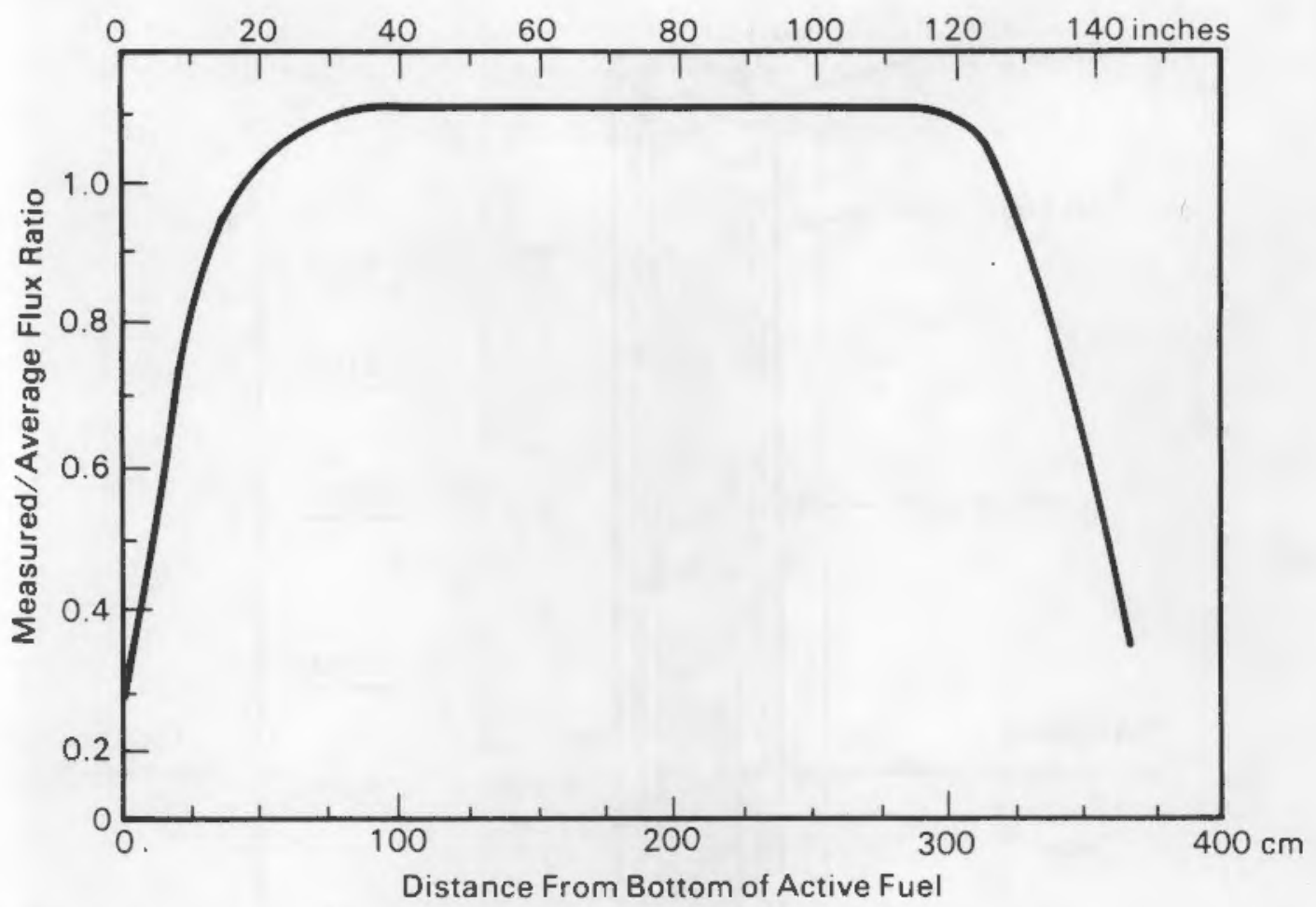

EIGURE 4.2. Assumed Axial Power Profile for a PWR Spent Fuel Assembly

Surrounding the canister assembly was an 457.2-mm-diameter carbon steel pipe referred to as the liner. Thirty-four electric-band trace heaters were placed along the liner outside surface to impose an elevated axial temperature distribution along the canister surface. The liner and band heaters were surrounded by a stainless steel insulation sheath; wrapped around the sheath was an insulation blanket to further reduce the test assembly radial heat loss. Additional trace heating was applied in the liner bottom and top plates.

A total of 71 thermocouples were secured to the liner. Of these, 55 provided temperature data; the remaining 18 provided temperature feedback information to the heater controllers. The liner data thermocouples were located midway between the band heaters.

Operation of the test assembly was carried out in atmospheres of air, helium, and a vacuum. For each of the tests, the liner heater controllers 


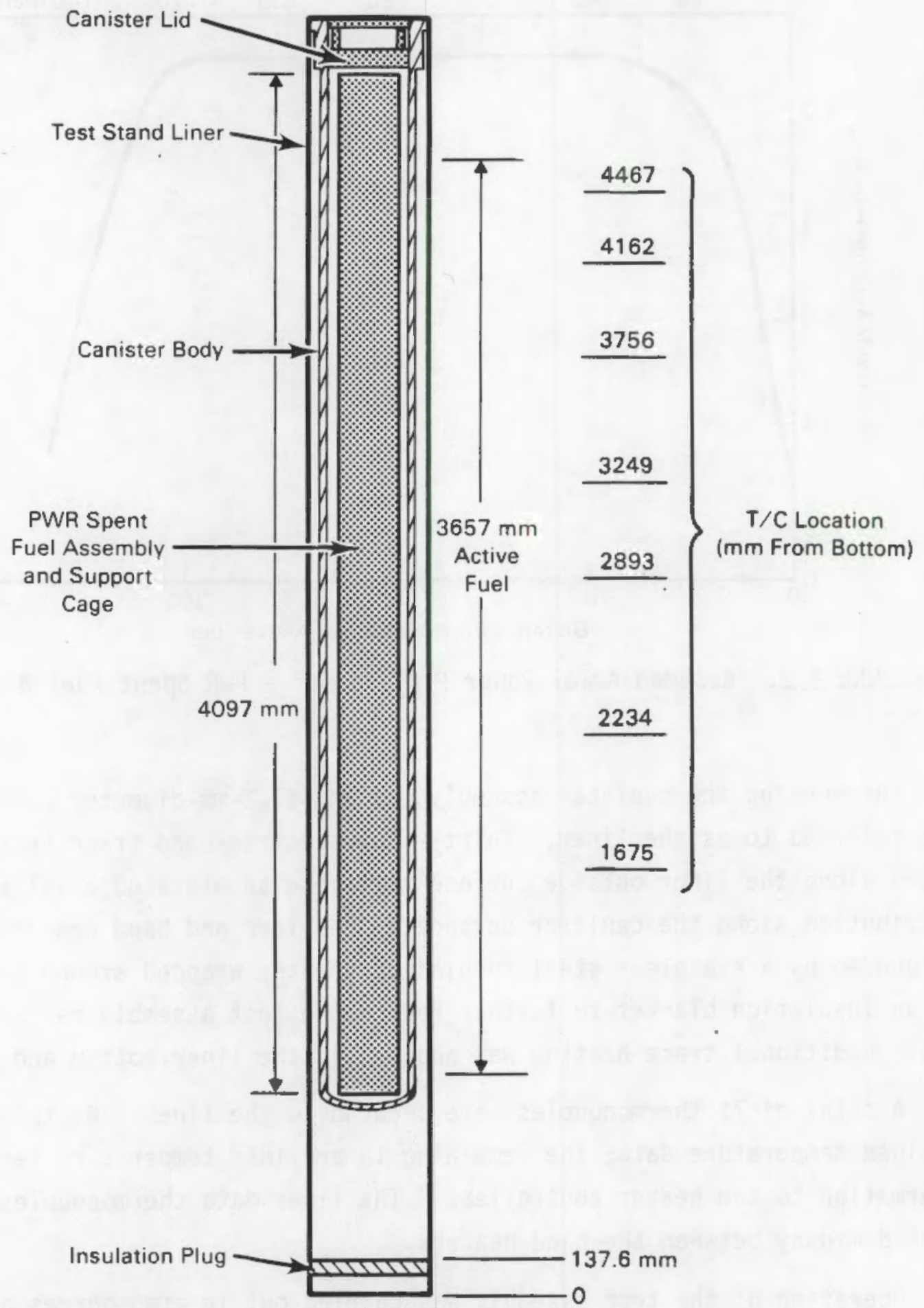

EIGURE 4.3. Test Assembly Axial Profile and Thermocouple Locations 


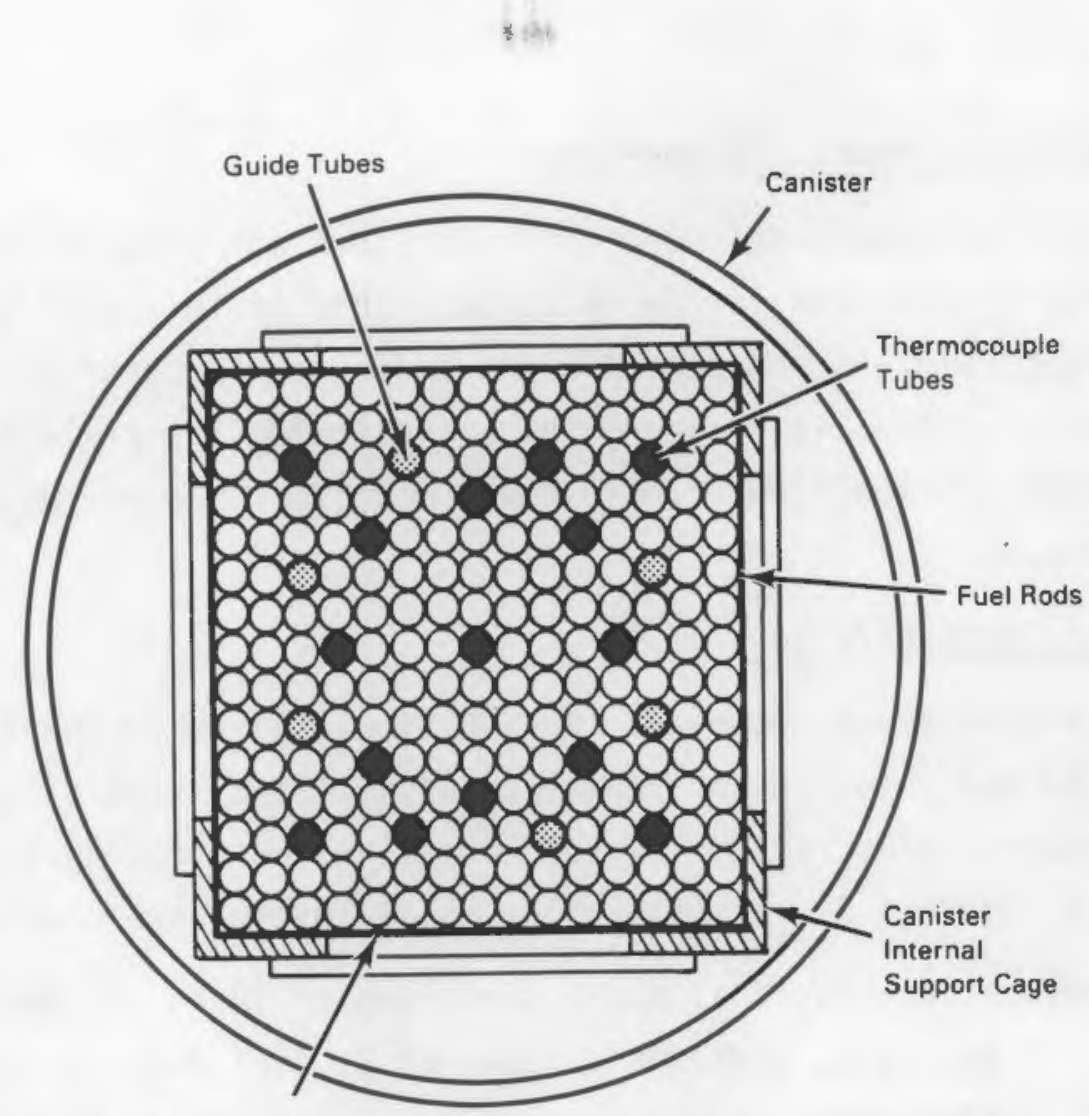

FIGURE 4.4. Cross Sectional View of Fuel Assembly and Canister

were set to provide a predetermined temperature profile along the canister. Fuel temperature data were taken when thermal stabilization was reached. For the air tests, the vent valve was left open to the atmosphere; in the helium tests the canister was backfilled and pressurized to $6.9 * 3.5 \mathrm{KPa}(1.0 \pm$ $0.5 \mathrm{psig}$ ). All vacuum tests were conducted with the vacuum pump running and the cask internal pressure maintained at approximately $-610 \mathrm{~mm}(-24 \mathrm{in.})$ of mercury. The degree of vacuum imposed in these tests represents a low pressure condition, sufficient to eliminate convection, but not low enough for free molecular flow. Thus, the gas thermal conductivities were assumed to be unaffected at these low pressures. 


\subsection{COMPUTATIONAL MODEL DESCRIPTION}

The computational model used in the prelook analysis to simulate the PWR Single Assembly Heat Transfer Tests is described in this section, along with the modeling parameters and correlations employed. A brief discussion of the modeling uncertainties is also provided. Following the prelook analysis this original model was modified. These model modifications are described in Section 4.3.1.4.

\subsubsection{Nodal Representation}

A three-dimensional model of the PWR Single Assembly Spent Fuel Test was used for this analysis. A horizontal cross sectional view of the computational cell arrangement illustrating the subchannel and wall noding employed is displayed in Figure 4.5. A total of 34 axial levels were used in the model.

The prelook computational model consisted of three assemblies. The inner, or fuel bundle assembly, contains a total of 31 fuel rods, 4 control rod thimble guide tubes, (water rods), an instrumentation guide tube, and 28 fluid subchannels. The second, or downcomer assembly, models the large flow area defined between the outer row of rods and the canister wall. A single subchannel is used to define the flow path for this assembly.

In the version of COBRA-SFS used for the prelook analysis, it was assumed a priori that the mass flow rates in the fuel bundle and downcomer assemblies were equal but opposite in direction. Convergence of the computed flow field was determined when the prescribed flow rates produced equal pressure drops over the model length. To isolate the assembly flows, a row of pseudo walls were situated along the outer row of rods. The pseudo walls prevented crossflow but did not impede conductive or radiative heat transfer between the two assemblies.

The third assembly, which consisted of a single large channel and heater rod, was used to impose the measured boundary temperature distribution in the model. An iterative procedure was used to determine the input axial power 


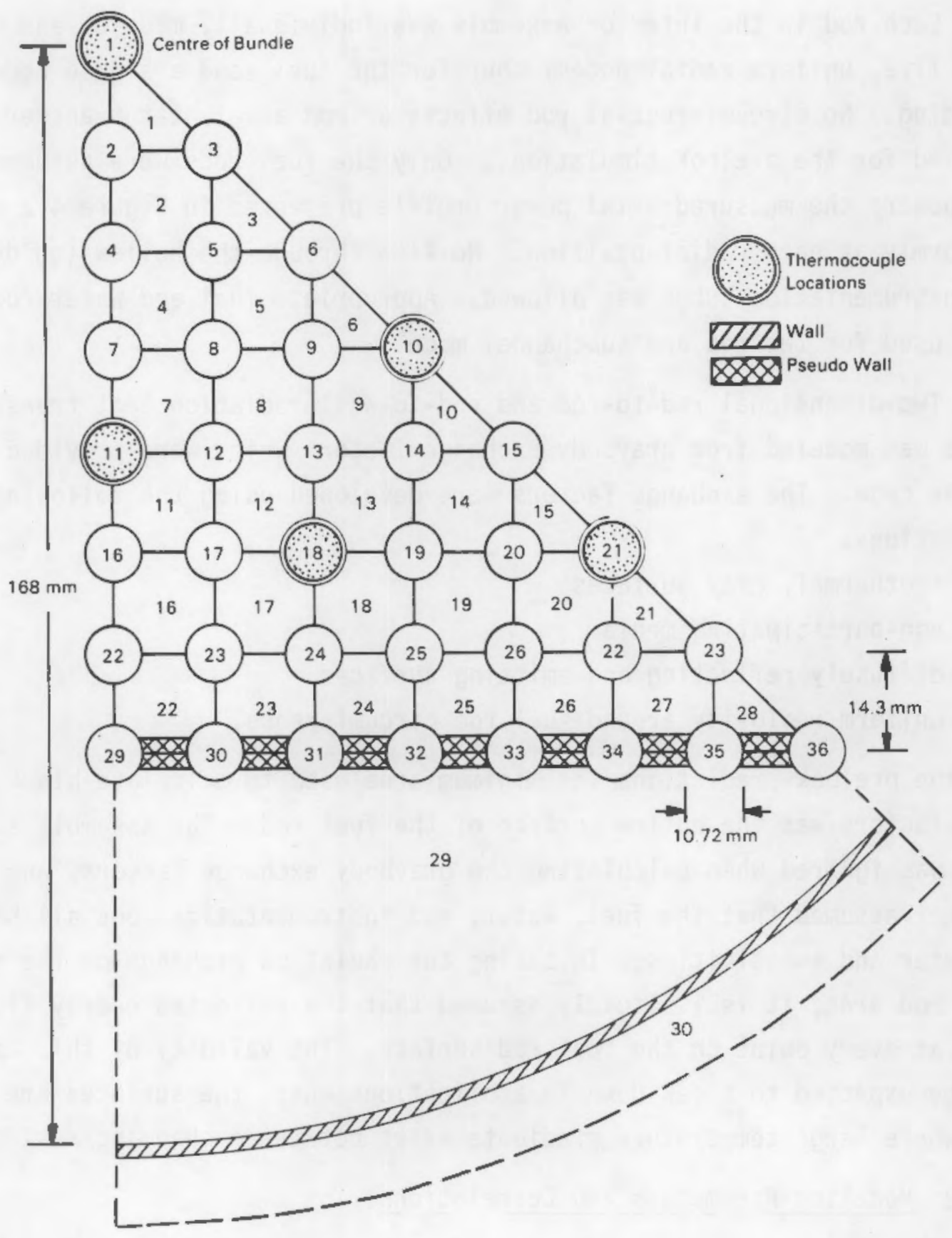

FIGURE 4.5. Cross Section of COBRA-SFS Prelook Computational Model for the PWR Single Assembly Test 
distribution for this rod. The shape of the power distribution was changed until the measured temperature distribution was achieved within $\pm 1^{\circ} \mathrm{C}$.

Each rod in the interior assembly was individually modeled and divided into five, uniform radial nodes: four for the fuel, and a single node for the cladding. No circumferential rod effects or rod axial heat transfer were modeled for the prelook simulations. Only the fuel rods were assumed to produce any power; the measured axial power profile presented in Figure 4.2 was applied uniformly at each radial position. No flow through the hollow (guide) water or instrumentation tubes was allowed. Appropriate fuel and water rod diameters were used for the rod and subchannel models.

Two-dimensional rod-to-rod and rod-to-wall radiation heat transfer in a plane was modeled from graybody exchange factors which were provided as input to the code. The exchange factors were developed using the following assumptions:

- isothermal, gray surfaces

- non-participating media

- diffusely reflecting and emitting surfaces

- uniform radiosity around fuel rod circumference.

For the prelook predictions the minimum area used to calculate black body view factors was the entire surface of the fuel rod. The assembly support cage was ignored when calculating the graybody exchange factors, and it was further assumed that the fuel, water, and instrumentation rods all have the same diameter and emissivities. In basing the radiation exchange on the entire fuel rod area, it is implicitly assumed that the reflected energy flux is the same at every point on the fuel rod surface. The validity of this approach can be expected to break down in applications where the surfaces are curved and where large temperature gradients exist between exchanging surfaces.

\subsubsection{Modeling Parameters and Correlations}

The material properties used in the computational model, with the exception of emittances, were well defined. Solid properties were assumed to be independent of temperature, while fluid properties were input as functions of 
temperature and continuously updated during the simulation. The emissivity values used for the highly oxidized-zircaloy clad fuel rods and stainless steel canister inner wall were best-estimate values, selected at 0.8 and 0.3 , respectively (Peterson 1975, Siegal et al. 1972).

Fluid conduction was included for all fill media, but was most important for helium. Conduction lengths on the order of the fuel rod pitch were used ${ }^{(a)}$. Fluid conduction between the edge row of subchannels in the fuel rod assembly and the single channel downcomer assembly was accounted for in the treatment of the pseudo walls.

The flow resistance of the test section is important in defining the overall contribution of convection heat transfer within the cask. Rod and wall friction losses were modeled using an analytical solution for fully developed laminar flow in a circular tube; $f=64 /$ Re (Poiseuille's law). Loss coefficient for grid spacers, entrance, and exit losses were assumed to be negligible.

Heat transfer from the rods and walls to the coolant was prescribed using a film coefficient of the form $\mathrm{Nu}=4.364$ (Kays and Crawford 1980). This formulation is an exact solution of the energy equation for a constant heat rate with fully developed velocity and temperature profiles in a circular tube. The film coefficient was evaluated as a function of temperature at each location and was applied to both the fuel assembly and downcomer assemblies. For the low pressure air case (vacuum), no enhancement of the heat transfer by convection was assumed; thus, $\mathrm{Nu}=1.0$.

\subsubsection{Modeling Uncertainties}

The computational model used in the analysis was based on information provided by Westinghouse, Advanced Energy Systems Division (Unterzuber 1981) and summarized by Bates (1986). In developing the model, significant

(a) In calculating the heat transfer between adjacent subchannels, the distance used to define the temperature gradient is called the conduction length. 
uncertainties were associated with the following important heat transfer and fluid flow parameters:

- material emissivities

- radiation shielding effects

- contact heat transfer

- flow resistances

- power generation profiles.

The rod and canister wall emissivities are key parameters in the radiation model. A wide range of emissivity values was observed in the literature for these components and was found to be dependent upon oxidation buildup, fabrication technique, and temperature. The values used for the fuel rods and canister wall, 0.8 and 0.3 , respectively, are best estimates. Confidence in these values is not absolute, and variation of the emissivity from rod to rod may exist. Axial variations in rod emissivity may exist as well.

The shielding effect of the fuel assembly support cage is another uncertainty in the radiation model. The angle-iron structures and horizontal support plates of the support cage act as an intermediate radiation shield; however, the effect was ignored for simplicity of model setup. The consequences of ignoring the shielding effects of the support cage is expected to be most severe for the vacuum run.

The unmodeled contact between the fuel assembly and the support cage is another uncertainty. The effect of contact would be to slightly lower and/or skew the fuel rod temperature distribution within the bundle. Since the existence and type of contact were not well defined, the fuel assembly was assumed centered vertically within the canister. Some contact of the spent fuel assembly bottom inlet nozzle with the canister bottom was also expected. Again, specific details of this contact are not known and were not modeled. Thus, an additional source of uncertainty exists in the unmodeled axial heat transfer from the lower regions of the fuel assembly to the canister bottom.

A good deal of uncertainty exists in the modeling of the test section flow resistances. Unmodeled flow resistances include those of the grid spacers, 
and the fuel assembly inlet and outlet nozzles. The unmodeled losses from these components should enhance the natural convection predicted within the cask. The form drag correlation used for the fuel rods and canister wall was assumed to be that for flow in a circular duct. Application of this correlation to the noncircular geometry of the fuel rod and downcomer assemblies thus represents another uncertainty.

The assumption of symmetry in fuel loading and geometry allowed simulation of the test apparatus using a one-eighth sector model. Some uncertainty may be attributed to this assumption, since the radial power distribution within a spent fuel assembly can be significantly asymmetric depending on its exposure history. A small uncertainty exists in the measured axial power profile as well.

\subsection{COMPARISONS OF PREDICTIONS TO DATA}

The single assembly test apparatus described in Section 4.1 was used to determine the temperature distributions of a vertically oriented, spent PWR fuel assembly in atmospheres of air, helium, and a vacuum. The COBRA-SFS computational model used to predict the prelook temperatures and velocity distributions within the cask is described in Section 4.2; a sample input, representing the post-test air case, is given in Appendix A. In this section, a comparison of the prelook predictions, performed without any prior knowledge of the data, are compared to the measured test data. Following the prelook data comparison, improvements in the computational model and code were made and their effects verified in the post-test simulations.

\subsubsection{Prelook Predictions}

Representative prelook and post-test predicted axial temperature profiles for the instrumented control rod guide tubes are plotted with the experimental test data for the three fill media cases in Figures 4.6 through 4.8 . The data is presented for rod number 1 (center rod) as a function of elevation from the cask bottom for each fill media (see Figure 4.5). Prelook axial temperature profiles below the instrumented fuel region (elevation $0-160 \mathrm{~cm}$ ) 


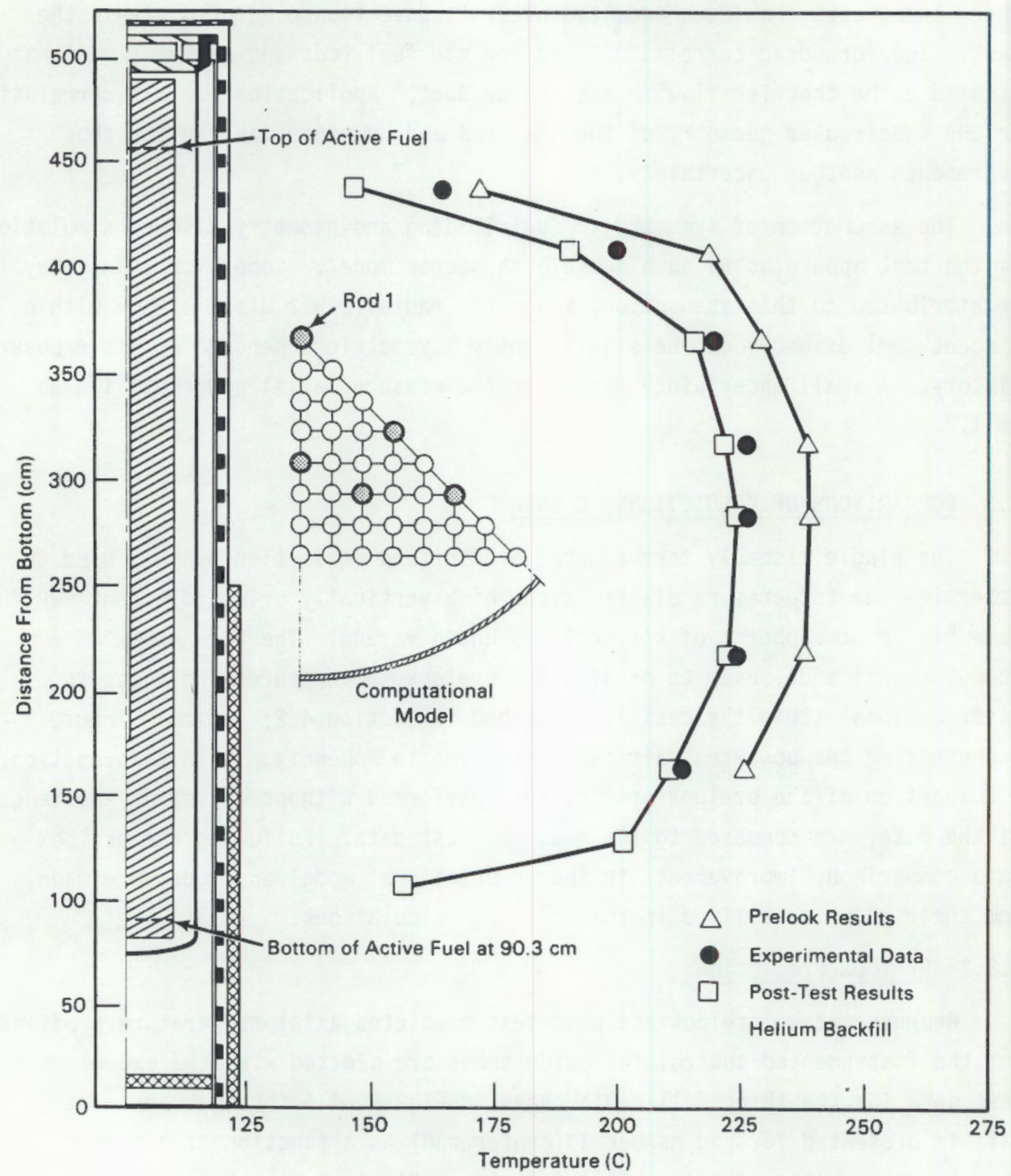

FIGURE 4.6. Predicted and Experimental Axial Profiles: Helium Case, Rod No. 1, PWR Single Assembly Test 


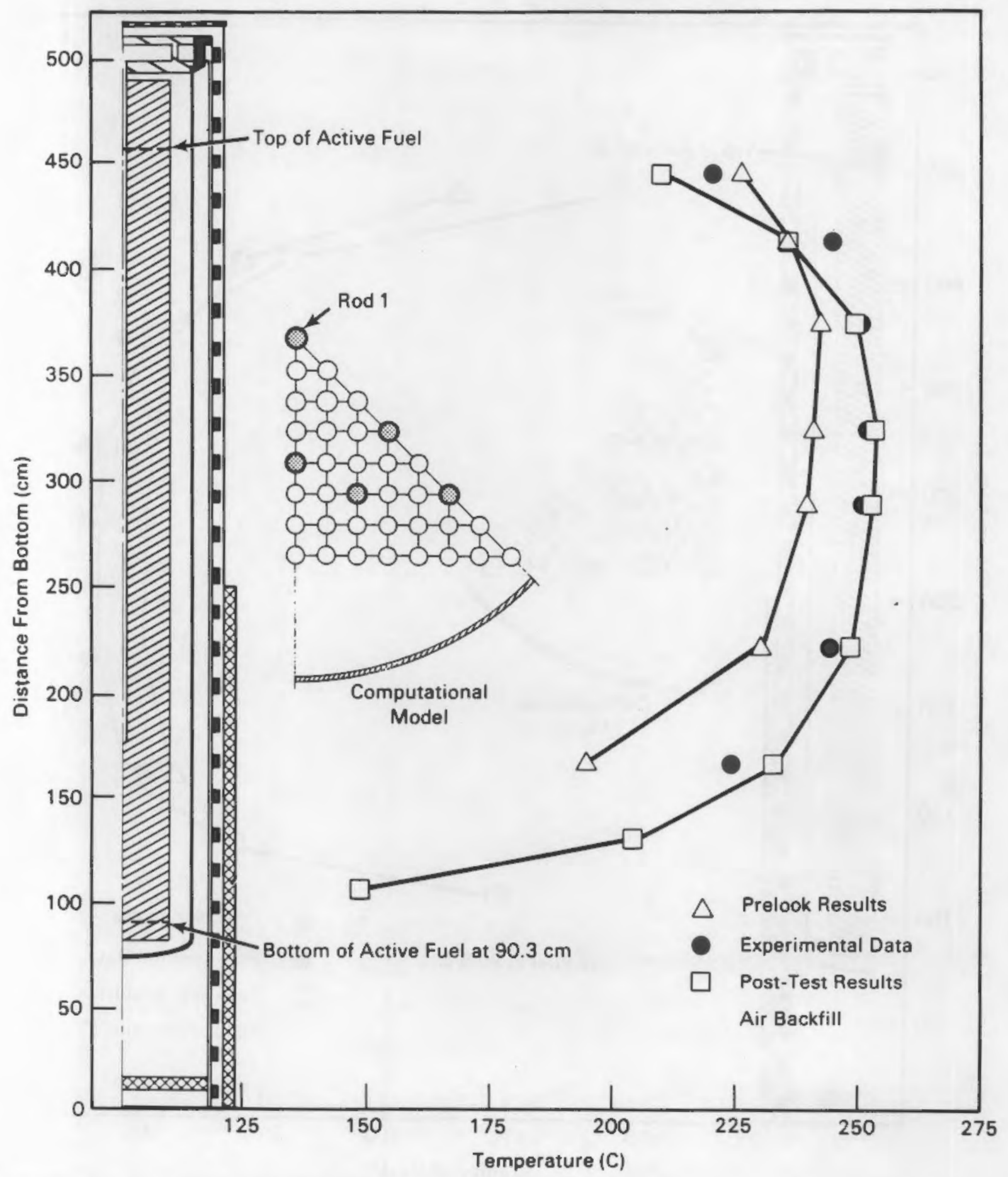

EIGURE 4.7. Predicted and Experimental Axial Profiles: Air Case, Rod No. 1, PWR Single Assembly Test 


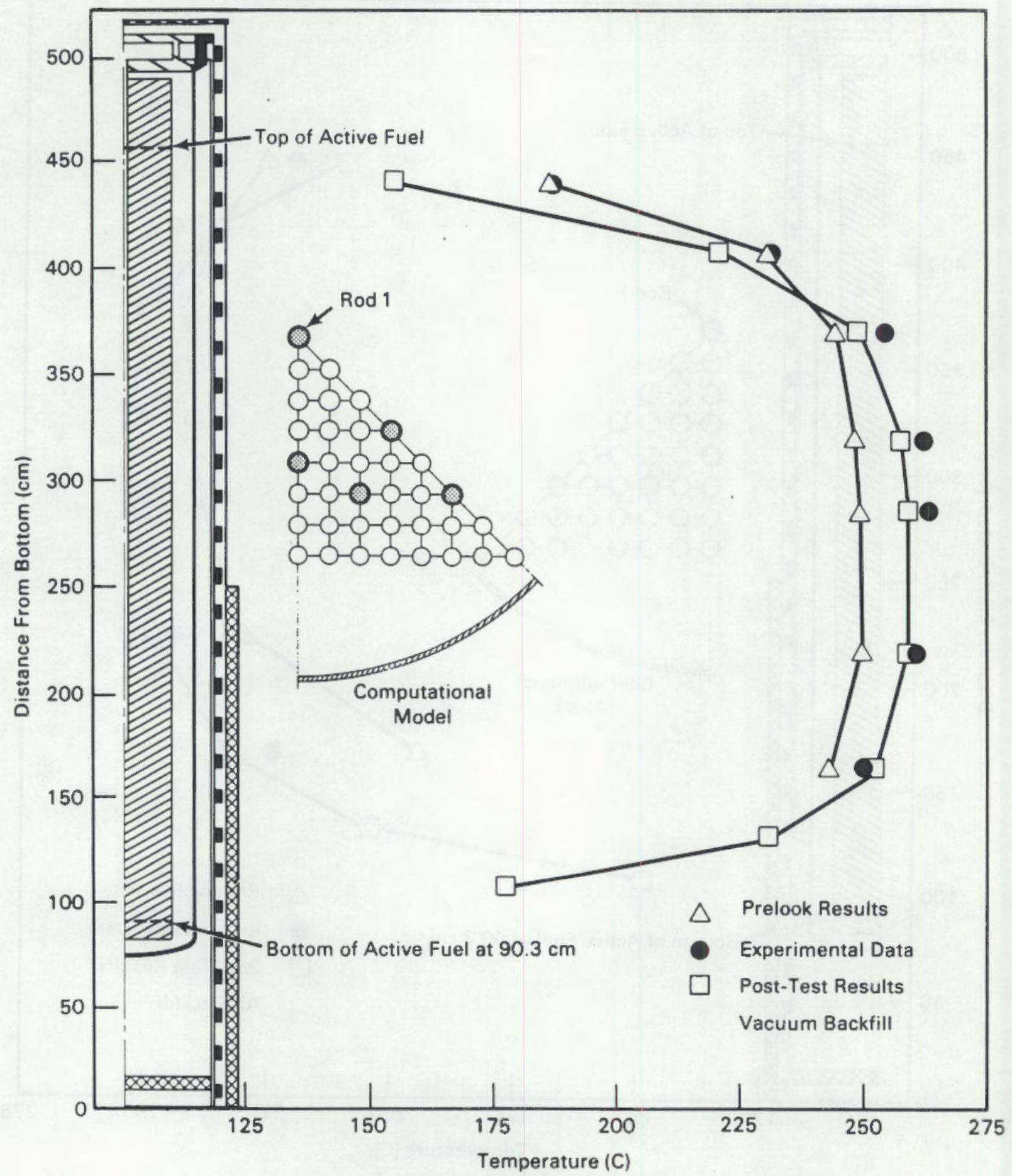

EIGURE 4.8. Predicted and Experimental Axial Profiles: Vacuum Case, Rod No. 1, PWR Single Assembly Test 
are not presented in Figures 4.6 through 4.8 because the prelook results, obtained well before this study was undertaken, consisted of graphical output on which elevations $0-160 \mathrm{~cm}$ were not plotted. Prelook and post-test radial profiles are also plotted with the data at an elevation $185 \mathrm{~cm}$ above the cask bottom in Figures 4.9 through 4.11. Both the axial and radial plots are presented in order of increasing system temperature, i.e., helium, air, and vacuum backfills. To avoid repetition of the data, the post-test results are also presented here (a discussion of the post-test results is presented in Section 4.3.2). Similar axial profile comparisons are provided in Appendix $B$ for calculated-versus-experimental results for other fuel rod locations.

Rod temperature data were obtained from thermocouples located inside instrument tubes inserted into the hollow control rod guide tube of the spent fuel assembly. The two cylinders surrounding the thermocouple act as radiation shields, so that the recorded temperature is slightly lower than the surface temperature. The code predictions represent rod surface or cladding temperatures, which should thus be slightly higher than the internally measured rod data.

In all prelook prediction versus data comparisons, the air and vacuum predictions were found to fall below the data by approximately $10^{\circ} \mathrm{C}$. The helium data was overpredicted by a similar amount in the assembly center with the comparison improving with radial position. The shape of the axial temperature profiles were in general agreement with the data for all cases, with the largest discrepancy occurring for the air backfill. A discussion of the results by fill media follows.

\subsubsection{Helium Backfill Results}

The variation in agreement with radial position for the helium case shown in Figure 4.9 suggests that the thermal resistance of the assembly interior was incorrectly modeled. This is supported by comparing the predicted center-to-outer rod temperature difference for the three fill media. This comparison shows the rod-to-rod temperature difference to be independent of the fill media. The reduced rod-to-rod temperature difference observed in the 


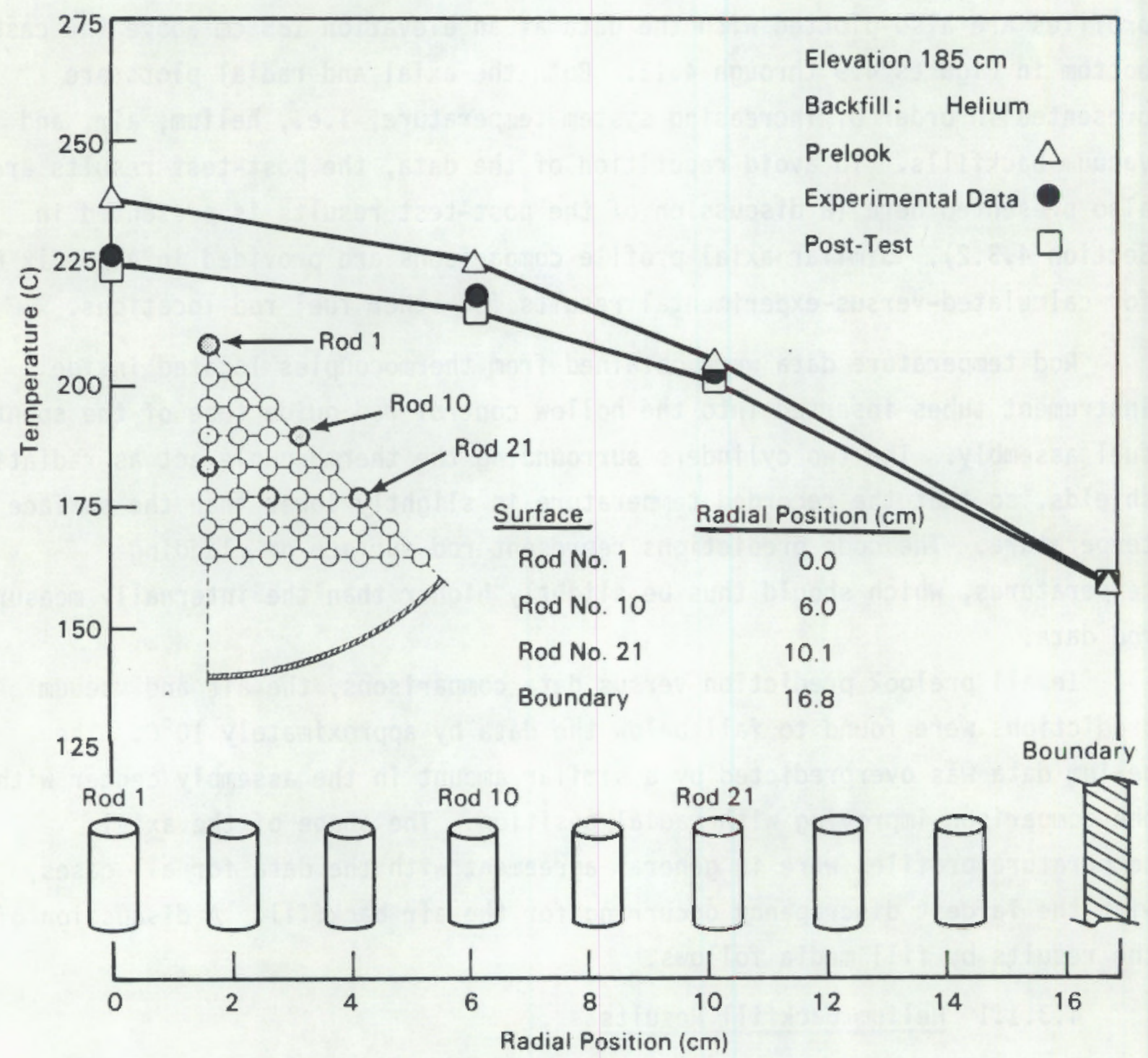

FIGURE 4.9. Predicted and Experimental Radial Profiles at Elevation $185 \mathrm{~cm}$ : Helium Backfill, PWR Single Assembly Test 


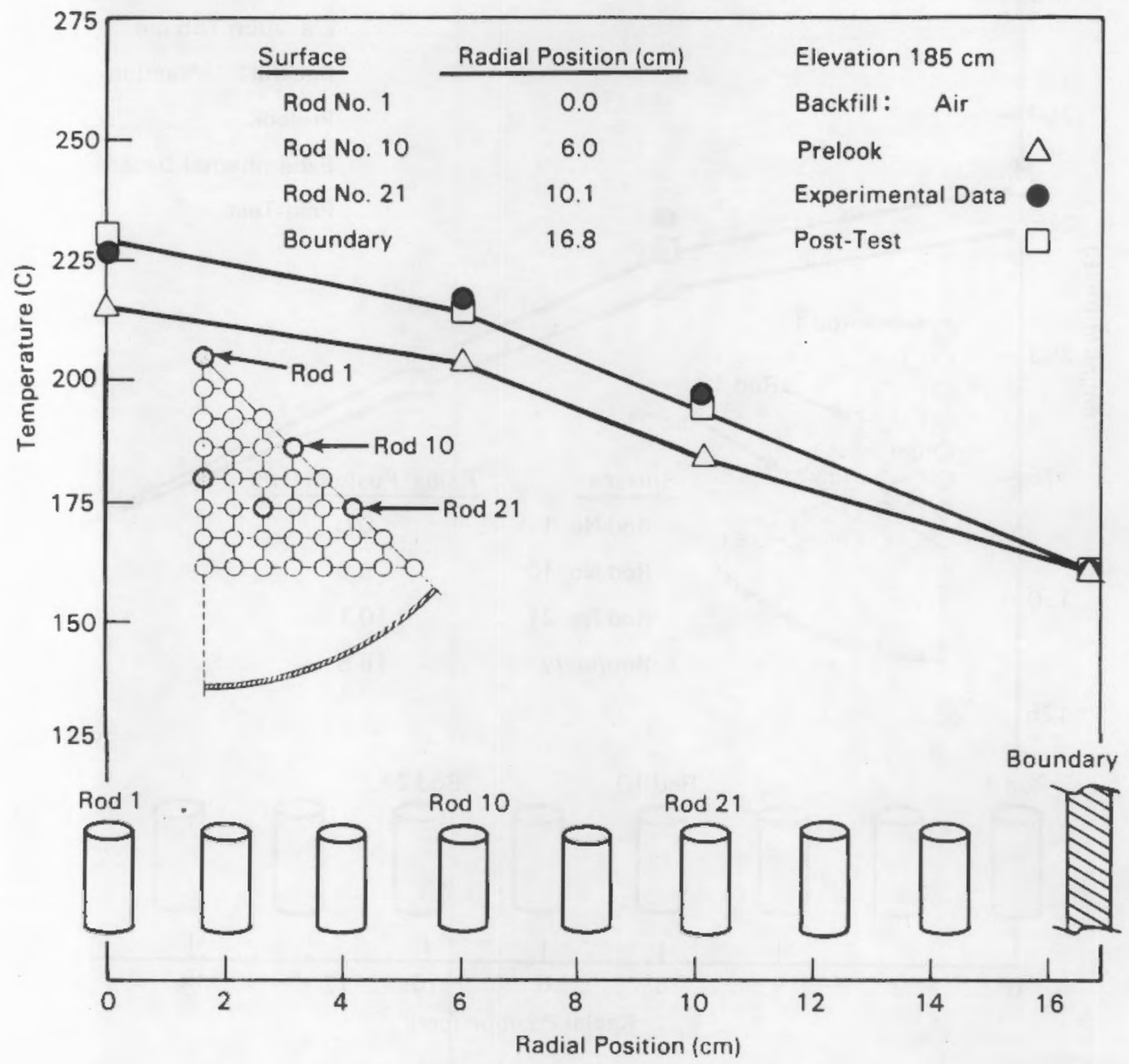

FIGURE 4.10. Predicted and Experimental Radial Profiles at Elevation $185 \mathrm{~cm}$ : Air Backfill, PWR Single Assembly Test 


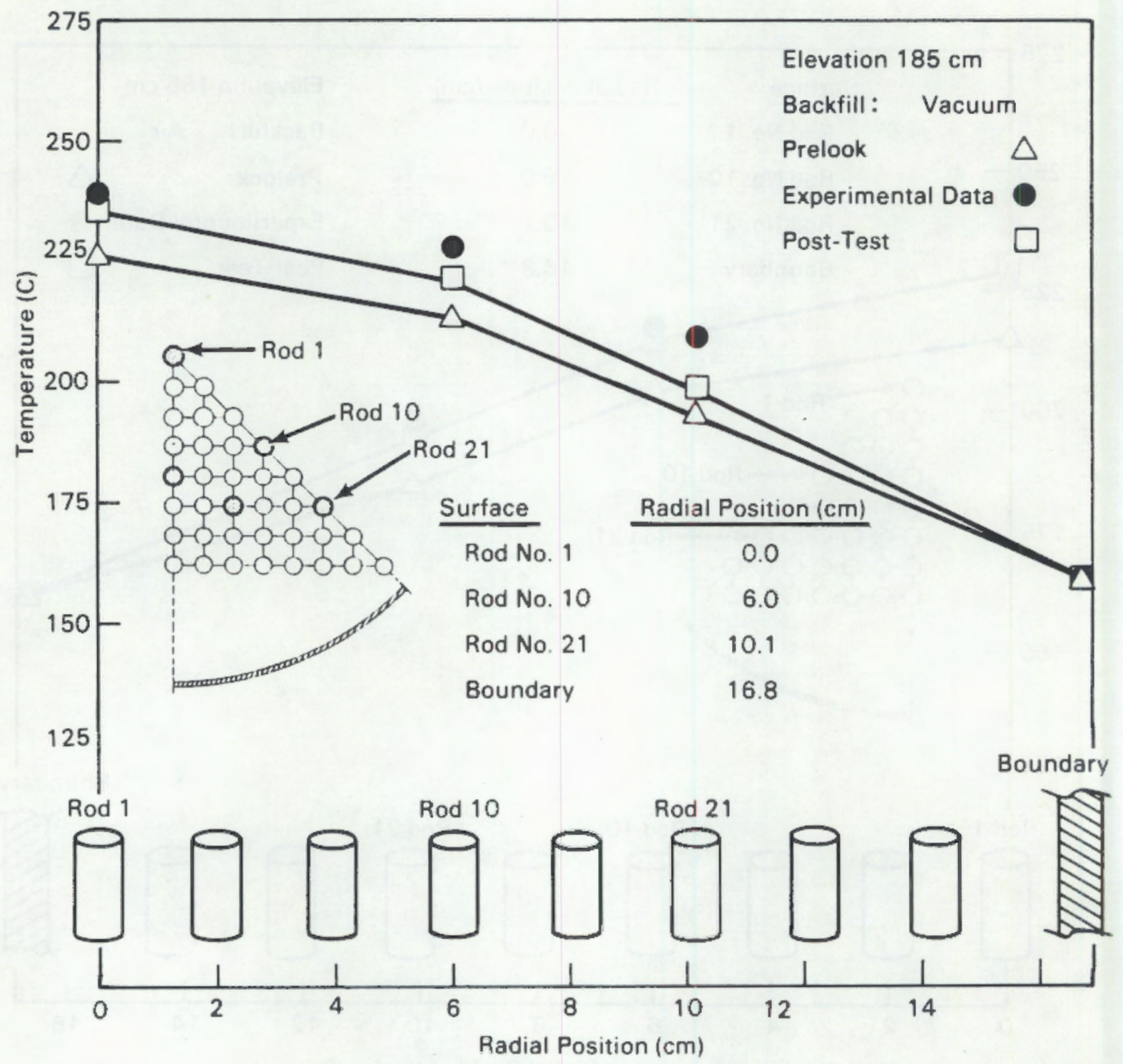

EIGURE 4.11. Predicted and Experimental Radial Profiles at Elevation $185 \mathrm{~cm}$ : Vacuum Backfil1, PWR Single Assembly Test 
helium data is due to the ten-fold increase in helium thermal conductivity over that of air; the fact that this reduction was not observed in the predictions suggests a deficiency in the fluid conduction or rod-fluid heat transfer models. In the prelook version of the code, rod-to-coolant heat transport is formulated to be proportional to the difference between the rod surface temperature and the average temperature of the surrounding fluid. This formulation tends to introduce artificial numerical thermal resistance in the transverse direction and would account for the above discrepancies in the rod-to-rod temperature differences. For the post-test analyses, the formulation of the rod-to-coolant heat transfer model was modified so that heat transport is proportional to the difference in rod surface temperature and the temperature of each individual subchannel around the rod. This formulation has the effect of lowering the thermal resistance in the transverse direction, and as the post-test analysis shows, appears to give a better approximation for spent fuel storage applications.

\subsubsection{Air Backfill Results}

The results for the air case, illustrated in Figures 4.7 and 4.10, consistently underpredict the data at all radial locations, with the greatest disagreement occurring in the lower elevations. Since radiation and convection are the predominant means of heat removal in an air backfill, one or both of these models may be in error. As discussed subsequently in the vacuum test data comparison, the radiative heat transfer model can be improved; however, even with the improvement, the test data was still underpredicted with excessive cooling still calculated in the lower elevations. This suggests an overprediction of the convection component.

The driving force (fluid density distribution) for natural convection depends on input correlations for both flow resistance and heat transfer, so, it is difficult to separate thermal effects from momentum effects in evaluating the momentum models. However, since the thermal models are evaluated essentially independently in the helium and vacuum cases, the momentum models must be evaluated in the air case. Differences in measured and predicted temperatures for the air backfill case were attributed therefore to errors in 
the calculated air circulation rate. These differences were in turn attributed to the application of a friction factor developed for pipe flow to rod bundle geometries, and the unmodeled assembly friction losses (inlet, exit, and spacers).

For the post-test analysis the method of Sparrow and Loeffler (1959) was used to obtain a friction factor correlation for flow between cylinders arranged in a square array. The resultant friction factor is defined as $f=100 /$ Re. This form produces a friction factor which is approximately $50 \%$ greater than those used in the prelook analysis.

A parameter study showed that the helium and air data trends were better represented by the correlation $\mathrm{Nu}=3.66$ which is derived using a constant temperature assumption. This compares to the correlation of $\mathrm{Nu}=4.36$ used in the prelook analysis which is a correlation derived by assuming constant heat flux.

\subsubsection{Vacuum Results}

The results of the vacuum run, displayed in Figures 4.8 and 4.11 , consistently underpredict the data at all radial locations, with best agreement seen at the upper elevations of the test section. The consistent underprediction in the middle elevations is attributed to uncertainty in the rod and wall emissivities, or the applicability of the rod radiation model, or a combination of both. Since the greatest uncertainty in developing the radiation exchange factors was expected to be the assumption of uniform radiosity, this model was evaluated first.

In the whole-pin approach, it was implicitly assumed that the reflected energy flux is the same at every point on the fuel rod surface. This allows radiation received on one side of a rod to be reflected out from the opposite side, an appropriate assumption for flat or concave surfaces, but inappropriate for circular or convex surfaces. To improve this model the number of circumferential nodes on the surface of each rod was increased from one to four. With this "quarter-pin" approach each quadrant acts independently in viewing and reflecting radiation, even though the entire rod surface is still 
assumed to be isothermal. Graybody exchange factors using the quarter-pin approach were employed in the post-test simulations for all media. Improved agreement with the vacuum data was observed with the new exchange factors as shown in Figures 4.8 and 4.11 .

\subsubsection{Post-Test Refinements}

The post-test calculations were made with an improved developmental version of the code which was undergoing modification simultaneously with the prelook analysis. In addition to the modification made to the rod-to-coolant heat transfer model discussed in Section 4.3.1.1, the developmental version also contained the added capabilities of being able to internally iterate to a zero-net flow solution, and included a more flexible boundary heat transfer model. The more versatile boundary model significantly simplified the cask noding in that the cask interior could be modeled using a single assembly instead of the three required previously.

The new model also allowed for direct input of the boundary temperature profile of the canister wall. The post-test single assembly cask model, displayed in Figure 4.12, consisted of 28 inner fluid subchannels, a single peripheral downcomer subchannel, 36 individually modeled fuel rods, and the canister wall. Although these refinements made the analysis easier to perform, it is not expected that these latter modifications influenced the accuracy of the predictions.

\subsubsection{Post-Test Predictions}

Subsequent to the availability of experimental data, a series of numerical and parametric studies were carried out to determine where improvements in the predictions could be made. A summary of the changes identified in the prelook comparison for each of the three cases follows.

The most noticeable disagreement for the prelook helium data comparisons was in the fuel assembly radial temperature distribution, an effect attributed to the formulation of the rod-to-coolant heat transfer model. This effect was modified by a revision of the model. The results of this modeling change 


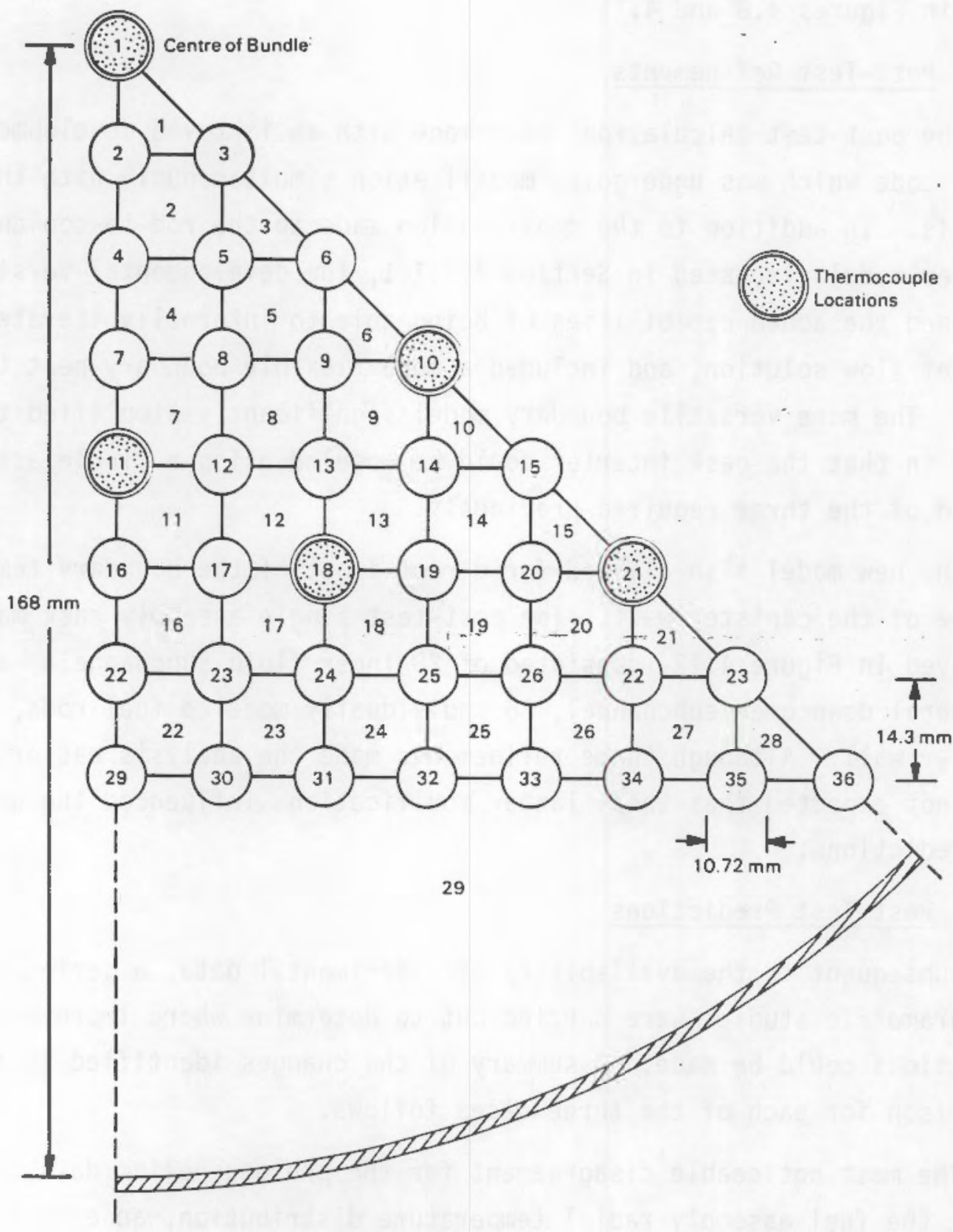

EIGURE 4.12. Cross Section of COBRA-SFS Post-Test Computational Model for the PWR Single Assembly Test 
can be seen in the improved agreement with the helium rod temperature data at all radial locations, as displayed in Figure 4.9. The agreement in peak rod temperature was seen to improve to within $\pm 3^{\circ} \mathrm{C}$ for the post-test predictions.

The prelook comparison with the air data shown in Figure 4.7 indicated a somewhat larger skew in the axial temperature profiles and excessive cooling in the lower elevations--trends which are expected to occur with overpredicted convection. The amount of convection was reduced by modifying the rod friction factor so that the effect of adjacent rods on the flow field are accounted for. This was accomplished by increasing the friction factor from $64 / \operatorname{Re}$ to $100 / \mathrm{Re}$. The increased friction assumed in the post-test simulations provides a much better agreement in the axial temperature profiles, and appears to have provided a better match with the lower elevation data.

In addition to the increased friction, a new heat transfer correlation was adopted which represents a constant surface temperature solution for pipe flow; $\mathrm{Nu}=3.66$, a 16 percent reduction from the prelook correlation, $\mathrm{Nu}=4.464$ (constant heat rate solution). Both changes in friction factor and heat transfer correlations were accomplished by modifying the model input and not by code modifications. As a result of these changes, the agreement in the air backfill peak rod temperature improved significantly to within $\pm 3^{\circ} \mathrm{C}$.

The prelook vacuum data comparison consistently underpredicted the data at all radial locations. Although the disagreement may be due to uncertainty in the fuel rod and canister emissivities, it was felt that the assumption of uniform radiosity over the fuel rod surface was in error. This assumption is not valid for the circular, densely packed geometry of a fuel assembly, since radiation received on one side of a rod is not reflected out the opposite side, $180^{\circ}$ from the direction of incident radiation. To improve upon the assumption of uniform radiosity in the calculation of gray body exchange factors, the fuel rod surface was divided into four quadrants, each quadrant acting independently in receiving and reflecting radiation. The effect of this change is that radiation is reflected back in the general direction from which it is received. As a result, the agreement in peak rod temperatures 
was significantly improved to within $\pm 3^{\circ} \mathrm{C}$ of the data, as seen in Figures 4.8 and 4.11 .

In all cases, the agreement with the test data was considerably improved in the post-test simulations. The agreement in peak rod temperature for the helium, air, and vacuum runs were within $\pm 3^{\circ} \mathrm{C}$. This is approximately equal to the data scatter, estimated at $\pm 3^{\circ} \mathrm{C}$ (Bates 1986). The overall agreement with the data is quite good; however, some disagreement still remains, especially in the upper elevations. Specifically, the temperatures $310 \mathrm{~cm}$ above the test assembly bottom are consistently underpredicted in all media. This disagreement is attributed to the unmodeled heat transfer from the tubular heater located on the canister top lid. The presence of the fuel support cage horizontal support plate may also be a contributor to the higher measured temperatures at these elevations. 


\subsection{ELECTRICALLY HEATED PWR SINGLE ASSEMBLY SPENT FUEL TEST}

The temperature response of an electrically heated model PWR test assembly was investigated at two power levels in atmospheres of air, helium, and a vacuum, while oriented in horizontal, vertical, and inclined positions $\left(25^{\circ}\right.$ from horizontal). Experimental temperature data were recorded at several axial and radial positions in the test assembly. In this section, a description of the test apparatus, computational model, and modeling uncertainties are provided. Prelook code predictions are compared with available test data and changes made to improve agreement with data are presented. Post-test predictions are provided to demonstrate the effectiveness of the modifications.

\subsection{TEST DESCRIPTION}

The test assembly used to investigate the effects of gas backfill, orientation, and power levels on the thermal response of a model spent fuel assembly is illustrated in Figure 5.1. Major components of the test assembly consist of: 1) cask body, 2) model fuel bundle and fuel tube, 3) fuel-tube transition piece, and 4) closure lids. A brief description of each of the major components is given below.

The cask body is a cylindrical vessel formed from two concentric steel cylinders. Mating flanges were welded to each end of the containment for the closure lids. The resulting interior cavity of the cask is $444.5 \mathrm{~mm}$ in diameter and $4826 \mathrm{~mm}$ long. In this series of tests, the cask annulus contained air at one atmosphere. Natural convection within this annulus was observed as expected.

Encircling the cask exterior wall are three electrical resistance strip heaters, which are spirally wound in parallel along the length of the cask barrel. The heaters provide elevated boundary temperatures for the model fuel bundle, typical of what may be expected in a multiassembly storage system. The heaters are controlled by means of an "off-on" adjustable setpoint 


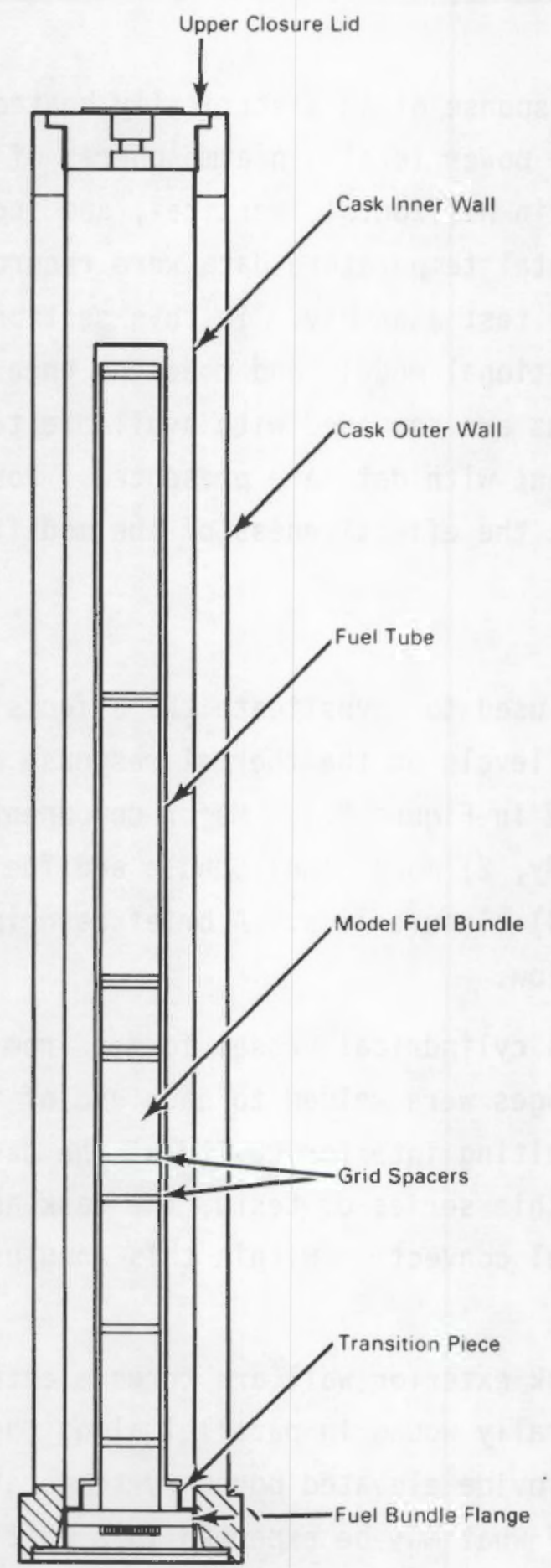

EIGURE 5.1. Electrically Heated PWR Single Assembly Test Apparatus 
thermostat to establish the desired axial temperature profile on the cask inner wal1. A 50.8-mm-thick insulation blanket covered the cask barrel and strip heaters to minimize heat losses. Twenty thermocouples are located on the annulus inner wall to determine the cavity temperatures. The thermocouples are attached to flexible, stainless steel bands which fit into the cask I.D. at 5 axial positions. An additional thermocouple is used for temperature feedback control of the cask strip heaters.

Enclosed within the cask cavity is the electrically heated model fuel bundle and fuel tube. The fuel bundle was designed to simulate a $15 \times 15$ light water reactor PWR fuel assembly--the fuel tube was an actual spent fuel assembly storage tube as used in the reactor pools. Two-hundred and fourteen heater rods and 11 unheated (water) rods compose the model fuel bundle. In addition to the unheated water rods, five of the model fuel rod leads were shorted out or disconnected, and thus, did not generate power. A cross section of the model fuel assembly showing the heater, water, and zero-power rods is displayed in Figure 5.2. Not shown on this figure are the four "egg-crate" spacers and the four "bar" grid spacers which maintain the fuel rod array in a fixed, vertical orientation. The bar-type spacer refers to a grid spacer fabricated from stainless steel bars; the egg-crate spacers are prototypic of those found in actual PWR fuel assemblies.

The heater rods were assumed to produce a uniform axial power profile over their 3658-mm active length; the total rod length is $4216 \mathrm{~mm}$. The model fuel rods extend through a 51-mm-thick flange plate at the test section bottom which is bolted to the transition piece. A uniform radial power profile was obtained by matching rod electrical resistance values. Total bundle power was measured by calibrated watt transducers. Sixty type " $T$ " thermocouples are located at strategic radial and axial positions along the rod bundle. The thermocouples were positioned and locked midway between two adjacent heater rod sheaths by means of a thermocouple "pad", or positioned directly on the rod surface by means of a thin steel band. 
Row

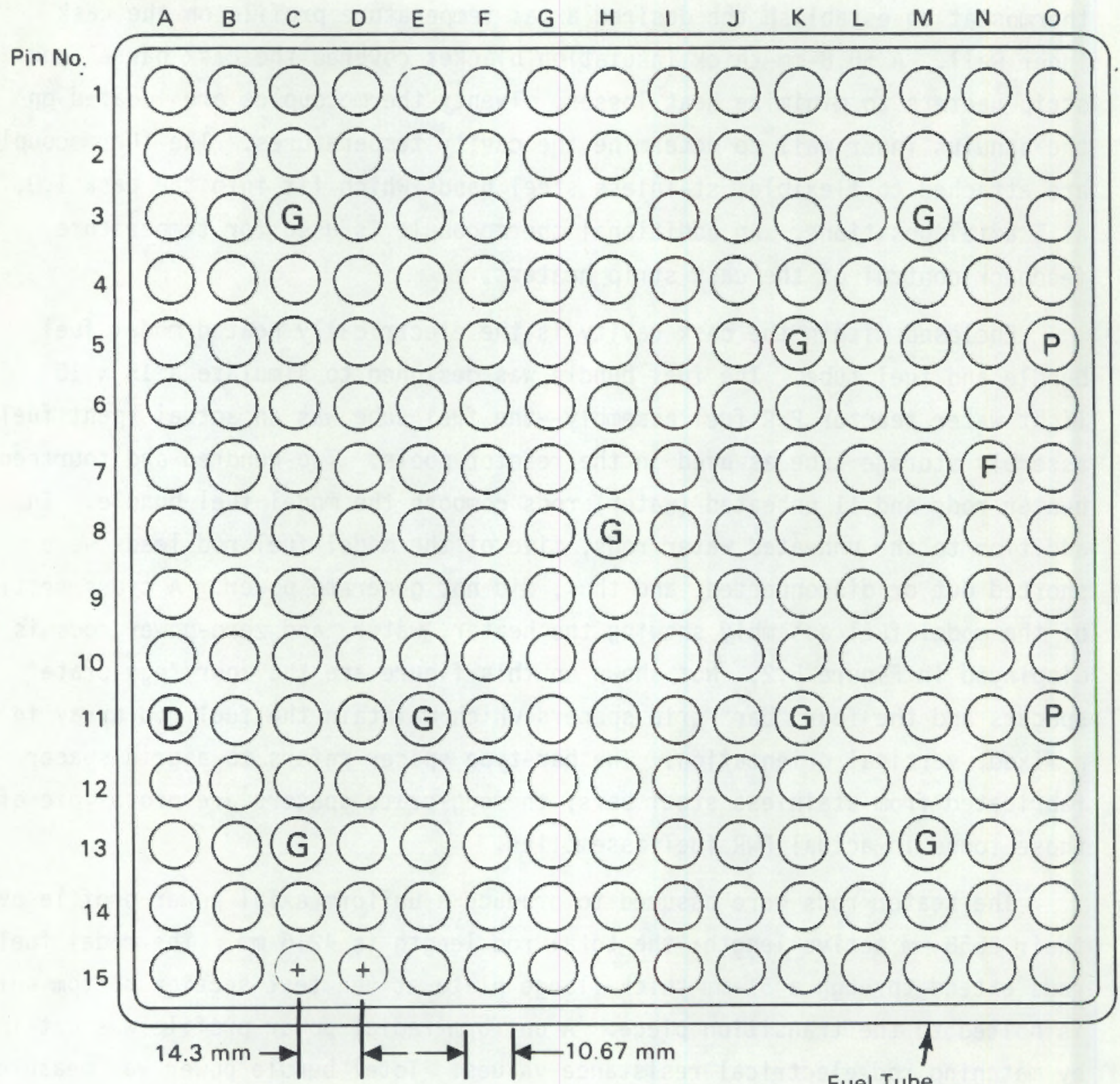

Fuel Tube

$$
\begin{aligned}
& G=\text { Unheated Guide Tubes } \\
& F=\text { Failed Heater Element } \\
& D=\text { Power Leads Disconnected } \\
& P=\text { Pressure Tap Tube }
\end{aligned}
$$

EIGURE 5.2. Cross Sectional View of Electrically Heated Single Assembly Test Section 
Enclosing the model fuel assembly is the fuel tube, a square walled, stainless steel-clad Boral tube with rounded corners. The fuel tube is approximately $4089 \mathrm{~mm}$ in length and is corrugated with $1.27-\mathrm{mm}$-high dimples spaced uniformly along the length of the tube. The fuel tube acts as a thermal radiation shield for the assembly and defines two distinct flow regions within the cask interior.

The lower end of the fuel tube is welded to the fuel tube-transition piece, a stepped, perforated, cylindrical pedestal which supports the model fuel assembly and allows for flow communication between the interior and exterior regions of the fuel tube. The transition piece, shown in Figure 5.3, contains two rows of $25.4-\mathrm{mm}$-diameter holes in the upper pedestal (50 total) for flow recirculation, which approximates the flow area of a prototypic fuel assembly end fitting. The base of the transition piece is bolted to the cask bottom end piece to form the lower end seal. Penetrations in the lower flange include instrument leads and vent lines for cask internal atmosphere control. Additional thermocouple leads exit through the upper closure lid, a flanged, metal cylinder which is bolted to the cask body to form a pressure tight seal.

The assembled test cask was used to investigate the thermal response of the model fuel bundle with backfill gases of air, helium, and a vacuum in vertical, horizontal, and inclined orientations (25 degrees from horizontal). The tests were repeated at bundle power levels of 0.5 and $1.0 \mathrm{~kW}$. Additional tests were run to determine characteristic cask boundary conditions and experiment repeatability. For all tests, the annular space between the cask inner and outer wall was air-filled and sealed. For tests with an air environment, the cask interior was vented to the atmosphere. With the cask sealed, the vacuum tests were operated at pressure of 0.1 atmospheres; a minimum low pressure of 0.04 atmospheres was reached to investigate the effect of vacuum level on the assembly thermal response. For the helium tests, the cask was sealed, evacuated, and repressurized with helium to approximately 1.1 atmospheres with a pressurized helium supply. An outline of the test matrix is presented in Table 5.1 . 


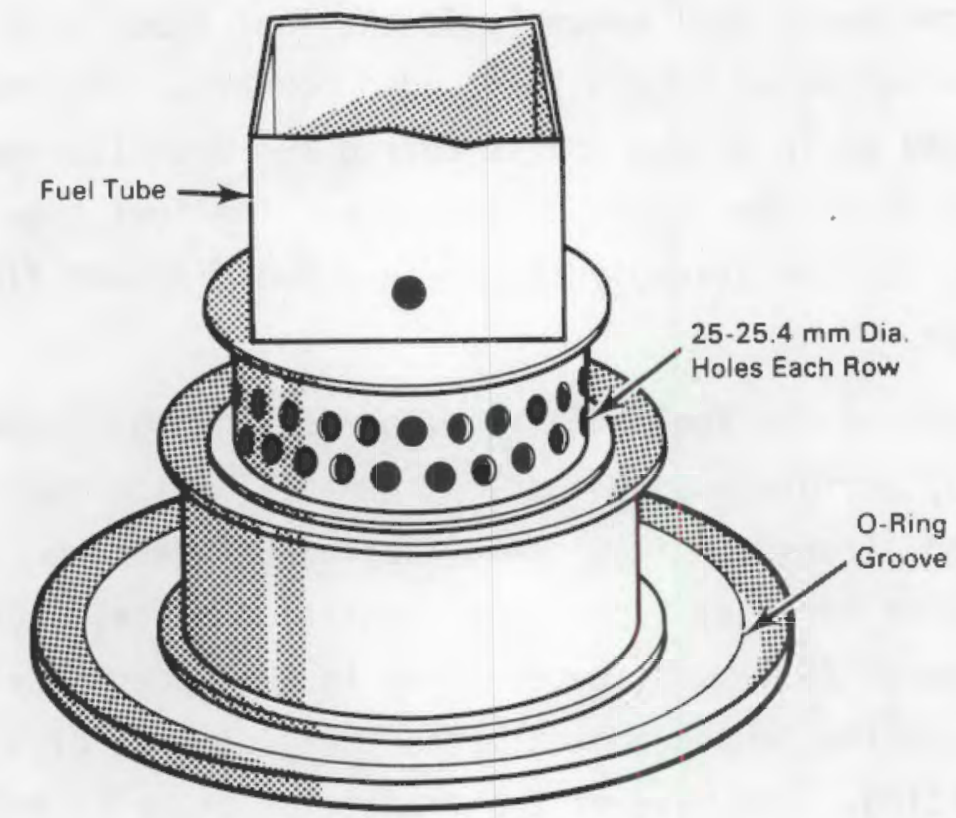

EIGURE 5.3. Fuel-Tube Transition Piece

IABLE 5.1. Electrically Heated PWR Single Assembly Test Matrix

Test Actual No. Attitude Power (kW)

Power

$\begin{array}{rllllll}1 & 25^{\circ} & 1.0 & .951 & \text { AIR } & 0.98 & 28^{\circ} \mathrm{C} \\ 2 & 25^{\circ} & 1.0 & .940 & \text { VAC } & 0.11 & 30^{\circ} \\ 3 & 25^{\circ} & 1.0 & .956 & \text { He } & 1.04 & 27^{\circ} \\ 4 & 25^{\circ} & 0.5 & .501 & \text { He } & 1.04 & 23^{\circ} \\ 5 & 25^{\circ} & 0.5 & .484 & \text { VAC } & 0.11 & 28^{\circ} \\ 6 & 25^{\circ} & 0.5 & .477 & \text { AIR } & 0.98 & 24^{\circ} \\ 7 & H & 0.5 & .487 & \text { AIR } & 0.98 & 23^{\circ} \\ 8 & H & 0.5 & .486 & \text { VAC } & 0.12 & 26^{\circ} \\ 9 & H & 0.5 & .500 & \text { He } & 1.04 & 21^{\circ} \\ 10 & H & 1.0 & .964 & \text { He } & 1.03 & 23^{\circ} \\ 11 & H & 1.0 & .949 & \text { VAC } & 0.11 & 23^{\circ} \\ 12 & H & 1.0 & .943 & \text { AIR } & 0.98 & 27^{\circ} \\ 13 & V & 1.0 & .994 & \text { AIR } & 0.98 & 19^{\circ} \\ 14 & V & 1.0 & .977 & \text { VAC } & 0.10 & 17^{\circ} \\ 15 & V & 1.0 & .995 & \text { He } & 1.03 & 21^{\circ} \\ 16 & V & 0.5 & .501 & \text { He } & 1.03 & 21^{\circ} \\ 17 & V & 0.5 & .496 & \text { VAC } & 0.11 & 22^{\circ} \\ 18 & V & 0.5 & .515 & \text { AIR } & 0.98 & 22^{\circ}\end{array}$




\subsection{COMPUTATIONAL MODEL DESCRIPTION}

The computational model used to simulate the Electrically Heated Single Assembly Heat Transfer Tests is presented in this section along with the modeling parameters and correlations employed. A brief discussion of the modeling uncertainties is also provided.

\subsubsection{Nodal Representation}

A three-dimensional model of the electrically heated single assembly test section was developed for the COBRA-SFS analysis. A horizontal cross section of the computational cell arrangement is presented in Figure 5.4 which illustrates the subchannel and wall noding employed. A total of 24 uniform axial nodes were used to model the axial direction. Only the interior components were modeled since the inner wall temperatures were provided as a boundary condition.

The test section was modeled as two assemblies: the interior, or rod bundle assembly, and the exterior, or downcomer assembly. In the interior assembly, 256 subchannels were used to describe the flow paths at each axial level; an additional 16 subchannels defined the downcomer flow paths. Conduction between fluid subchannels was accounted for in both assemblies. Rod and wall surface drag, spacer grid losses, and fuel tube inlet and exit losses were all accounted for in the model.

Each of the 225 heater rods in the interior assembly was individually modeled and was divided into five radial nodes: four for the fuel, and a single node for the cladding. In the prelook model, no circumferential rod effects or rod axial heat transfer effects were included. Uniform axial and radial power profiles were assumed. A total of 15 of the rods failed and did not produce any power. The diameter difference of the water and heater rods was properly accounted for in the subchannel model, but the radiation heat transfer model assumed all rods to be equal in diameter. Flow through the water rods was not modeled. 


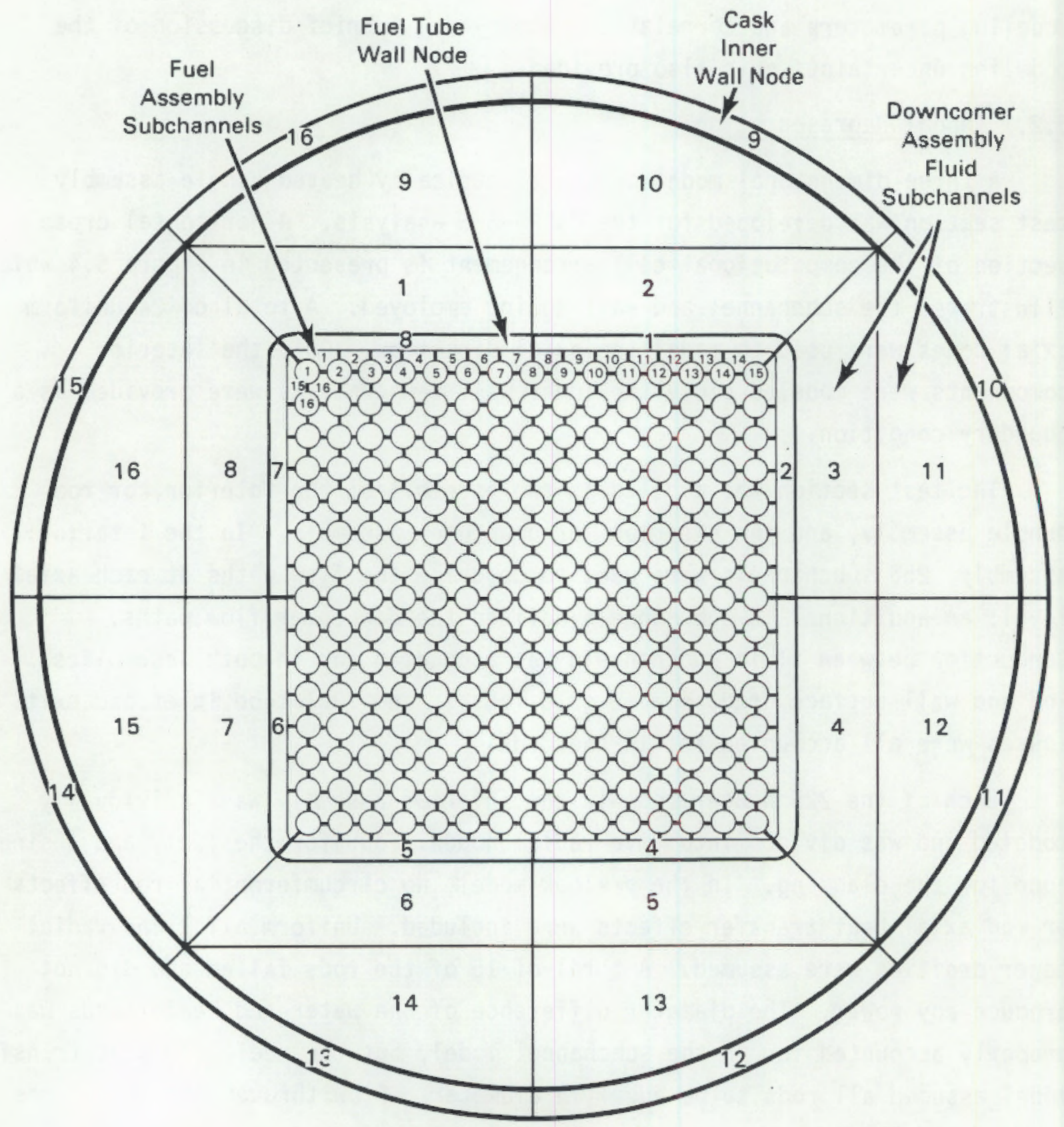

EIGURE 5.4. Cross Section of COBRA-SFS Prelook Computational Model for Electrically Heated PWR Single Assembly Test 
The fuel tube and cask inner wall were each modeled with eight uniform nodes. The eight cask wall nodes were used to represent the temperature boundary conditions set during testing. In the horizontal and inclined positions, a circumferential gradient in the cask wall was measured due to the natural convection occurring within the air-filled annulus of the cask body. To accommodate the circumferential boundary temperature distribution, eight wall nodes were used to model the cask outer wall. Because the circumferential variation in boundary temperatures were expected to influence the fuel tube and fuel assembly temperature, eight wall nodes were used to model the fuel tube as well. The composite fuel tube wall was modeled using a single radial node. Both axial and circumferential heat transfer were accounted for in the fuel tube and cask wall nodes. Radiation heat exchange between the walls and rods on a plane was determined from graybody exchange factors prescribed for the interior and exterior assemblies.

In the interior assembly, the exchange factors were derived from one-quarter rod surface segments, a more exact approach than the assumption of uniform radiosity over a surface. Proper subdivision of the fuel rod surface was shown in the PWR Single Assembly Spent Fuel Test comparison to be significant in determining the proper radiative heat exchange within an enclosed assembly (Section 4.3.1.3). The graybody exchange factors specified for the downcomer assembly were based on wall node surface areas equal to one-eighth of the total heat transfer area. All gaseous fill media were considered nonparticipating with respect to radiation heat transfer.

As-measured temperatures along the cask interior wall were applied in the model by use of specified boundary temperature profiles in the downcomer assembly. Additional temperature measurements in the upper and lower plenums completed the prescribed boundary temperature field of the cask cavity.

Upper and lower plenums were employed to model the large mixing volumes and heat transfer areas that exist in the cask cavity above and below the model fuel bundle. The plenum models allow for mixing of the upflow and downflow channels and provide a means of adding or removing heat from these regions. 
No flow field is calculated within the plenums; however, one-dimensional radial and axial heat losses were modeled. Heat transfer from the upper and lower closure lids was simulated using this approach. Axial heat transfer from the fuel tube walls to the plenum region was also modeled. A sample COBRA-SFS input listing for this test is provided in Appendix $C$.

\subsubsection{Modeling Parameters and Correlations}

The material properties used in the computational model, with the exception of emittances, were well defined. Fluid properties were input as functions of temperature and updated continuously during the simulation. A range of emissivity values was identified for the solid structures within the test section. Emissivity is known to be dependent upon fabrication technique, oxidation buildup, and temperature. Unique values of emissivity were used for each of the stainless steel components: an emissivity of 0.2 was assumed for the stainless steel-clad fuel tube; whereas an emissivity of 0.6 was assumed for the heater rods. The larger value of emissivity chosen for the heater rods reflects the many hours of high-temperature operation in an oxidizing environment. The emissivity value used for the fuel tube lies in the range of experimental data previously obtained from a similarly constructed fuel tube (Taylor 1983) prior to exposure to high temperature. Allowing for some oxidation of the cask stainless steel inner liner, an emissivity value of 0.6 was assumed.

Heat transfer from the rods and walls to the coolant was prescribed through use of a film heat transfer coefficient of the form $\mathrm{Nu}=4.364$ (Kays and crawford 1980). This formulation is an exact solution of the energy equation for a constant heat rate and fully developed velocity profiles in a circular tube. The film coefficient was evaluated as a function of temperature at each location. For the low pressure air case (vacuum), no enhancement of the heat transfer by convection was assumed; thus, $\mathrm{Nu}=1.0$.

The overall flow resistance of the test assembly was assumed to be a combination of:

- rod and wall surface drag 
- spacer losses

- fuel tube inlet and exit losses

- model fuel bundle inlet and exit losses.

For the interior assembly, rod and wall friction were modeled from an analytical solution for fully developed laminar flow along cylinders arranged in a square array; $f=100 / \operatorname{Re}$ (Sparrow and Loeffler 1959). This correlation was found to provide the best estimates of wall friction as determined in the PWR Single Assembly Spent Fuel Test post-test analysis. This estimate of form friction was also used in the downcomer for the helium and vacuum cases, but was not applied in the air case, as discussed below.

A substantially larger value of friction was required for the downcomer assembly in the ajr case to lessen the magnitude of numerically induced flow oscillations. Small changes in the system pressure drop produced corresponding large changes in the downcomer velocity field. The favorable buoyant properties of air and the large subchannel areas in the downcomer are thought to be responsible for the oscillations observed. To stabilize the flows, a friction factor of 100 was applied in the downcomer region. Evaluation of the effect of the increased downcomer flow resistance indicated a $\pm 10^{\circ} \mathrm{C}$ change in peak clad temperature.

Spacer pressure losses were defined for both the egg-crate and bar-type spacers as $K=1$ and $K=8$, respectively. Losses due to the area changes at the model fuel assembly exit were modeled by a loss coefficient of 1.0 . Losses at the model fuel assembly inlet included losses due to area change as well as losses from the fuel tube-transition piece (Figure 5.3). A loss coefficient of 18 was used for the downcomer and model fuel assembly inlet (Idel'Chik 1966).

Heat losses from the plenum regions to the boundary required the specification of the thermal resistance from the bulk mixed-mean fluid temperature to the film boundary layer. For the air cases, a correlation of the form $\mathrm{Nu}=50$ was used to define this resistance for both plenum regions, and was based on results for air flowing in a pipe (Kreith 1965). A correlation 
of the form $\mathrm{Nu}=10$ was used in the helium backfill cases which incorporates an increase in the bulk-to-film thermal resistance due to the reduced natural convection characteristics of helium.

\subsubsection{Modeling Uncertainties}

The computational model developed for the analysis was based on drawings supplied by Allied General Nuclear Services, fabricators of the test assembly, and descriptions of the components, instrumentation, and test operation provided in the data report published by the MRS Program Office (Bates 1986). In developing the model, significant uncertainties were associated with the following important heat transfer and fluid flow parameters:

- materiat emissivities

- model fuel rod pitch

- plenum thermal resistance

- test section flow resistance.

Each of these uncertainties is addressed below.

The surface emissivity values were a major source of uncertainty in these simulations. A wide range of emissivity values was observed in the literature for the test section components and was found to be dependent upon oxidation buildup, fabrication technique, and temperature. Values used in the prelook predictions were 0.6 for the stainless steel cask inner wall, 0.2 for the stainless steel-clad fuel tube, and 0.6 for the stainless steel-clad heater rods. The values chosen represent best estimates. Confidence in these values is low, and variation of emissivity from rod to rod probably existed. Uncertainty of the graybody assumption exists for all surfaces.

It is interesting to note that uncertainty in the fuel tube emittance affects the thermal resistance of both the rod bundle and downcomer assemblies, whereas errors in the heater rod or cask inner wall emittance alters the thermal resistance for that assembly only. Additionally, because of the relatively low value of fuel tube emittance, 0.2, a small change in this parameter represents a large change in the radiative heat transfer to and from the fuel tube. 
Thus, the fuel tube emittance is a critical parameter in determining the proper radial temperature profile through the cask.

An additional parameter which influences the radiation and convection heat transfer within the cask is the model fuel rod pitch. Use of the bar-type grid spacers, in conjunction with the larger diameter water rods, effectively spreads the fuel assembly cross section such that the rod pitch is altered. The concentration of bar-type spacers in the upper elevations of the fuel assembly suggests that axial variation of the fuel rod pitch may exist. In fact, measurement of the as-built fuel rod pitch in the upper elevations indicates an increase from the nominal value of $14.3 \mathrm{~mm}$ to $14.76 \mathrm{~mm}$. The uncertainty in the fuel rod pitch is significant because radiation heat transfer within the enclosure is a function of the "view" each rod has of adjacent rods and the walls. When the pitch is increased, the views increase as well, enhancing the radiative heat removal. Uncertainty in the rod pitch also affects the convection established within the cask as the film coefficient and the friction factor are both functions of the equivalent hydraulic diameter. Thus, uncertainty in the rod pitch can affect the radiation and convection heat removal within the cask. Other uncertainties resulting from the use of the bar-type spacers are the localized flow blockage, radiation shielding, and radial conduction effects. No attempts were made to model these details. Elimination of these effects from the computational model represents another uncertainty.

A large degree of uncertainty existed in defining the plenum region heat transfer, due in part to the many simplifying assumptions that were made. Most importantly, it was assumed that the heat transfer from the plenums is a function of the natural convection established; that is, backfill gasses with good buoyant properties are expected to produce higher fluid velocities, and thus, improved heat transfer. values of the plenum bulk-to-film resistance were employed globally over the plenum surfaces, neglecting any local effects. The effect of solid structures within the plenums was also ignored. To complete the thermal model of the plenum regions, a plenum boundary temperature must be prescribed. Identifying a proper plenum boundary temperature was complicated 
because the cask closure pieces were not insulated and the cask heaters did not extend over the entire length of the test assembly. Therefore, very severe axial temperature gradients occurred within the plenum regions. The nonuniform plenum surface temperatures were approximated by an integrated temperature for the boundary, which represents another approximation.

The major uncertainty in the cask flow resistance is associated with the fuel tube-transition piece. The complex geometry and multiple flow paths of this structure make specification of the actual flow resistance difficult. Additional uncertainty exists with the loss coefficients applied to the bar-type grid spacers, and to the fuel tube exit. As discussed earlier, the artificially high flow resistance applied in the downcomer assembly to aid in the computational stability of the air backfill cases is also a cause of uncertainty.

One mode of heat transfer not well defined in these simulations is the rod axial conduction from the lower regions of the model rod to the heater rod flange. Large uncertainties exist in the heater rod-to-flange contact resistance as well as the contact heat transfer area. The version of COBRA-SFS used in this analysis does not include the capability of transferring heat axially from the rods to a plenum structure (the heater rod flange), so it was not modeled.

The electrically heated bundle was assumed to have uniform radial and axial heat generation profiles. Uniformity of the radial power distribution was assured by individual electrical resistance measurements of all rods. However, the axial power profiles of the heater rods were not verified. Therefore, by assuming a uniform power profile over the heated length, the effects of $\mathrm{Ni}$-chrome wire heater element resistance temperature dependence were ignored.

For this analysis, it was assumed that there was no fuel assembly/fuel tube contact, and that the fuel assembly remained centered within the fuel tube for all orientations. Both assumptions represent additional uncertainties in the simulation of the horizontal and inclined cases. 
In addition to the major uncertainties described above, uncertainties exist in the heater rod and wall film coefficients, rod and wall friction, and in the test section geometry. Uncertainties in the graybody radiation model, and the finite difference treatment of the axial and transverse momentum equations, are implicitly contained within the COBRA-SFS code.

\subsection{COMPARISONS OF PREDICTIONS TO DATA}

The single assembly test apparatus described in Section 5.1 was used to determine the temperature distribution of a model electrically heated PWR fuel assembly in atmospheres of air, helium, and vacuum, under two power levels, and three orientations. A total of 18 tests were performed as described in Table 5.1. In this section, a comparison of the prelook predictions performed without any prior knowledge of the data are compared to the measured test data. Following the prelook data comparison, justified improvements in the computational model were made and their effects verified in several, select post-test simulations.

\subsubsection{Prelook Predictions}

Predicted axial temperature profiles for selected, instrumented model fuel rods and the cask wall are plotted with the experimental test data for 5 of the 18 test cases in Figures 5.5 through 5.9. In each figure, four axial profiles are presented which provide the cask radial temperature distribution along the fuel tube diagonal: a center heater rod (Row $\mathrm{H}$, Pin 9, Figure 5.2), corner rod (Row $A, P i n$ 1), the fuel tube, and the cask inner wall. In all figures, the data are plotted as a function of elevation from the cask bottom. Similar axial profiles for the entire 18 run matrix are presented in Appendix $D$, along with the results of select post-test simulations.

All temperature data with the exclusion of center rod $\mathrm{H} 9$ were obtained from thermocouples welded directly onto the measurement surface. Data for rod H9 were obtained using the thermocouple pad described earlier which measures the average temperature of two adjacent, contacting rods. The code predictions 


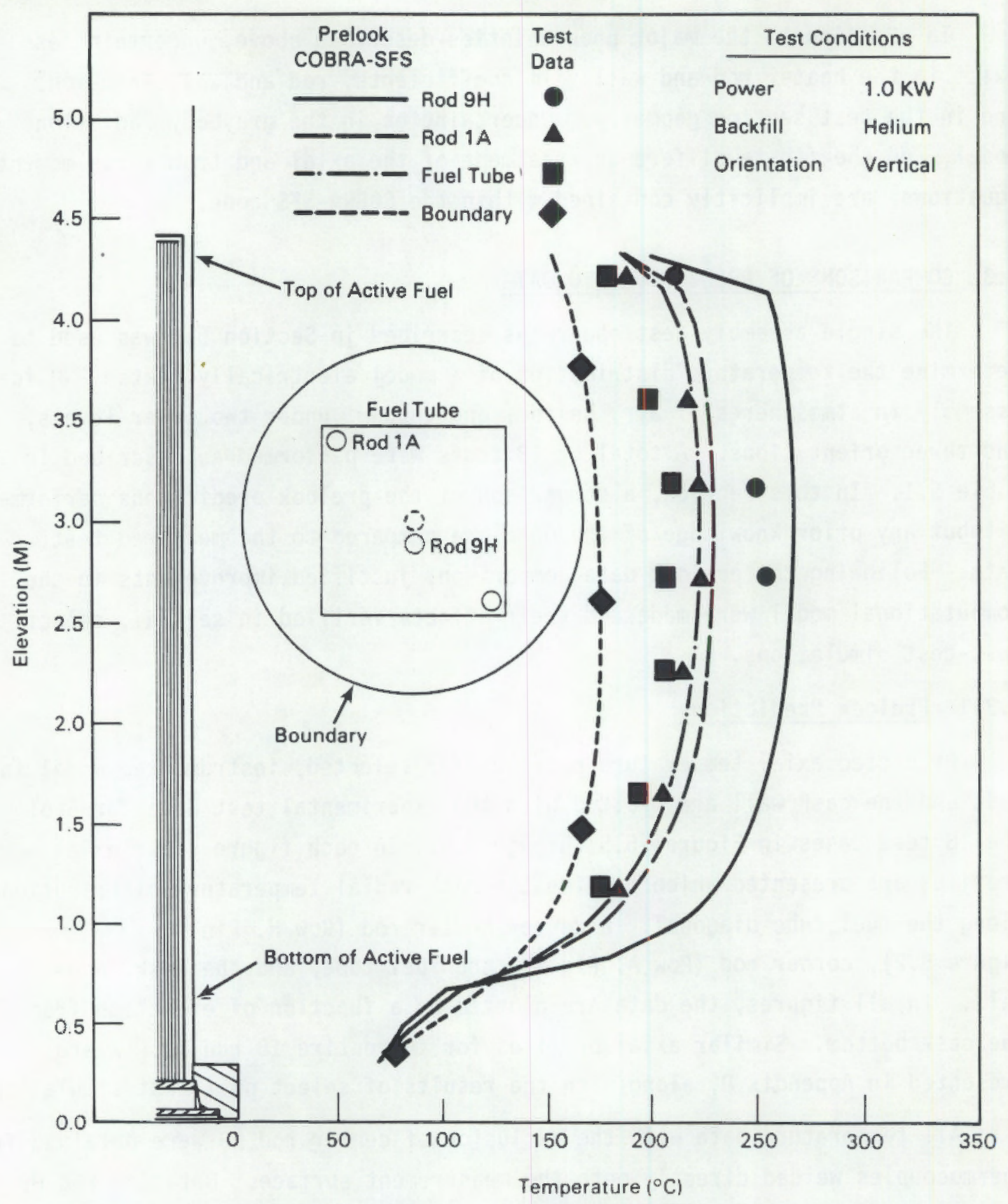

EIGURE 5.5. Prelook Predicted and Experimental Axial Profiles: $1.0 \mathrm{~kW}$, Vertical, Helium Run, Electrically Heated PWR Single Assembly Test 


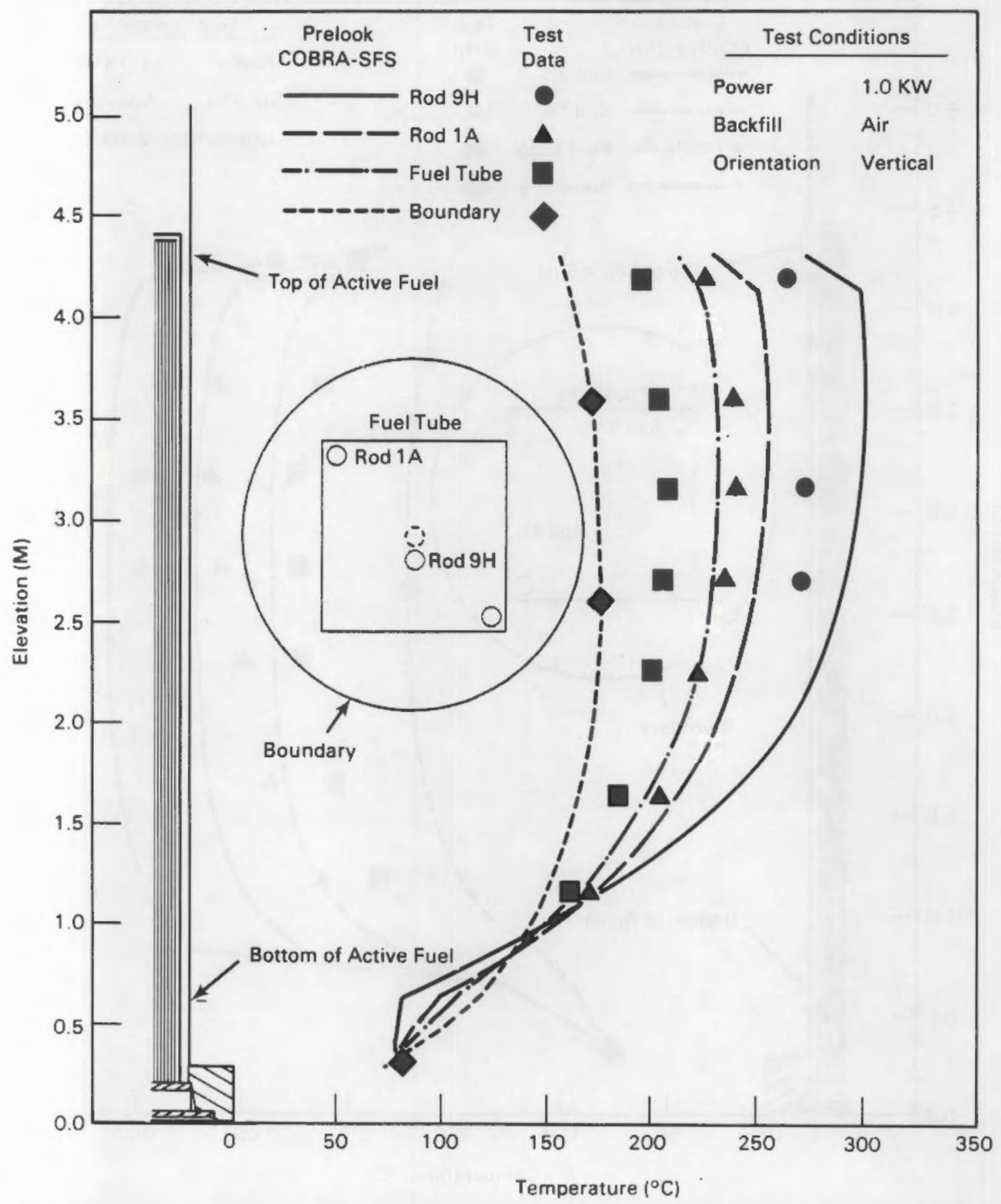

EIGURE 5.6. Prelook Predicted and Experimental Axial Profiles: $1.0 \mathrm{~kW}$, Vertical, Air Run, Electrically Heated PWR Single Assembly Test 


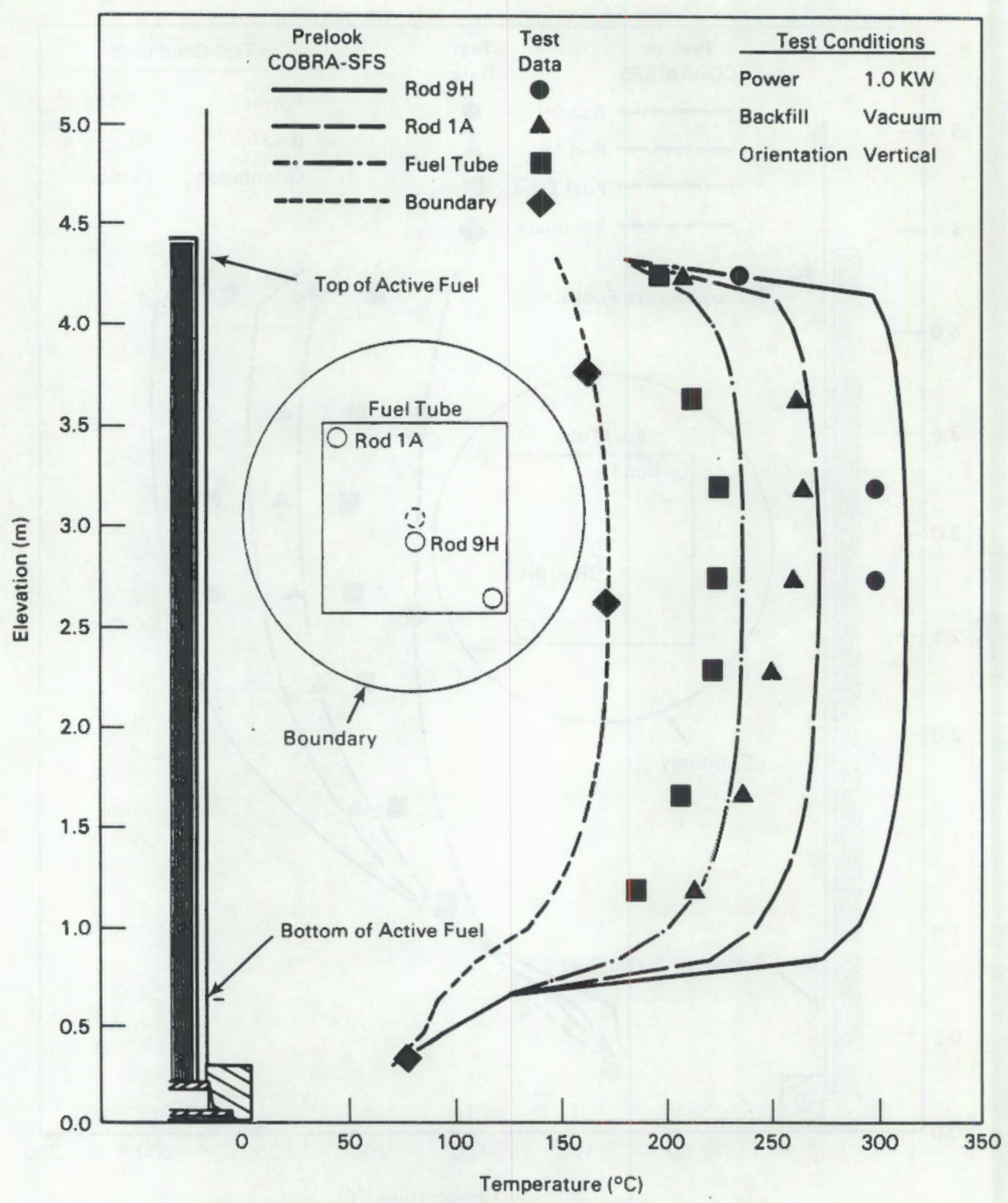

FIGURE 5.7. Prelook Predicted and Experimental Axial Profiles: $1.0 \mathrm{~kW}$, Vertical, Vacuum Run, Electrically Heated PWR Single Assembly Test 


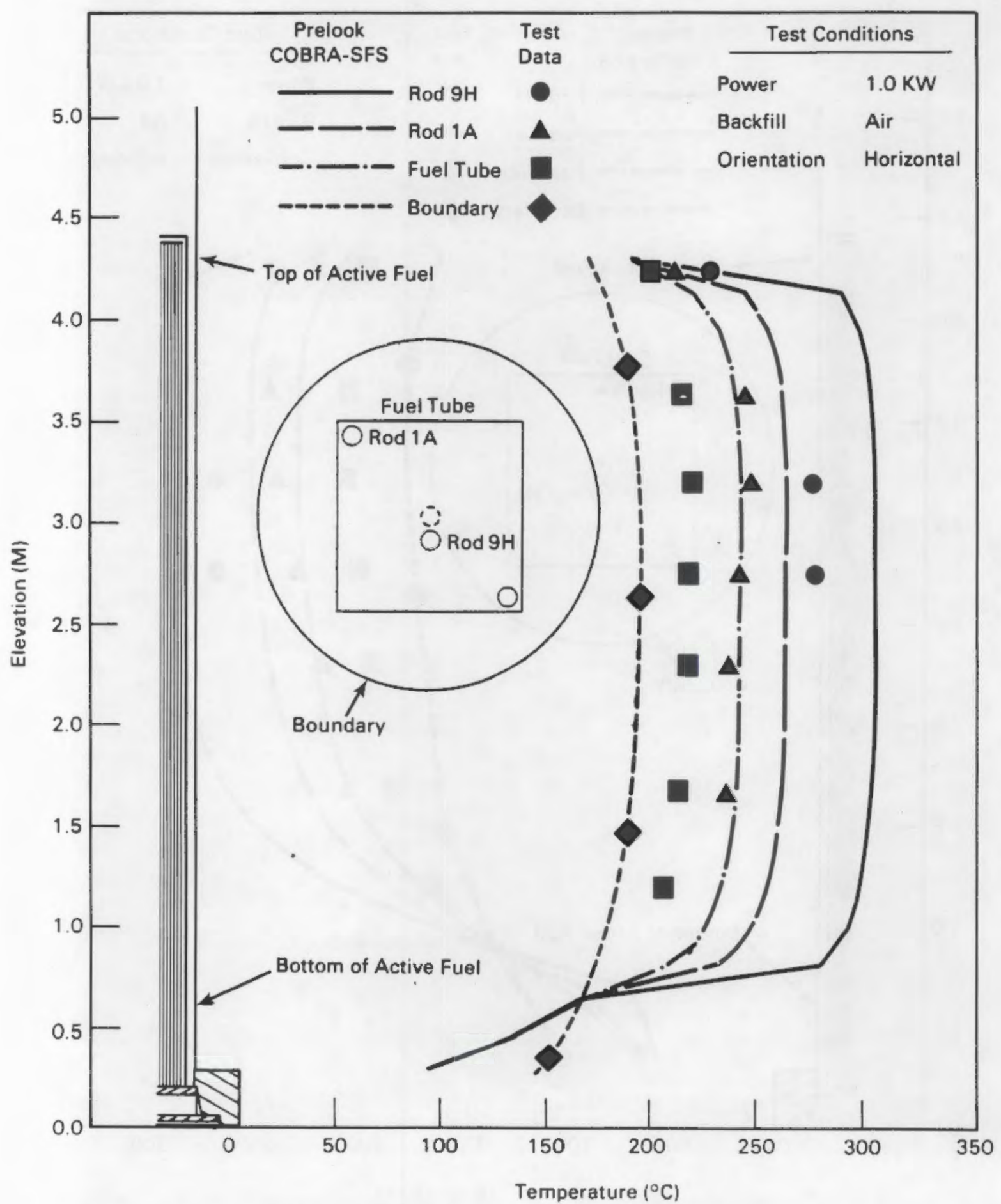

EIGURE 5.8. Prelook Predicted and Experimental Axial Profiles: $1.0 \mathrm{~kW}$, Horizontal, Air Run, Electrically Heated PWR Single Assembly Test 


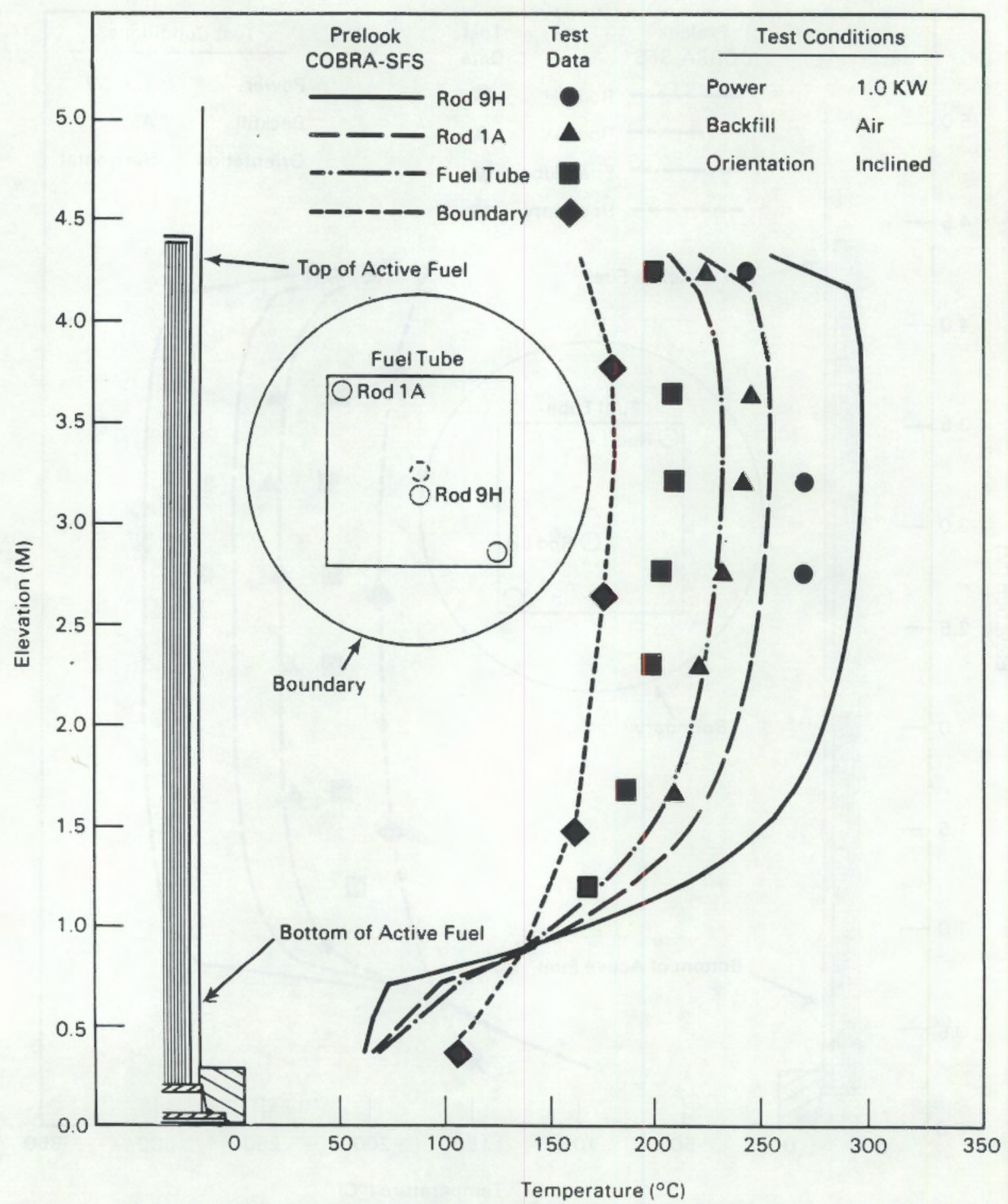

FIGURE 5.9. Prelook Predicted and Experimental Axial Profiles: $1.0 \mathrm{~kW}$, Inclined, Air Run, Electrically Heated PWR Single Assembly Test 
represent temperatures of rod H9 only and, thus, should compare slightiy higher than the data.

The results of the data comparison are organized and discussed by test orientation. Figures 5.5 through 5.7 present the vertical orientation data comparison, Figure 5.8 the horizontal, and Figure 5.9 the inclined results. Before details of individual data comparisons are discussed, a general overview of the predictions relative to the data is presented.

A review of data comparisons for all 18 runs, as displayed in Figures 5.5 through 5.9 and Appendix $C$, show that the code consistently overpredicted the data at each radial location in the cask, with the agreement generally improving for the low power cases. As expected, the most severe overpredictions were observed in the horizontal cases. For each orientation, the largest discrepancy was observed in the air backfill cases. For all runs, the temperature drop from the fuel tube-to-cask wall showed the most disagreement with the data; the overprediction of peak temperature is attributed in part to the overprediction of the fuel tube-to-cask wall temperature difference. Fairly good agreement in the axial temperature profiles is observed, al though the data comparison was complicated by the sparseness of temperature data at the lower elevations of the test assembly. Faulty and dislocated thermocouples eliminated four of the axial temperature data points for the hot center rod, leaving just three axial temperature measurements for comparison, all of which are above the $2.5 \mathrm{~m}$ elevation. Since the uncertainty associated with fuel assembly/fuel tube contact may be significant and because limited buoyancy effects are modeled in the horizontal and inclined orientation simulations, the vertical tests are emphasized in the data comparisons presented below.

\subsubsection{Vertical Orientation Results}

The data comparison for the vertical orientation cases, shown in Figures 5.5 through 5.7, display the same tendency towards overprediction seen in the horizontal and inclined results. Overprediction of the peak temperature can be traced to the overprediction of the fuel tube-to-cask wall temperature difference, or downcomer thermal resistance. Inspection of the 
vertical vacuum run, displayed in Figure 5.7, shows that a correction in the fuel tube-to-cask temperature difference would shift the remaining predicted profiles closer to the data. Since heat removal in the vacuum runs is radiation dominated, a change in the fuel tube-to-cask wall thermal resistance can only be effected through a change in the material emissivity or in the radiation heat transfer model. Earlier predictions for the PWR Single-Assembly Spent Fuel Test vacuum backfill demonstrated that the radiation model is performing adequately. Therefore, since the temperature drop from the fuel tube-to-corner rod is generally overpredicted as well, the fuel tube emissivity value is probably slightly higher than its assumed prelook value of 0.2 .

An additional trend observed in the vertical vacuum test data is the skew in the axial temperature profiles, especially noticeable at the higher power levels. A shift in the axial profiles can result from the establishment of natural convection within the cask, significant fuel rod axial conduction, or from nonuniform axial power profiles. The relatively low pressures attained in the vacuum runs, approximately 0.1 atmospheres, are expected to significantly reduce the cask buoyancy force such that little or no natural convection is established. To verify this an additional test was run in which the level of vacuum was further reduced to 0.03 atmospheres. The results of this test were essentially identical to those of the nominal vacuum test. This supports the conclusion that natural convection is not responsible for the skew observed in the vacuum axial temperature profiles.

Axial conduction in the heater rods was not expected to be significant because of the relatively small heat transfer area offered by the stainless steel cladding. However, nine solid and two heavy walled stainless steel simulated guide tubes, whose lower ends were fastened to the heater rod flange of the fuel tube-transition piece, were located throughout the bundle cross section. The significant axial heat transfer area offered by the simulated guide tubes and unheated fuel tube enhances the effective axial conduction of the entire assembly and contributes to the overall temperature profile skew. 
In addition to the axial conduction effects, some nonuniformity of the heater rod axial profile may be contributing to the observed skew. The nonuniformity is not assumed to be significant, since the $\mathrm{Ni}$-chrome heater element electrical resistance is expected to vary only slightly over the operating temperature range. Since a fuel rod axial conduction model was not available and heater rod temperature-feedback effects were ignored, the axial temperature profile skew seen in the data was not predicted. The significant axial conduction observed in these tests is believed to result from specific design features of the simulated fuel assembly and cask, and therefore can be considered nonprototypic. This conclusion is supported by the fact that little, if any, skew is observed in the axial temperature profiles for a spent PWR fuel assembly in a vacuum environment (see Figure 4.8 ).

The temperature difference between the center and corner rods in helium was not correctly predicted as was the case in the prelook predictions for the PWR Single Assembly Spent Fuel Test described in Section 4.3.1.1. This indicates that the thermal resistance of the assembly interior was incorrectly modeled.

This effect can be clearly seen in the axial temperature profiles for the $1.0 \mathrm{~kW}$, vertical helium case, presented in Figure 5.5. It was expected that revising the rod-to-fluid heat transfer model to include asymmetric rod heat flux would provide more accurate predictions of the fuel assembly thermal resistance. This was the approach used in the post-test predictions.

The helium results show an overpredicted fuel tube-to-cask wall temperature difference, a trend also observed with the vacuum results. The proposed increase in the fuel tube emissivity deduced from the vacuum simulations was expected to provide better agreement of this temperature difference in the post-test helium predictions as well.

As with the other fill media cases, the fuel tube-to-cask wall temperature difference with an air backfill was overpredicted as displayed in Figure 5.6. Again, an increase in fuel tube emissivity was expected to correct this difference in the post-test simulations. The comparison of the predicted 
axial profiles with the data for the air backfill appears reasonable. However, the lack of reliable temperature data at the lower elevations makes further conclusions difficult. Changes to the predicted axial temperature profiles can be affected through changes in the system friction, plenum heat transfer, and radial heat transfer. No changes in the above parameters were made due to lack of data for comparison.

\subsubsection{Horizontal Orientation Results}

The horizontal orientation results are presented in Figure 5.8. It was expected that the code predictions for the horizontal cases would show the largest disagreement with the data due to the simplifying assumptions used in the analysis. These assumptions are: 1) the fuel assembly is centered within the fuel tube, 2) assembly/fuel tube contact is negligible, and 3) buoyancyinduced effects are negligible. However, comparisons of data and predictions between the vertical and horizontal orientations for the $1.0 \mathrm{~kW}$ air case, displayed in Figure 5.6 and Figure 5.8, respectively, show the measured and predicted results to be little influenced by orientation. This trend is repeated for the other fill media as well. Thus, the anticipated effects of fuel assembly position and buoyancy do not appear to have a significant influence for this test. Reasons for the uniformity of results in the vertical and horizontal orientations are discussed below.

The assumption of a centered fuel assembly is not expected to be much in error in the lower elevations, since the fuel tube and assembly geometry are fixed by the fuel tube-transition piece and heater rod flange. At the upper, unsupported end, some eccentricity of the fuel assembly/fuel tube may have occurred. Although difficult to discern from buoyancy-induced effects, a slight shift in the radial temperature profile is expected.

A more significant effect, which is avoided with this somewhat fixed test section geometry is assembly/fuel tube contact, a phenomena which has been shown both experimentally and analytically to provide significant reductions in assembly peak temperature (Wiles et al. 1986; Cuta, Rector, and Creer 1984). Since assembly/fuel tube contact is a significant uncertainty in tests with 
actual, unrestrained spent fuel, the assumed absence of any assembly/fuel tube contact in this series of tests provided an independent evaluation of buoyancy-induced effects in the horizontal orientation.

The final simplifying assumption employed in the horizontal runs is the elimination of buoyancy-induced effects--natural convection and thermal stratification. Flow recirculation in the horizontal orientation is not expected along the fuel assembly centerline, but is expected circumferentially about the fuel and downcomer assemblies. The effect of this limited convection, as with the case of flow stratification, is to enhance the cask heat removal and impose a transverse fuel assembly temperature gradient. This effect is found to be minor as evaluated from a comparison of center rod temperature data for the horizontal air and vacuum test cases. The peak rod temperature differences between these runs ranged from $8^{\circ} \mathrm{C}$ to $15^{\circ} \mathrm{C}$ for the 0.5 and $1.0 \mathrm{~kW}$ test series, respectively. Again, in tests with actual, unrestrained spent fuel, the buoyancy-induced effects may be significantly overshadowed by the assembly/fuel tube contact. This, in conjunction with the modest thermal benefit derived from the buoyancy-induced effects seen in this test, suggests that the modeling of this phenomena, although desirable, is not critical in determining the thermal response of a horizontally oriented storage system. Thus, the limited effects of buoyancy and fuel assembly contact greatly reduces the influence of orientation in this experiment. This trend was correctly predicted by COBRA-SFS.

\subsubsection{Inclined Orientation Results}

Neither the predictions or data for the inclined orientation cases, displayed in Figure 5.9, differ significantly from the horizontal results. This effect is demonstrated via a comparison of the $1.0 \mathrm{~kW}$, inclined, air case, displayed in Figure 5.9, with the comparable horizontal, air case shown in Figure 5.8. The differences in the modeling of horizontal and inclined orientations lie in the treatment of buoyancy and in the specified cask boundary conditions. Only partial treatment of the buoyancy effects was possible in the inclined simulations. In the axial direction, the buoyancy term in the 
momentum equations was reduced by the direction cosine, whereas buoyancy effects in the transverse direction were not modeled. As a result, only an axial velocity component is modeled in this orientation. In spite of the longitudinal natural convection, very little difference in peak temperature was observed between the horizontal and inclined predictions, a trend also seen in the data. As in the horizontal simulations, the skew in the predicted transverse assembly temperature profile is a direct result of the asymmetric boundary temperatures assigned to the cask inner wall. Again, the relatively modest effect of buoyancy-induced flows observed in the horizontal and inclined run suggests that buoyancy-induced effects can be eliminated in the computational model without the introduction of significant errors.

\subsubsection{Post-Test Refinements}

In the post-test analysis, the separate effects of refinements made in the rod-subchannel heat transfer, fuel tube emissivity value, and convective film coefficient were combined and the computed results again compared to the data. As in the PWR Single Assembly Test Post-Test Refinements (Section 4.3.2) the only change to COBRA-SFS was in the treatment of the rod-fluid heat transfer to model asymmetric rod heat flux. Refinements made to the assumed fuel tube emissivity (from 0.2 to 0.25 ) and the convective film coefficient (from $\mathrm{Nu}=4.364$ to $\mathrm{Nu}=3.66)$ were made via changes in input. No other modifications were made for the post-test analysis.

\subsubsection{Post-Test Predictions}

Subsequent to the availability of experimental data, a series of parameter studies were carried out to determine where improvements in the computational model or cask description could be made. A summary of post-test results follows.

The vertical orientations were emphasized in the post-test analysis because of the uncertainties associated with fuel assembly/fuel tube contact and the difficulty in modeling the transverse buoyancy effects for the horizontal and inclined cases. Additionally, the similarity observed in the data between the different orientations strongly suggests that effects of modifications to 
the vertical orientation model are representative of the changes which can be expected in the horizontal and inclined orientations. For these reasons, only the vertical orientation simulations were repeated in the post-test analysis.

Four cases were selected for the post-test analysis: a $0.5 \mathrm{~kW}$ vacuum run, and the three fill media at the $1.0 \mathrm{~kW}$ power level. Post-test axial profile temperature results for the 0.5 and $1.0 \mathrm{~kW}$ vertical vacuum cases are displayed in Figures 5.10 and 5.11, respectively; results for the vertical helium and air are presented in Figures 5.12 and 5.13, respectively. Radial temperature profiles which display prelook, post-test and experimental results at elevation $2.75 \mathrm{~m}$ for three fill media at $1.0 \mathrm{~kW}$ are shown in Figure 5.14 through 5.16 .

The most significant change made to the input was increasing the assumed fuel tube emissivity from 0.2 to 0.25 , a value well within the range of reasonable values for this parameter (Taylor 1983). As a result of this revision, the downcomer assembly thermal resistance was improved in all cases, with the agreement observed in the vacuum tests falling within the estimated data scatter (Figures 5.10 and 5.11).

The remaining discrepancy in fuel tube predicted temperature is attributed to the large friction applied to the downcomer assembly in the air case, and the difficulty of defining fluid heat transfer across the large flow area of the downcomer assembly with a helium backfill. A large value of friction was applied to the downcomer assembly to aid in the computational stability. The resulting increased system friction would be expected to lessen the role of convection in the cask heat removal and result in warmer downcomer and fuel assembly temperatures, a trend observed in the data comparisons. In helium, conduction is a significant means of heat transfer across the downcomer channel. Since the fluid thermal conductivity is a function of temperature, the calculated heat transfer rate is dependent on the number of subchannels used to model the radial heat transfer path. In the current model, two radial subchannels are employed and heat is transferred radially via conduction between the adjacent fluid subchannels. This provides sufficient resolution in the 


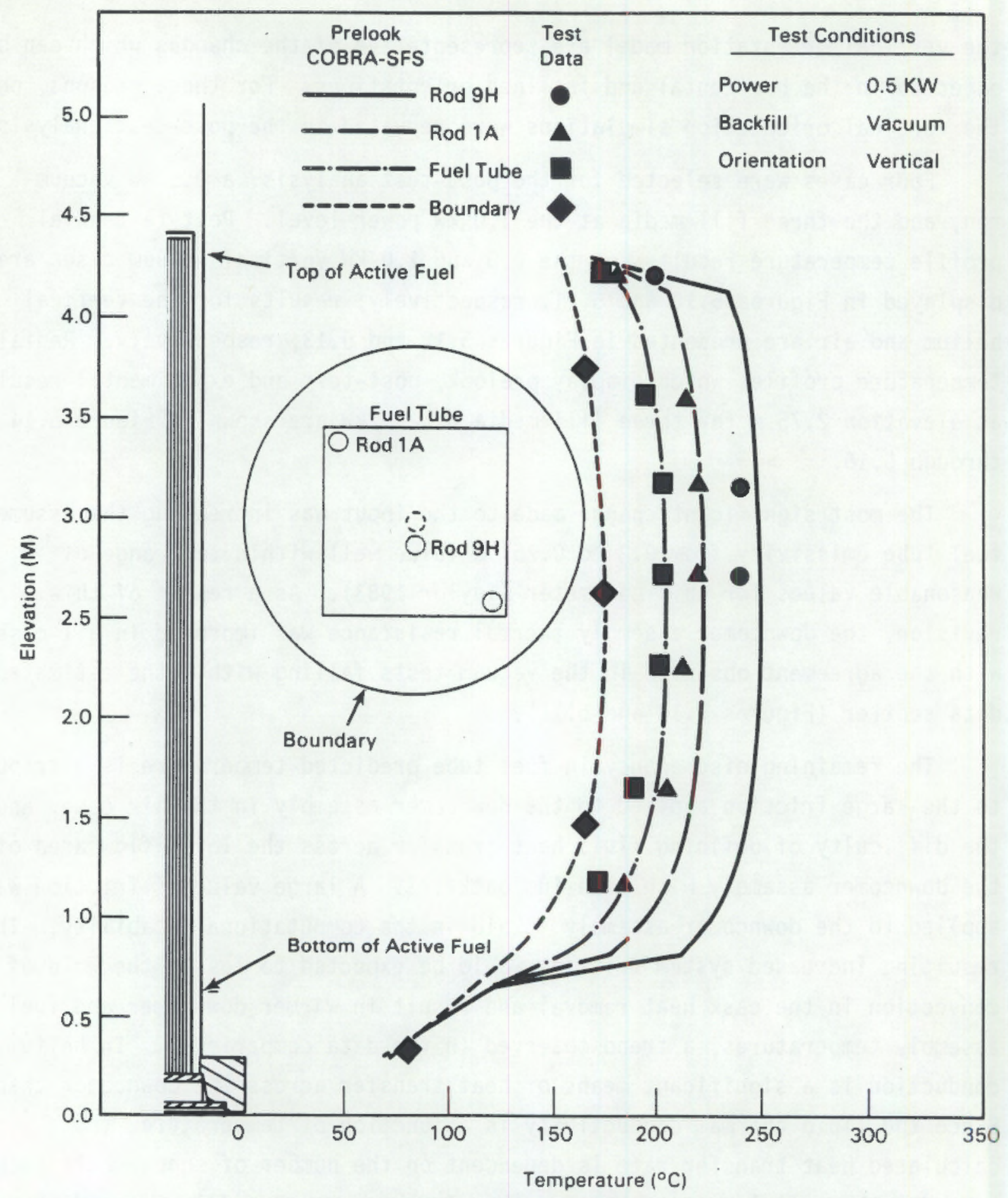

EIGURE 5.10. Post-Test Predicted and Experimental Axial Profiles: $0.5 \mathrm{~kW}$, Vertical, Vacuum Run, Electrically Heated PWR Single Assembly Test 


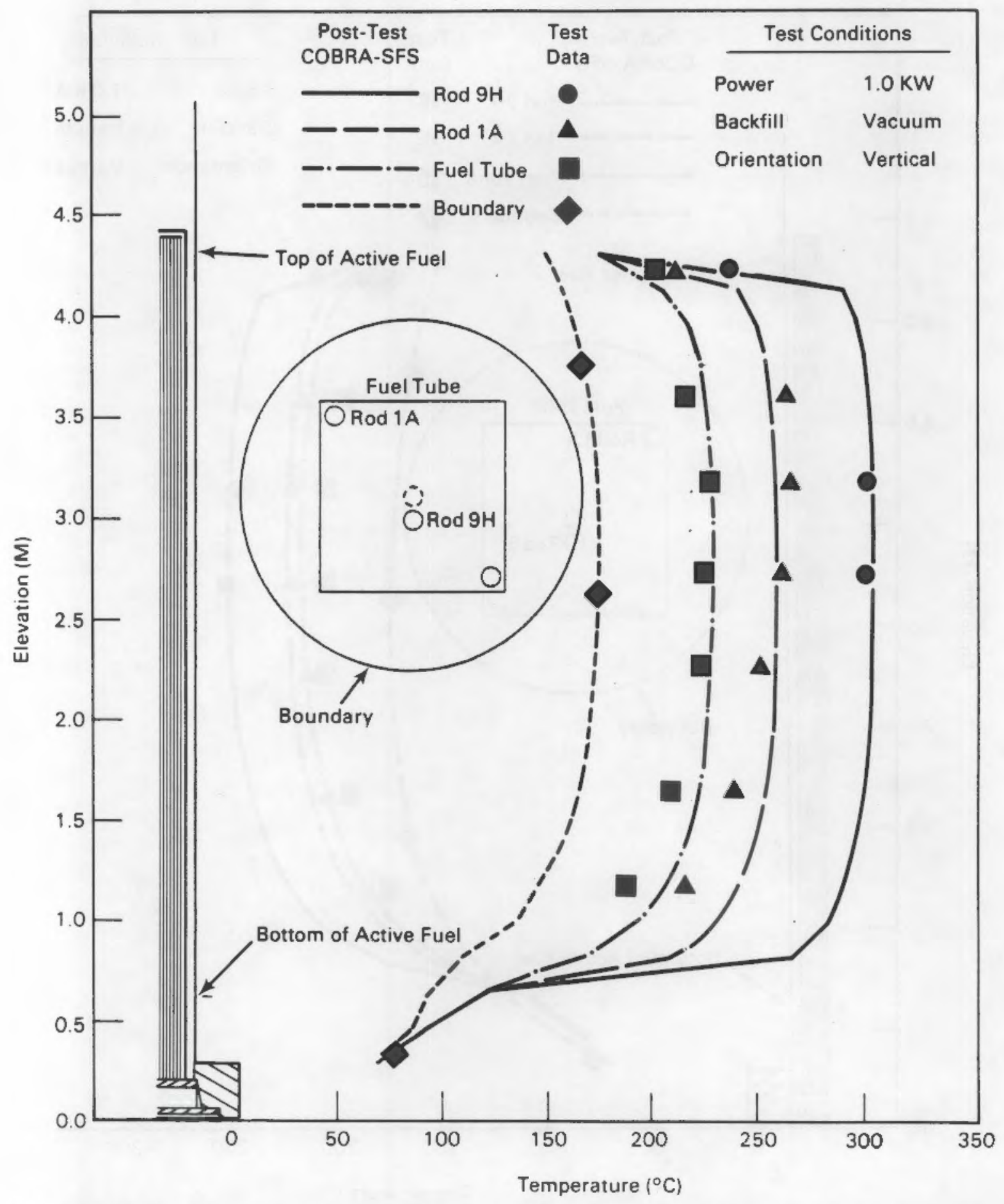

EIGURE 5.11. Post-Test Predicted and Experimental Axial Profiles: $1.0 \mathrm{~kW}$, Vertical, Vacuum Run, Electrically Heated PWR Single Assembly Test 


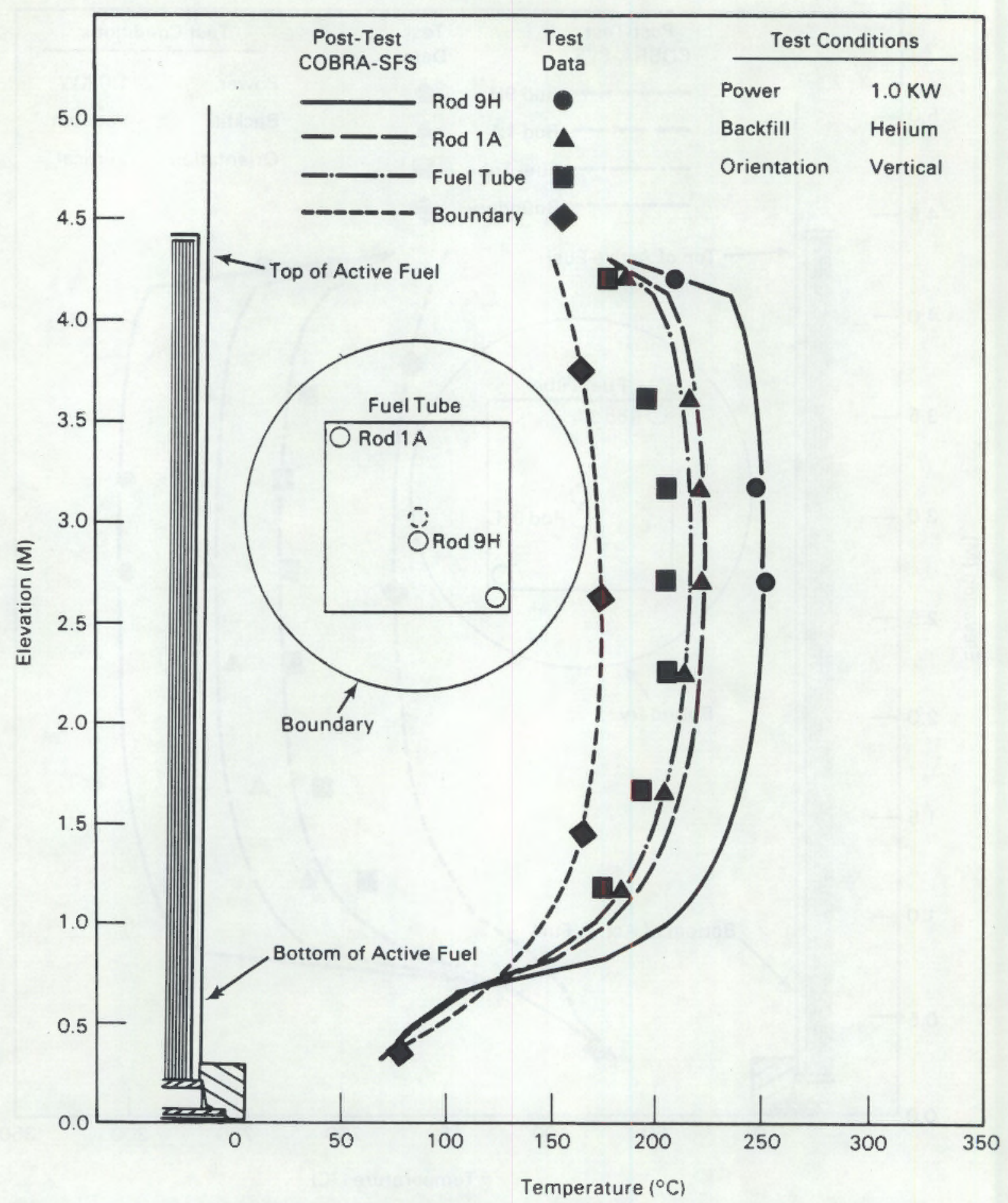

EIGURE 5.12. Post-Test Predicted and Experimental Axial Profiles: $1.0 \mathrm{~kW}$, Vertical, Helium Run, Electrically Heated PWR Single Assembly Test 


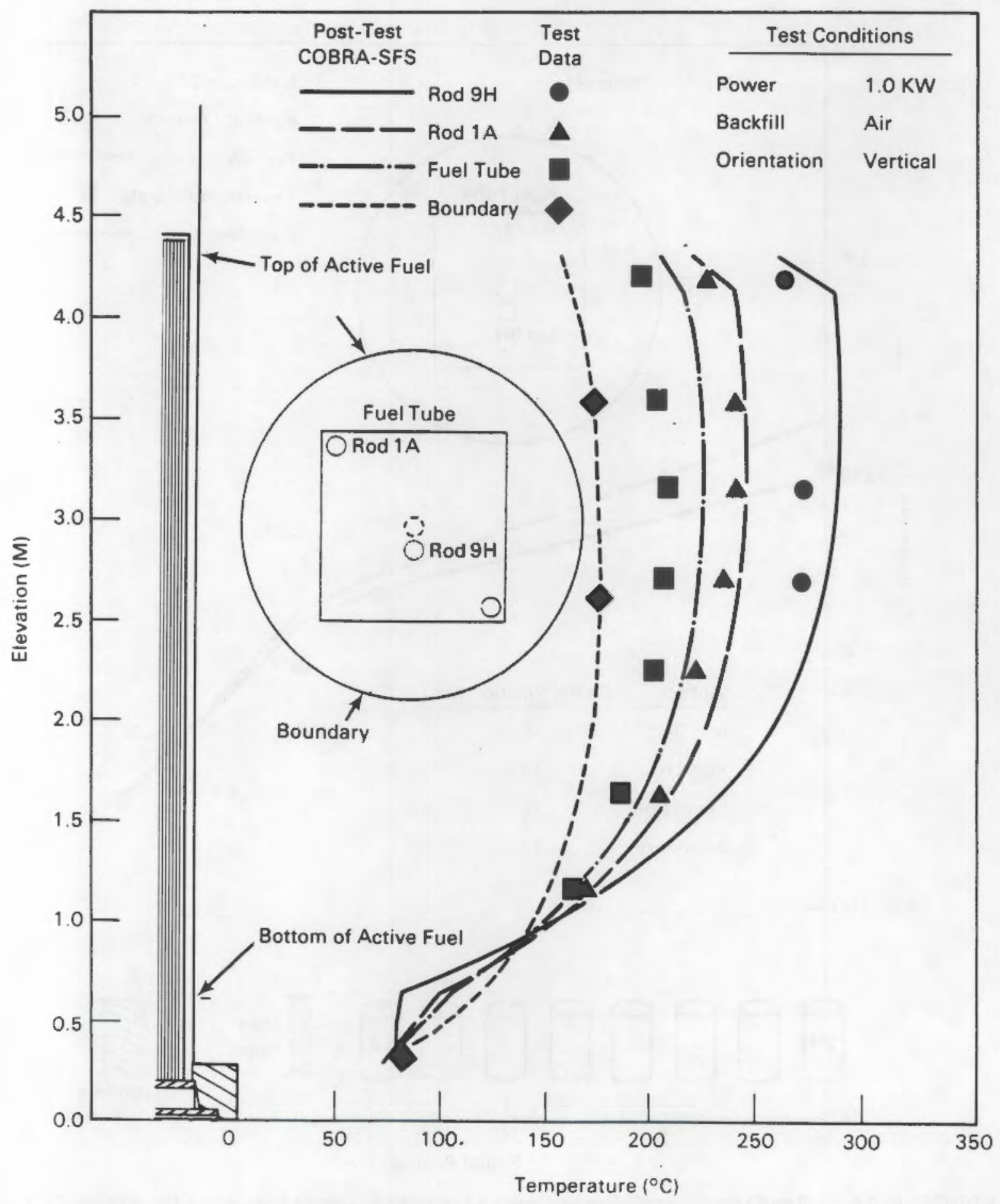

EIGURE 5.13. Post-Test Predicted and Experimental Axial Profiles: $1.0 \mathrm{~kW}$, Vertical, Air Run, Electrically Heated PWR Single Assembly Testand 


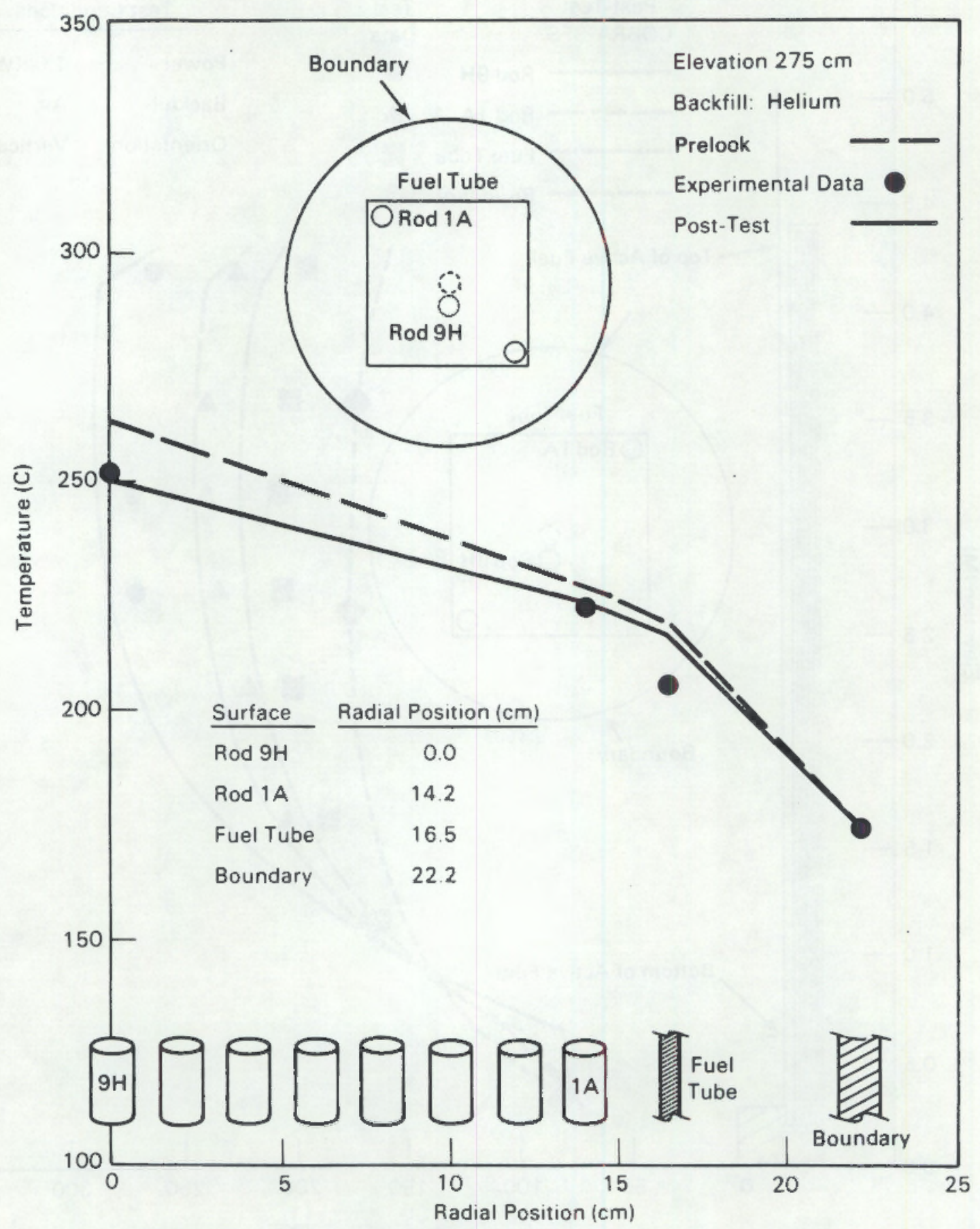

FIGURE 5.14. Predicted and Experimental Radial Profiles at Elevation $275 \mathrm{~cm}$ : $1.0 \mathrm{~kW}$, Vertical, Helium Case, Electrically Heated PWR Single Assembily Test 


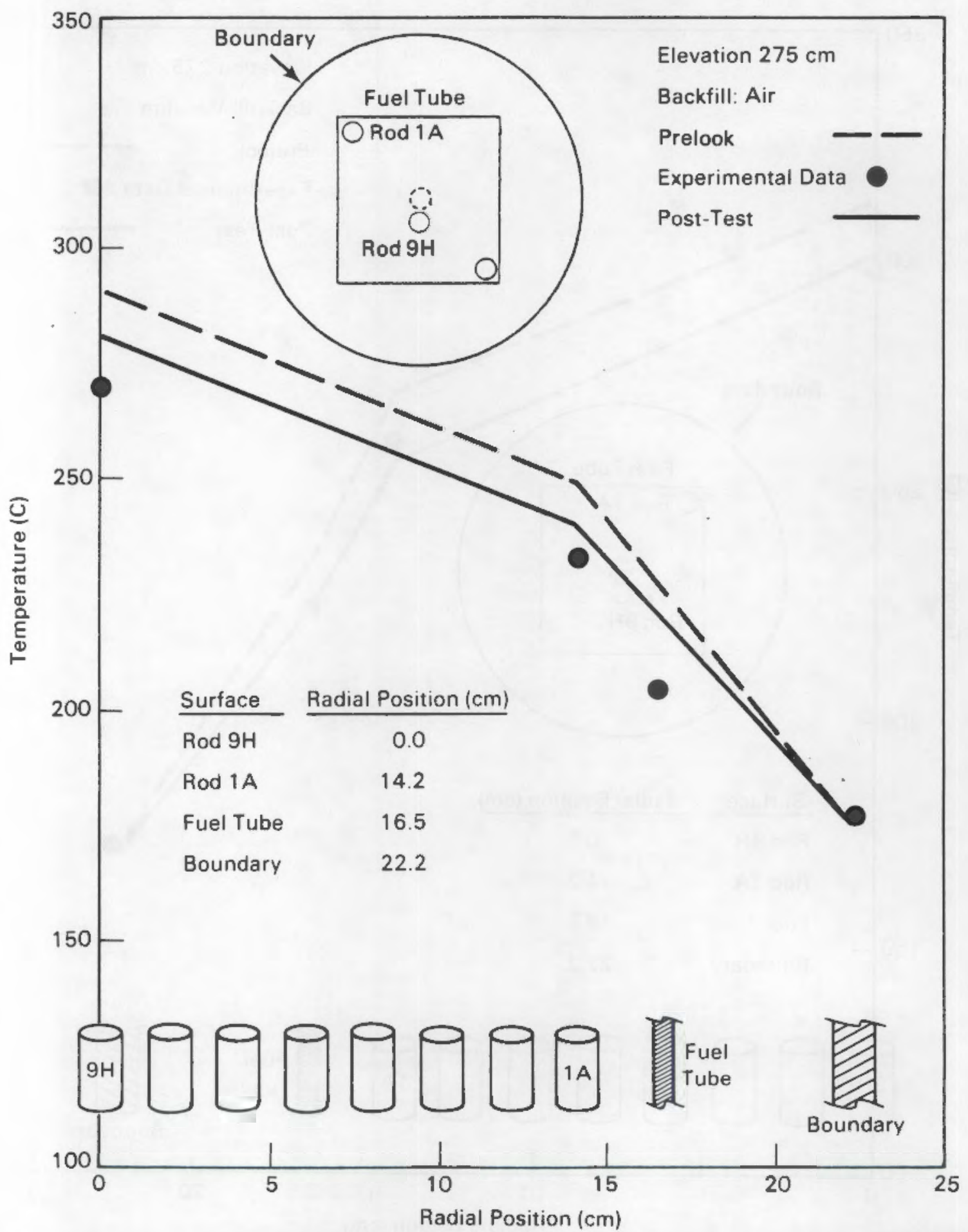

FIGURE 5.15. Predicted and Experimental Radial Profiles at Elevation $275 \mathrm{~cm}$ : $1.0 \mathrm{~kW}$, Vertical, Air Case, Electrically Heated PWR Single Assembly Test 


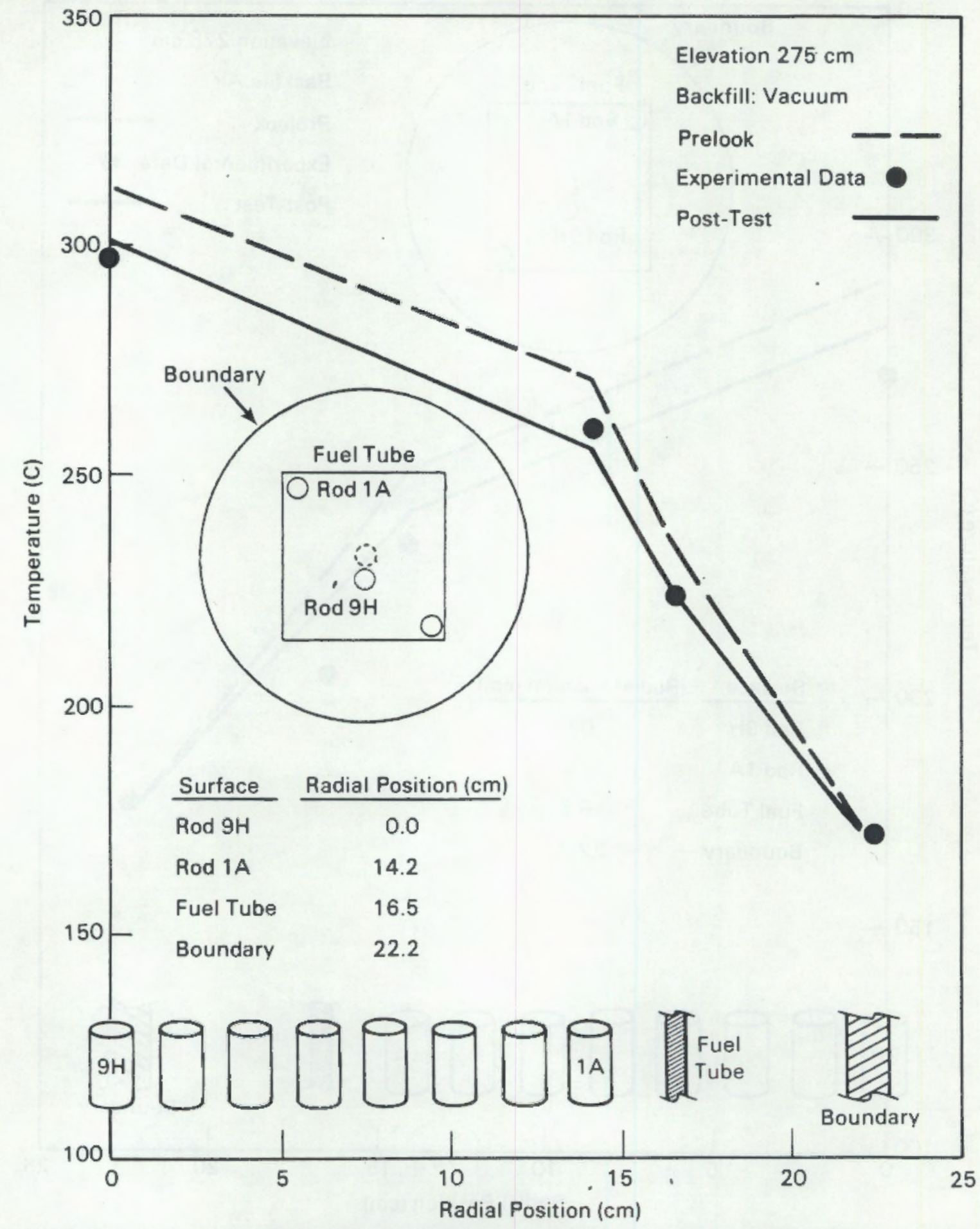

EIGURE 5.16. Predicted and Experimental Radial Profiles at Elevation $275 \mathrm{~cm}$ : $1.0 \mathrm{~kW}$, Vertical, Vacuum Case, Electrically Heated PWR Single Assembly Test 
vacuum cases where conduction through the fluid is limited and the transfer of heat radially is radiation dominated. However, in cases where the fluid conductivity is important or where the heat transfer in the downcomer channel is multidimensional (as with convection), the current downcomer subchannel model is inadequate. The subchannel resolution required to properly model the solidfluid and fluid-fluid heat transfer in the downcomer assembly was not determined due to the difficulty in solving the momentum equations for subchannels with large flow areas and very little frictional resistance (the same reason for which the downcomer flow resistance was initially increased). For future applications with large fluid conduction areas, a subchannel "mesh" study should be performed to determine the proper division.

In addition to the change in fuel tube emissivity, the rod-to-fluid heat transfer model was modified to account for asymmetric rod heat flux effects. The asymmetric rod heat flux model calculates rod-to-fluid heat transfer based on individual subchannel temperatures. Its use significantly improves the predicted assembly resistance for the high thermal-conductivity gas (helium); little differences were observed with the air backfill cases.

Finally, to be consistent with the PWR Single Assembly Heat Transfer Test post-test predictions, the convective film coefficient was modified from $\mathrm{Nu}=4.464$ to $\mathrm{Nu}=3.66$. The results were not significantly influenced by this revision.

In all post-test simulations the agreement with the test data was considerably improved over the prelook predictions. The major cause of the improvement is the revised value of fuel tube emissivity. Justification of the post-test emissivity value is supported by the agreement with the data seen in the radiation-dominated vacuum simulations at the two power levels of 0.5 and $1.0 \mathrm{kw}$. Reasonable agreement to peak temperatures for the air and helium runs were obtained in the post-test predictions; however, the fuel tube temperatures still show some disagreement with the data. The overall agreement with data displayed in the post-test analysis is good. 


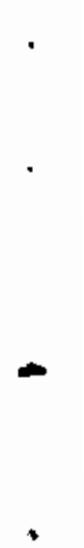

\author{
.
}




\subsection{REFERENCES}

Bates, J. M. 1986. Single PWR Spent Fuel Assembly Heat Transfer Data for Computer Code Evaluation, PNL-5571, Pacific Northwest Laboratory, Richland, Washington.

Cuta, J. M., D. R. Rector and J. M. Creer. 1984. Thermal-Hydraulic Analysis of Consolidated Spent PWR Fuel Rods, Electric Power Research Institute, Palo Alto, California.

George, T. L., et al. 1980. COBRA-WC: A Version of COBRA for Single-Phase Multiassembly Thermal-Hydraulic Transient Analysis. PNL-2359, Pacific Northwest Laboratory, Richland, Washington.

Idel'Chik, I. E. 1966. Handbook of Hydraulic Resistance, Coefficients of Local Resistance and of Friction. AEC-TR-6630, U.S. Atomic Energy Commission and the National Science Foundation, Washington.

Kays, W. M., and M. E. Crawford. 1980. Convective Heat and Mass Transfer, McGraw-Hill, Inc, New York.

Khan, E. U., W. A. Prather, T. L. George and J. M. Bates, 1981. A Validation Study of the COBRA-WC Computer Program for LMFBR Thermal-Hydraulic Analysis. Battelle, Pacific Northwest Laboratories, Richland, Washington.

Kreith, F. 1965. Principles of Heat Transfer. 2nd Edition, International Textbook Co., Scranton, Pennsylvania.

Peterson, C. 1975. Literature Search on Some Properties of Zircaloy-4 at High Temperatures, AECL-5101, Atomic Energy of Canada, LTD.

Rector, D. R and C. L. Wheeler. 1986. COBRA-SFS Thermal Analys is of a Sealed Storage Cask for the Monitored Retrievable Storage of Spent Fuel, Battelle, Pacific Northwest Laboratory, Richland, Washington.

Rowe, D. S. 1973. COBRA-IIIC: A Digital Computer Program for Steady-State and Transient Thermal-Hydraulic Analysis of Rod Bundle Nuclear Fuel Elements. BNWL-1695, Pacific Northwest Laboratory, Richland, Washington.

Siegel, R. and J. R. Howel1. 1972. Thermal Radiation Heat Transfer, 1st Ed. McGraw-Hill.

Sparrow, E. M., and A. L. Loeffler, Jr. 1959. "Longitudinal Laminar Flow Between Cylinders Arranged in Regular Array", AIChE Journal, Vol. 5, No. 3, p. 325-330. 
Stewart, C. W., et al. 1977. COBRA-IV: The Model and the Method. Battelle, Pacific Northwest Laboratories, Richland, Washington.

Taylor, R. E. 1983. Hemispherical Total Emissivity of Stainless Steel, TPRL 324, School of Mechanical Engineering, Purdue University, West Lafayette, Indiana.

Unterzuber, R. 1981. Spent Fuel Storage Technology Development: Fuel Temperature Measurements Under Imposed Dry Storage Conditions. DOE/NV/101/1-4, Westinghouse, Advanced Energy Systems Division, Pittsburgh, Pennsylvania.

Wheeler, C. L., et al. 1973. COBRA-IV-I: An Interim version of COBRA for Thermal-Hydraulic Analys is of Rod Bundle Nuclear Fuel Elements and Cores. BNwL-1962, Pacific Northwest Laboratory, Richland, Washington.

Wiles, L. E. et al. 1986. BWR Spent Fuel Storage Cask Performance Test Volume II - Pre and Post-Test Decay Heat, Heat Transfer and Shielding Analyses, Battelle, Pacific Northwest Laboratory, Richland, Washington. 
APPENDIX A

SAMPLE COBRA-SFS INPUT FOR THE PWR SINGLE ASSEMBLY

SPENT FUEL TEST 


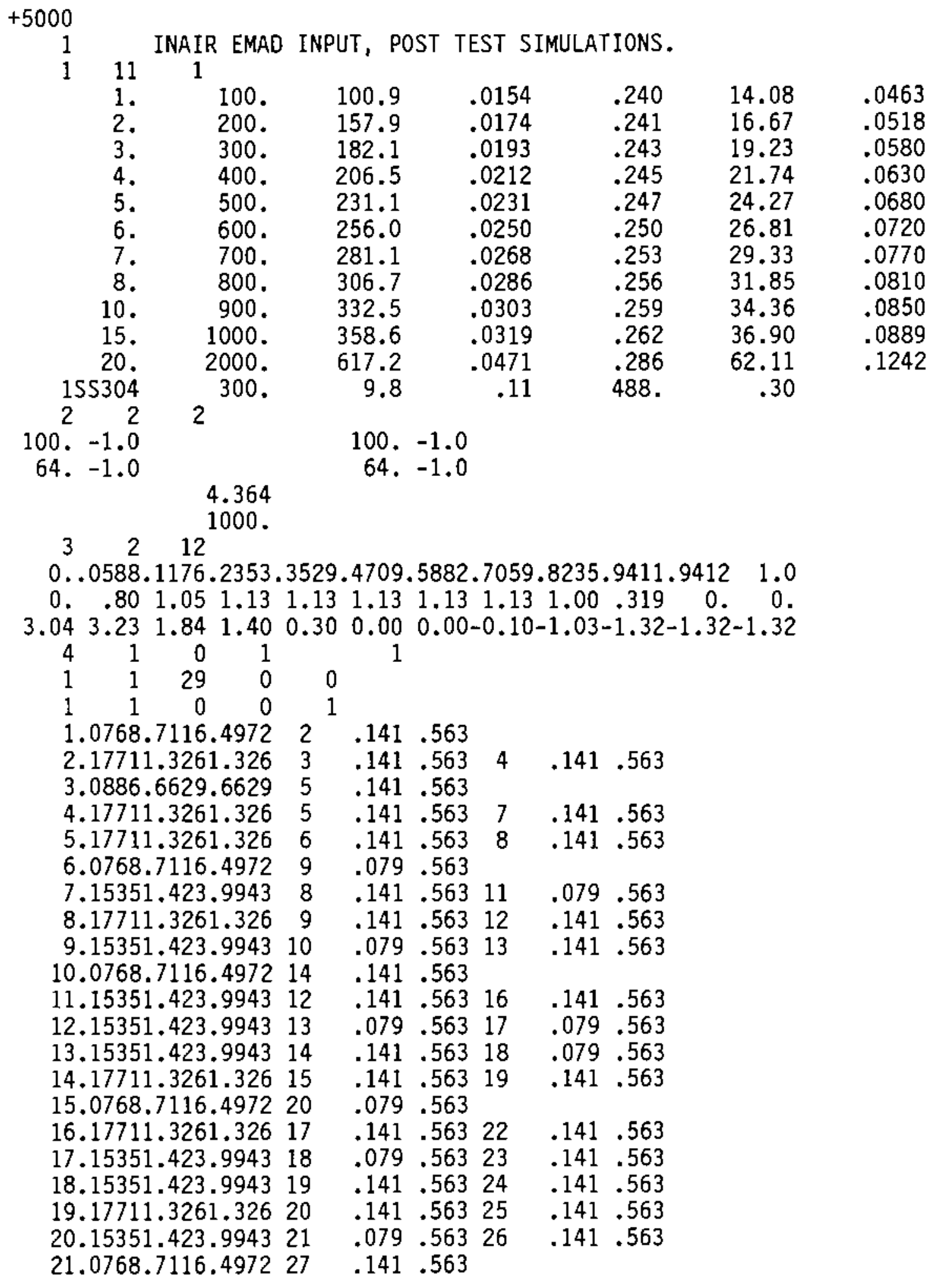




$$
\begin{aligned}
& \begin{array}{lllllll}
22.17711 .3261 .326 & 23 & .141 & .56329 & .141 & 1.68
\end{array}
\end{aligned}
$$

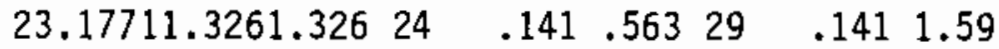

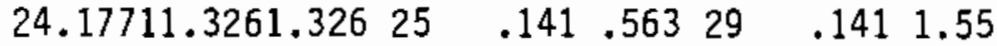

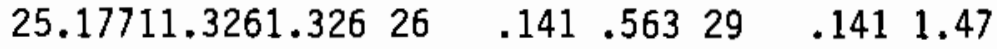

$$
\begin{aligned}
& \begin{array}{llllll}
26.17711 .3261 .326 & 27 & .141 & .56329 & .141 & 1.36
\end{array}
\end{aligned}
$$

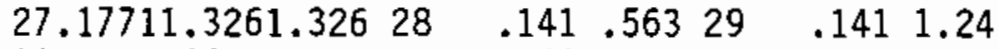

$$
\begin{aligned}
& 28.0886 .6629 .662929 \quad .141 \quad 1.07 \\
& 2 \quad 299.47010 .015 .203
\end{aligned}
$$

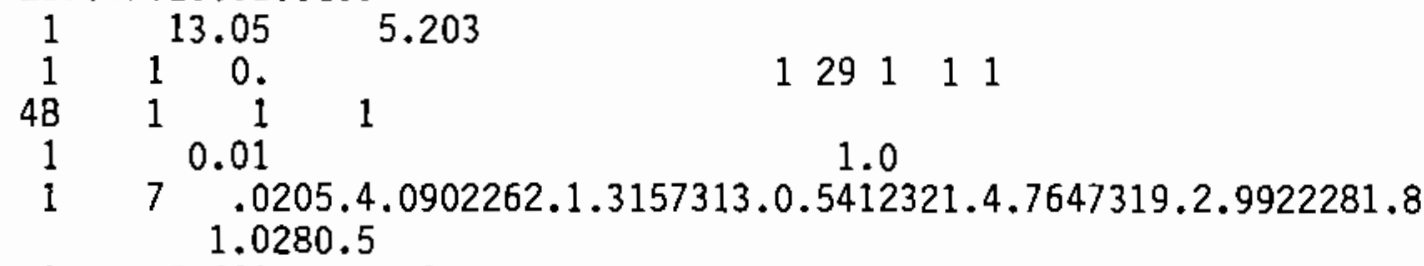

$$
\begin{aligned}
& \begin{array}{rrrrrr}
1 & 15.498 & 1 & 0.0 & \\
1 & 1.0 & 1 & 1.0 & 1 & \\
8 & 1 & 15 & 2 & & 1 \\
1 & 1 & 36 & 0 & &
\end{array} \\
& \begin{array}{llllll}
2 & 36 & .422 & 0.0 & 1.125
\end{array}
\end{aligned}
$$

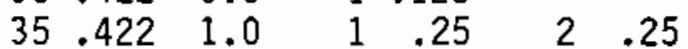

$$
\begin{aligned}
& \begin{array}{lllllll}
34.422 & 1.0 & 1 & .125 & 2 & .25 & 3.125
\end{array}
\end{aligned}
$$

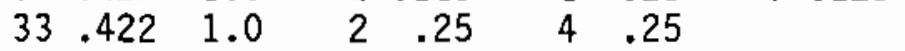

$$
\begin{aligned}
& \begin{array}{llllllllll}
32.422 & 1.0 & 2 & .25 & 3 & .25 & 4 & .25 & 5 & .25
\end{array} \\
& \begin{array}{lllllllll}
31.422 & 1.0 & 3 & .125 & 5 & .25 & 6 & .125 \\
30.422 & 1.0 & 4 & .25 & 7 & .25 & &
\end{array}
\end{aligned}
$$

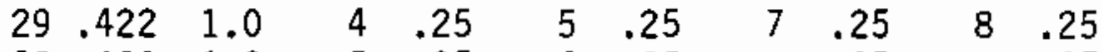

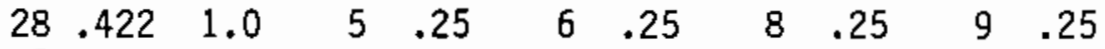

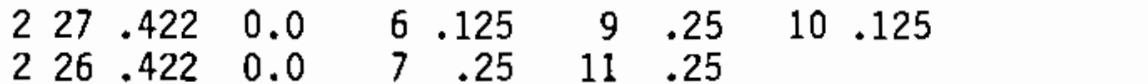

$$
\begin{aligned}
& \begin{array}{rrrrrrrrrrr}
2 & 26 & .422 & 0.0 & 7 & .25 & 11 & .25 & & & \\
25 & .422 & 1.0 & 7 & .25 & 8 & .25 & 11 & .25 & 12 & .25
\end{array} \\
& \begin{array}{lllllllllll}
24 & .422 & 1.0 & 8 & .25 & 9 & .25 & 12 & .25 & 13 & .25
\end{array}
\end{aligned}
$$

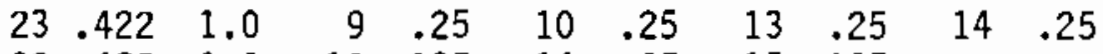

$$
\begin{aligned}
& \begin{array}{llllllll}
22 & .422 & 1.0 & 10.125 & 14 & .25 & 15 & .125
\end{array} \\
& \begin{array}{lllllll}
21 & .422 & 1.0 & 11 & .25 & 16 & .25
\end{array}
\end{aligned}
$$

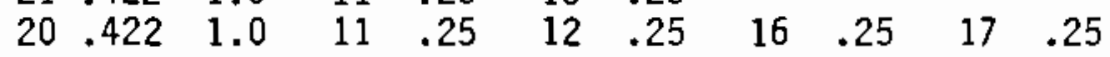

$$
\begin{aligned}
& \begin{array}{lllllllllll}
2 & 19.422 & 0.0 & 12 & .25 & 13 & .25 & 17 & .25 & 18 & .25
\end{array}
\end{aligned}
$$

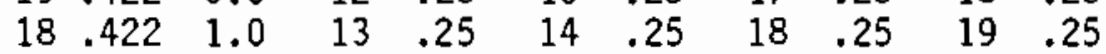

$$
\begin{aligned}
& \begin{array}{lllllllllll}
17.422 & 1.0 & 14 & .25 & 15 & .25 & 19 & .25 & 20 & .25
\end{array}
\end{aligned}
$$

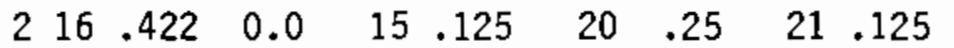

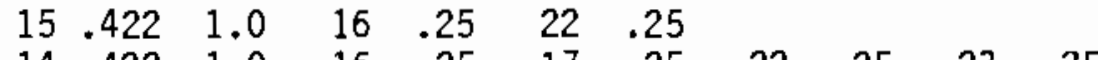

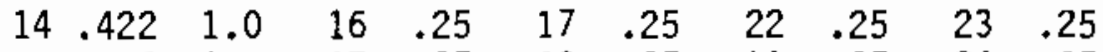

$$
\begin{aligned}
& \begin{array}{lllllllllll}
13 & .422 & 1.0 & 17 & .25 & 18 & .25 & 23 & .25 & 24 & .25
\end{array}
\end{aligned}
$$

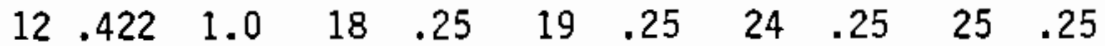

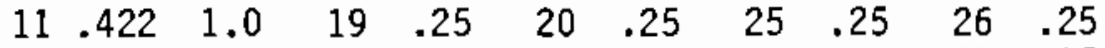

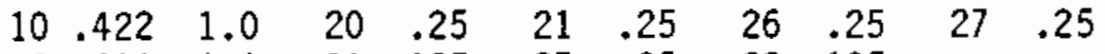

$$
\begin{aligned}
& \begin{array}{lllllllll}
9 & .422 & 1.0 & 21 & .125 & 27 & .25 & 28 & .125
\end{array} \\
& \begin{array}{lllllllll}
8 & .422 & 1.0 & 22 & .25 & 29 & .25 & & \\
7 & .422 & 1.0 & 22 & .25 & 23 & .25 & 29 & .50
\end{array}
\end{aligned}
$$




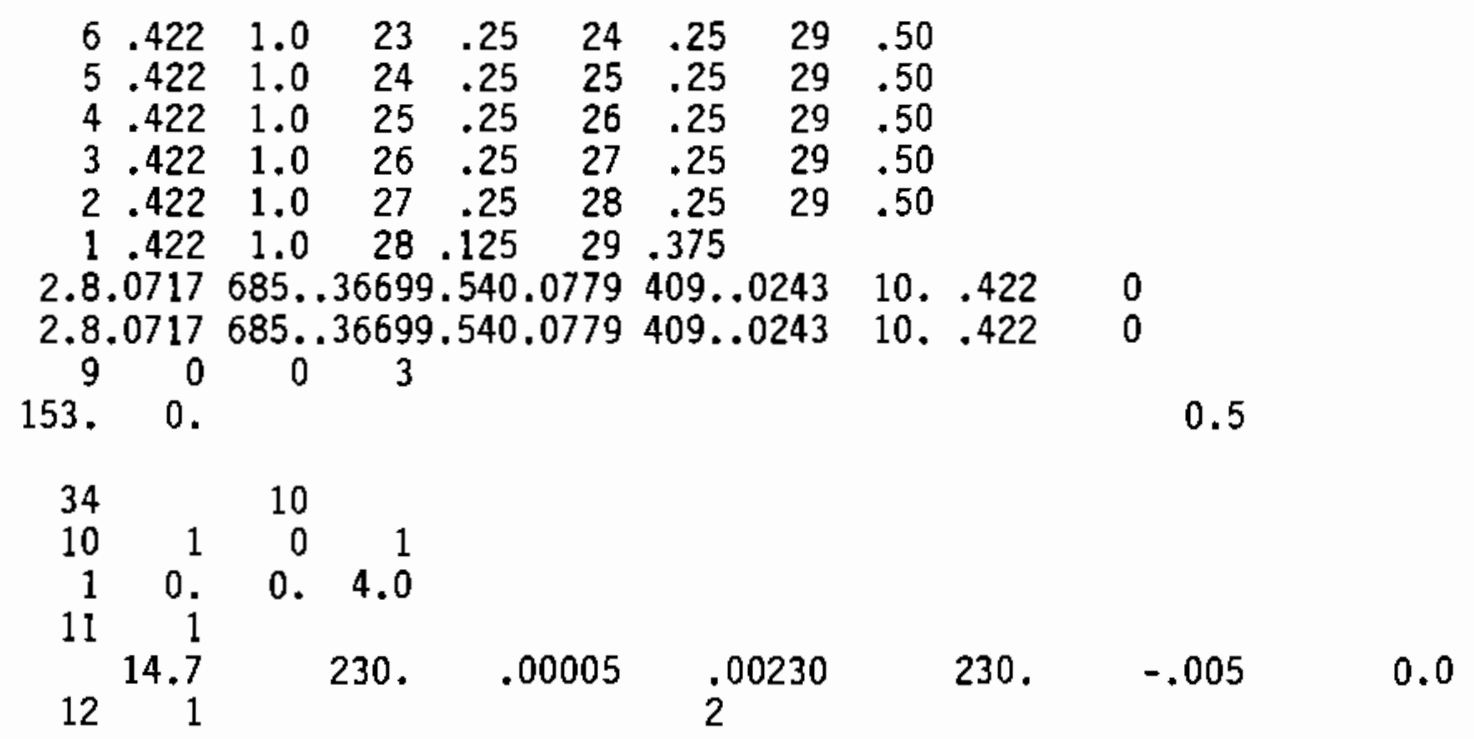

A. 3 
.

. 


\section{APPENDIX B}

PWR SINGLE ASSEMBLY SPENT FUEL TEST PREDICTED AND

EXPERIMENTAL AXIAL PROFILES 


\section{PWR SINGLE ASSEMBLY SPENT FUEL TEST PREDICTED AND}

\section{EXPERIMENTAL AXIAL PROFILES}

In the following figures, prelook and post-test predicted axial temperature profiles are plotted with the experimental data for five radial positions in the test assembiy (rods $1,10,11,18$, and 21).

B.1 


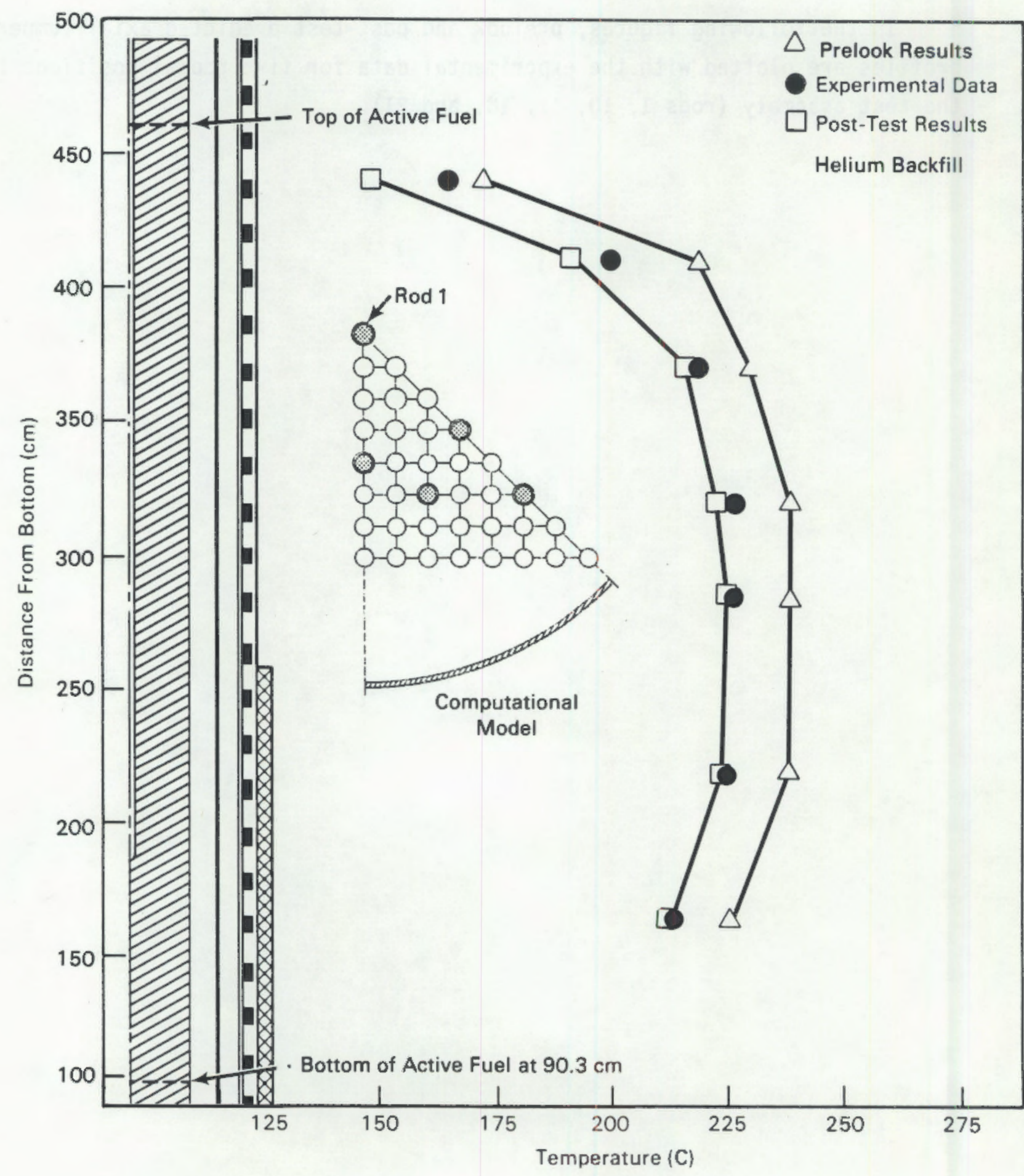

B. 2 



B. 3 


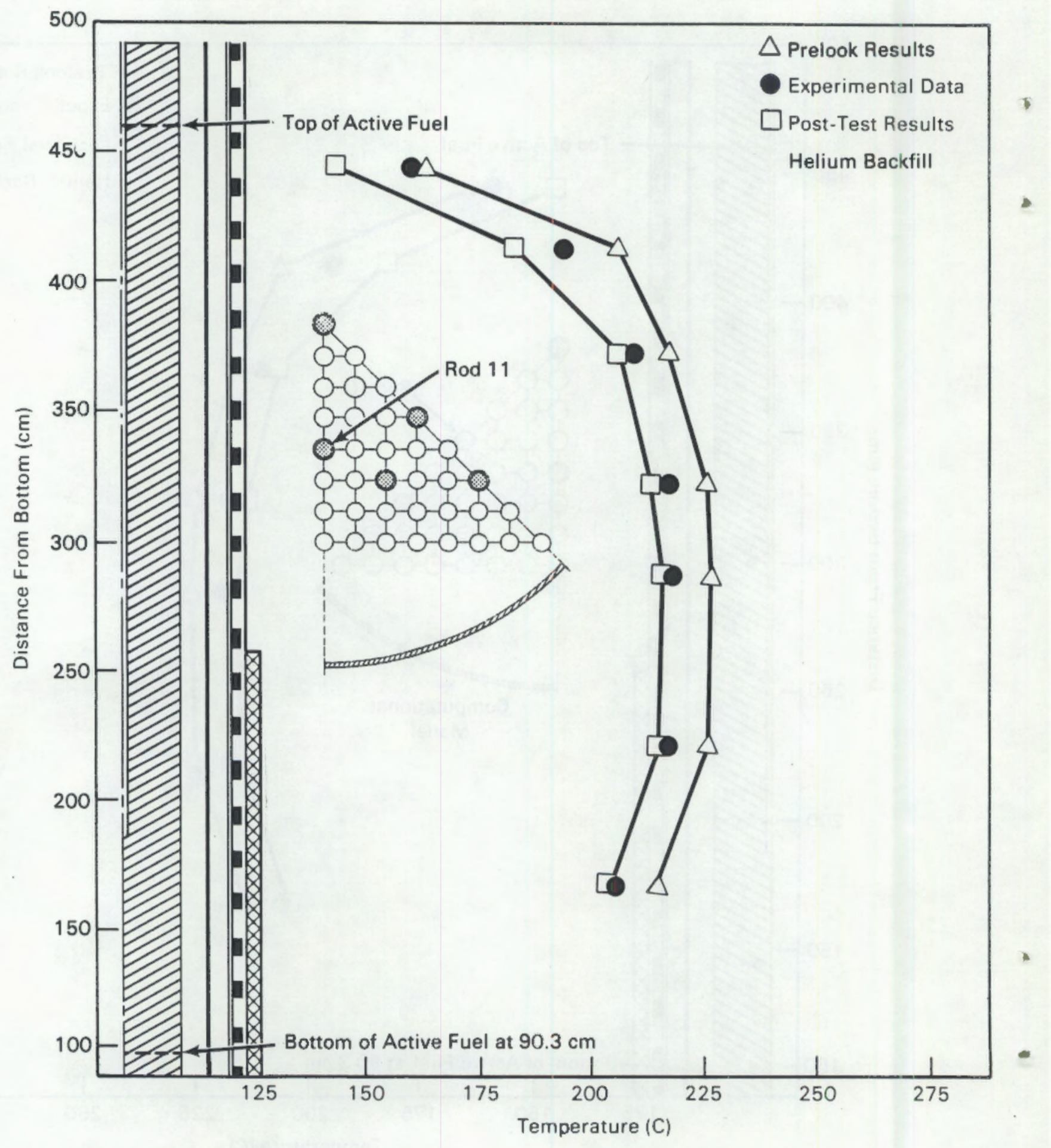

\section{B. 4}




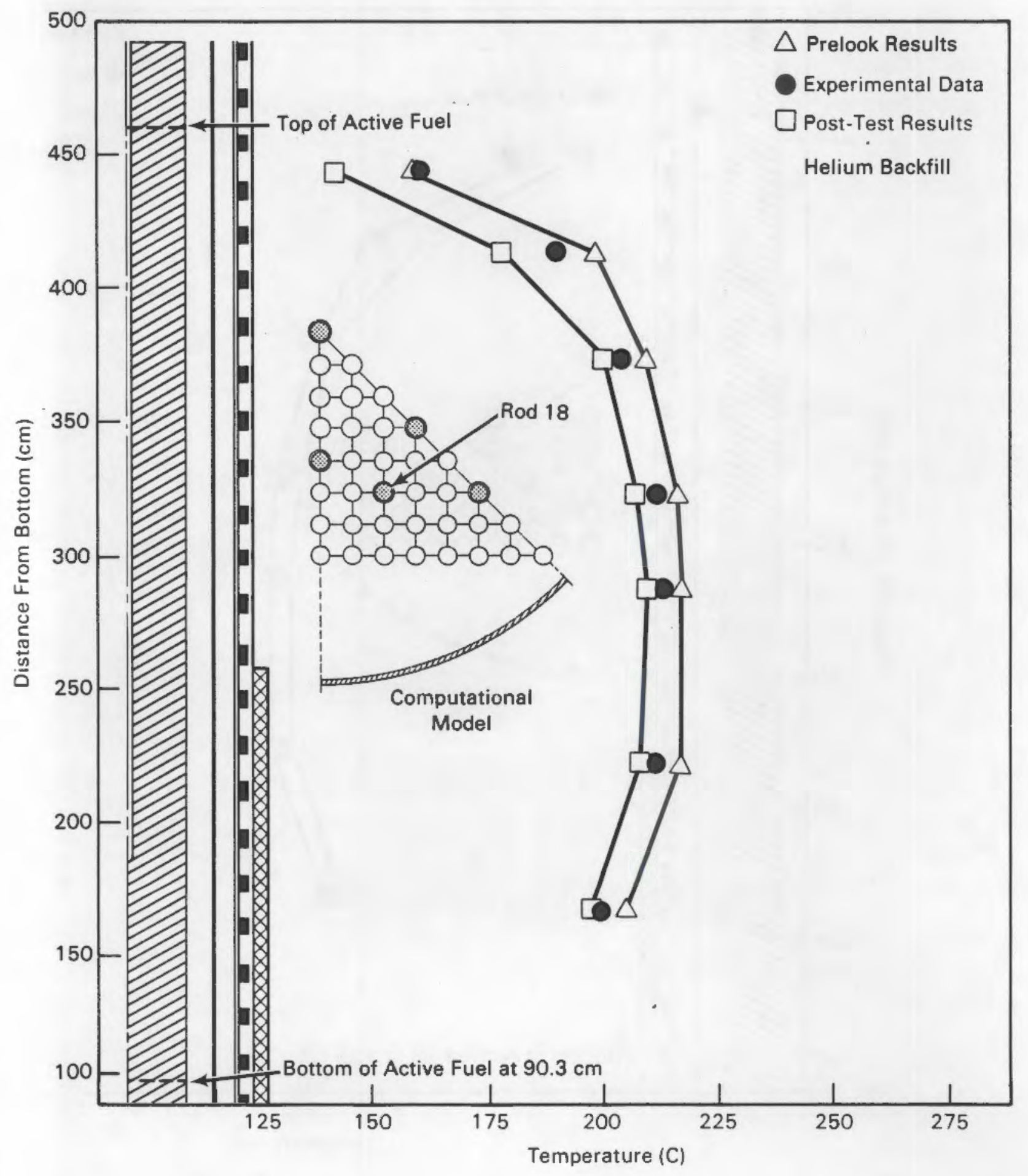

B. 5 


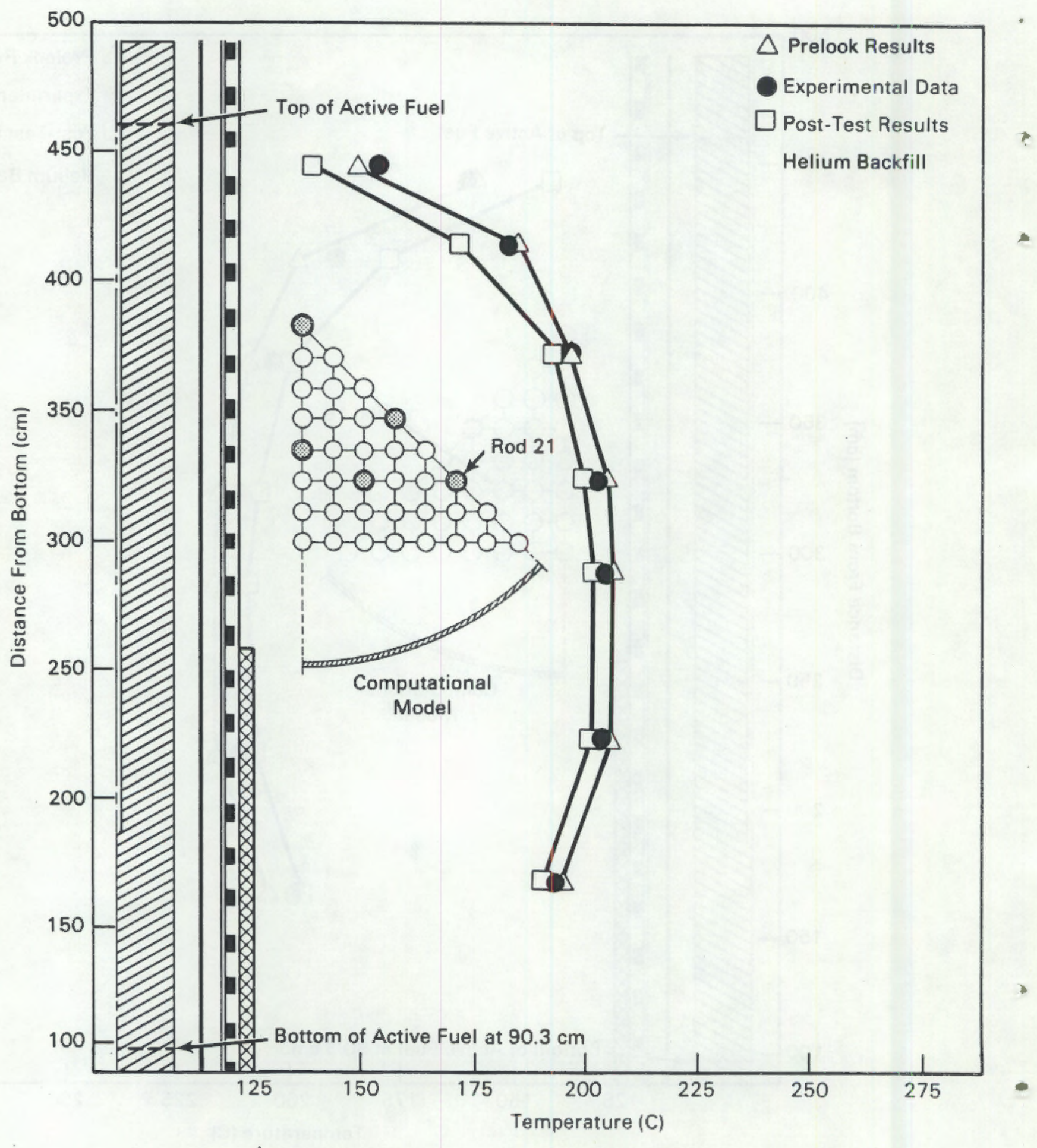

B. 6 


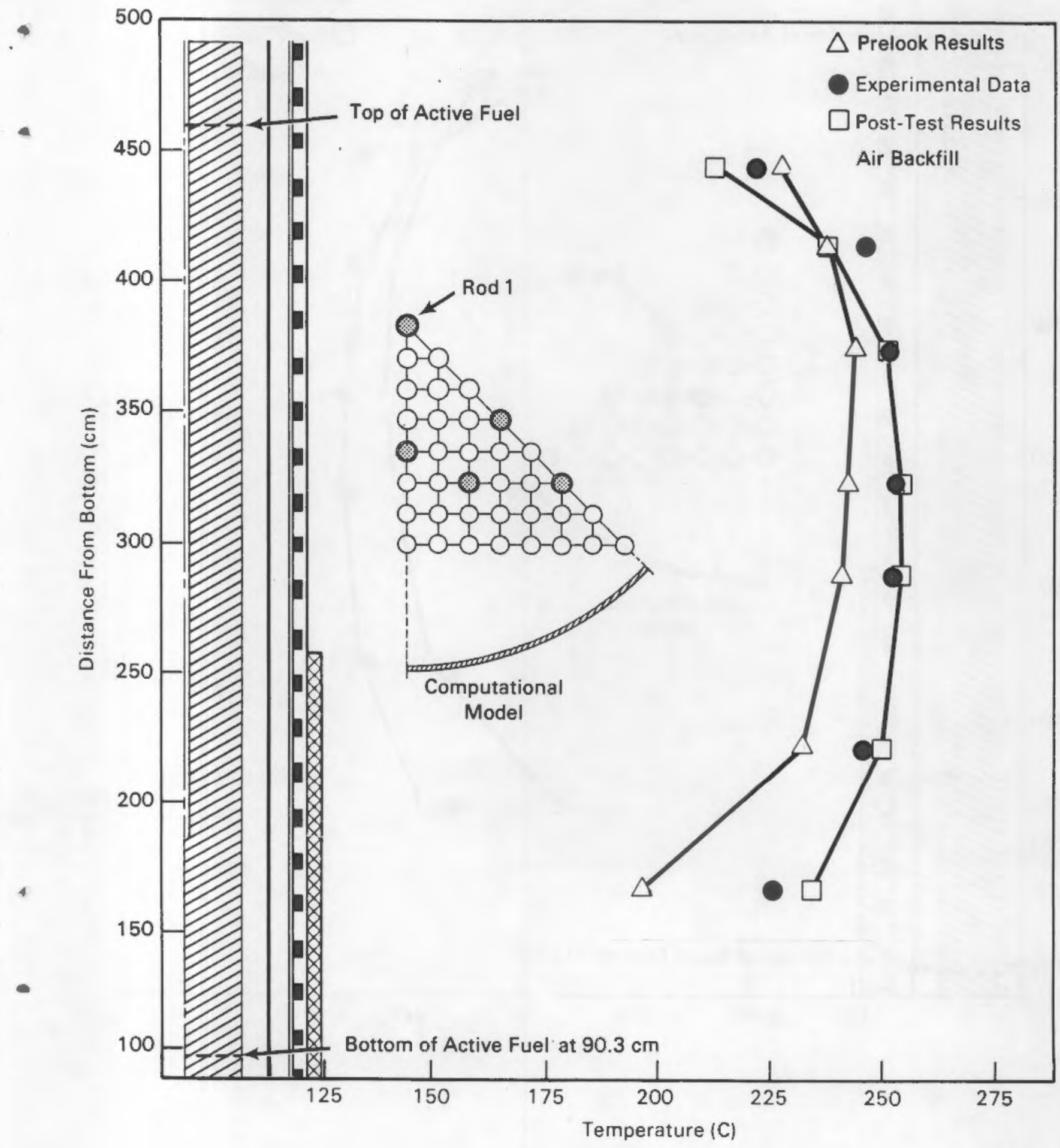




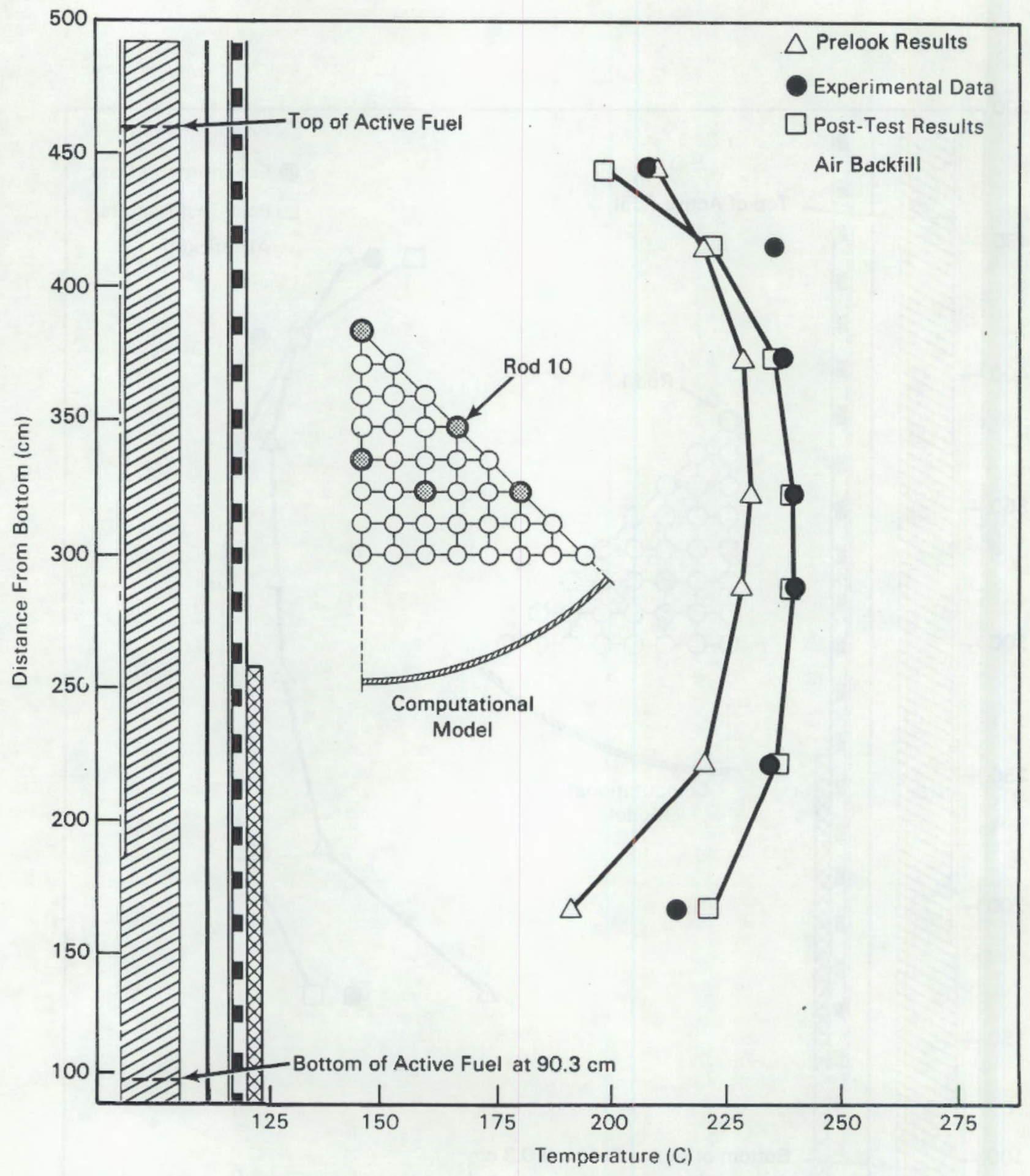

B. 3 


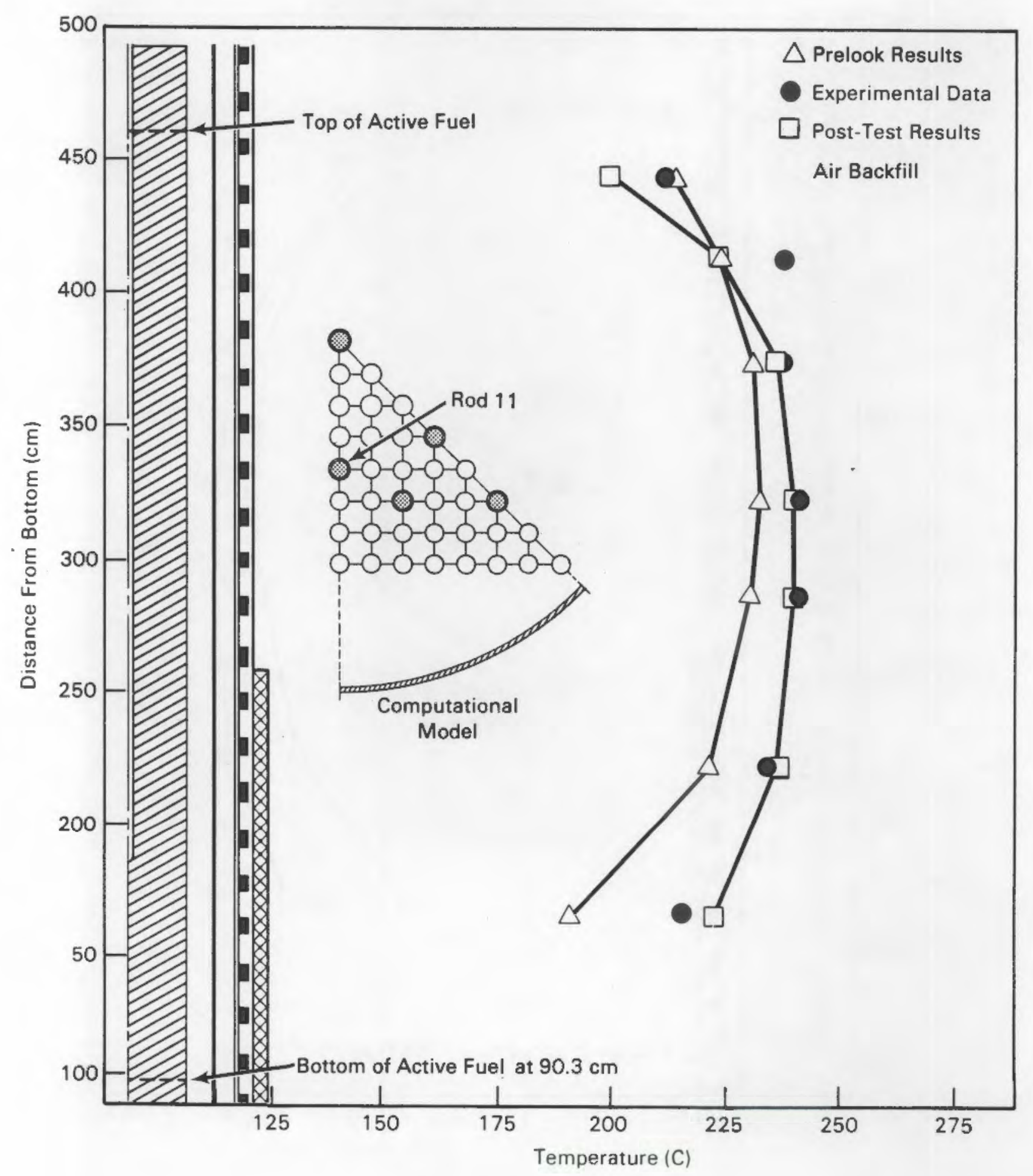

B. 9 


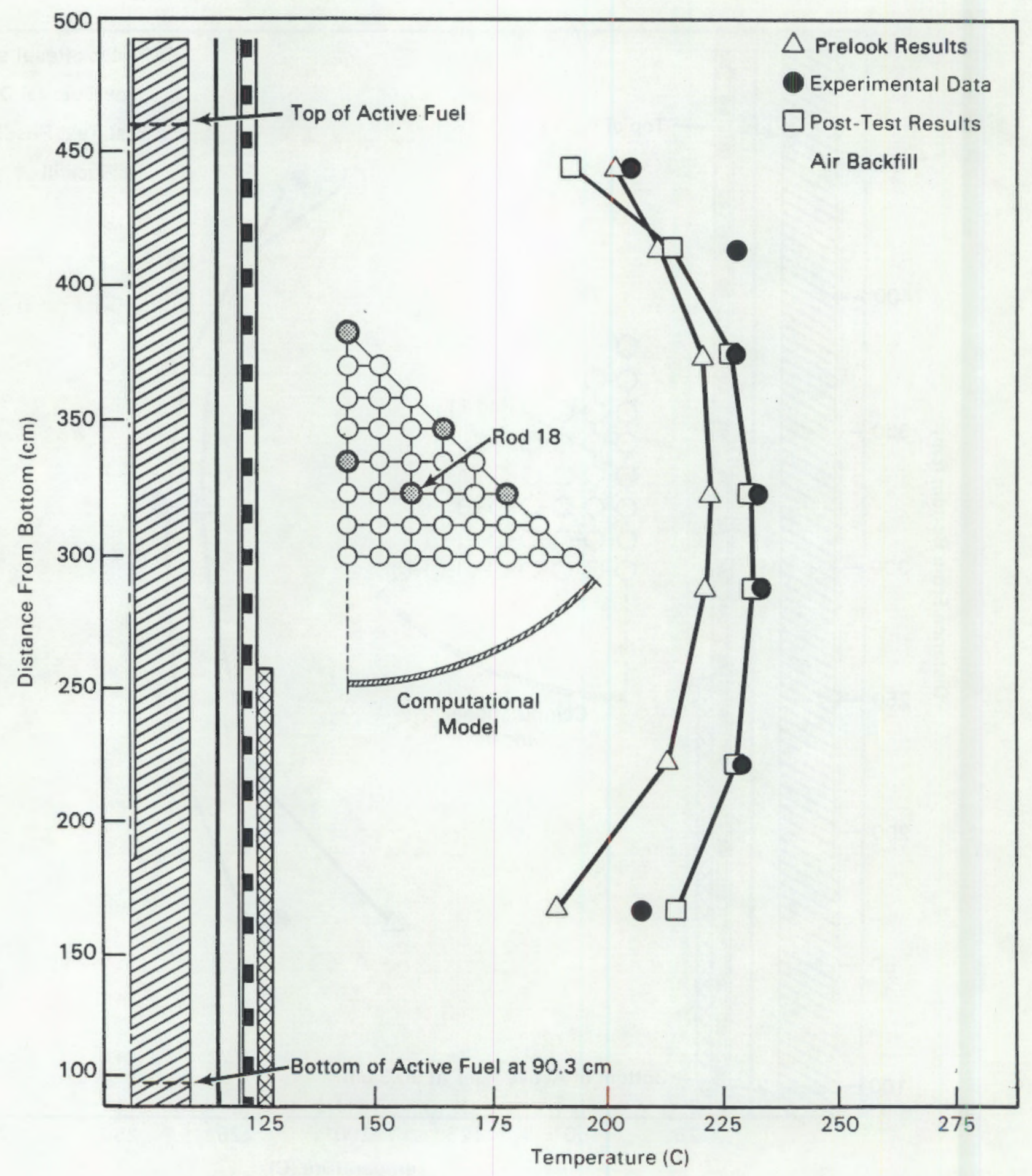

B. 10 


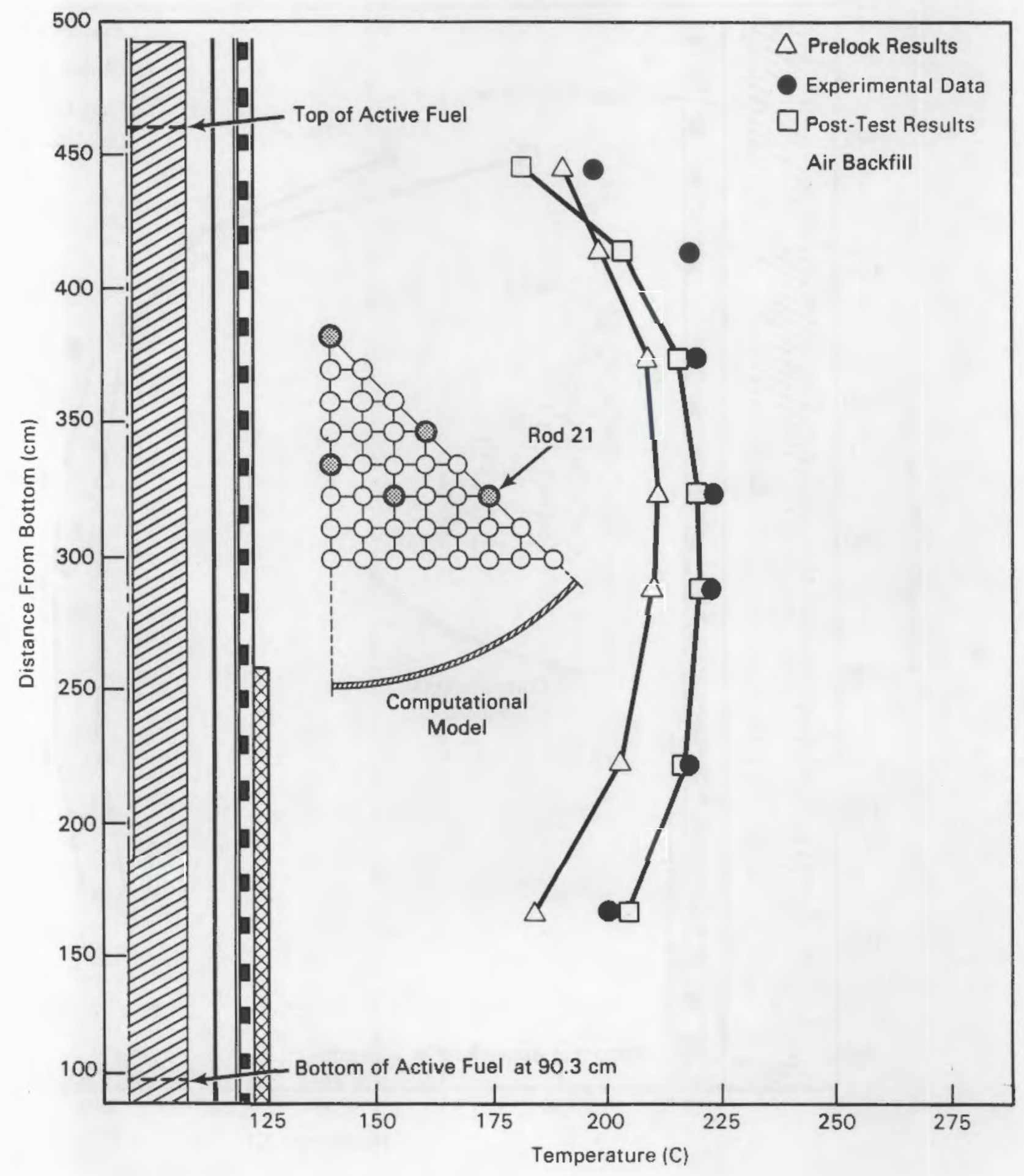

B. 11 


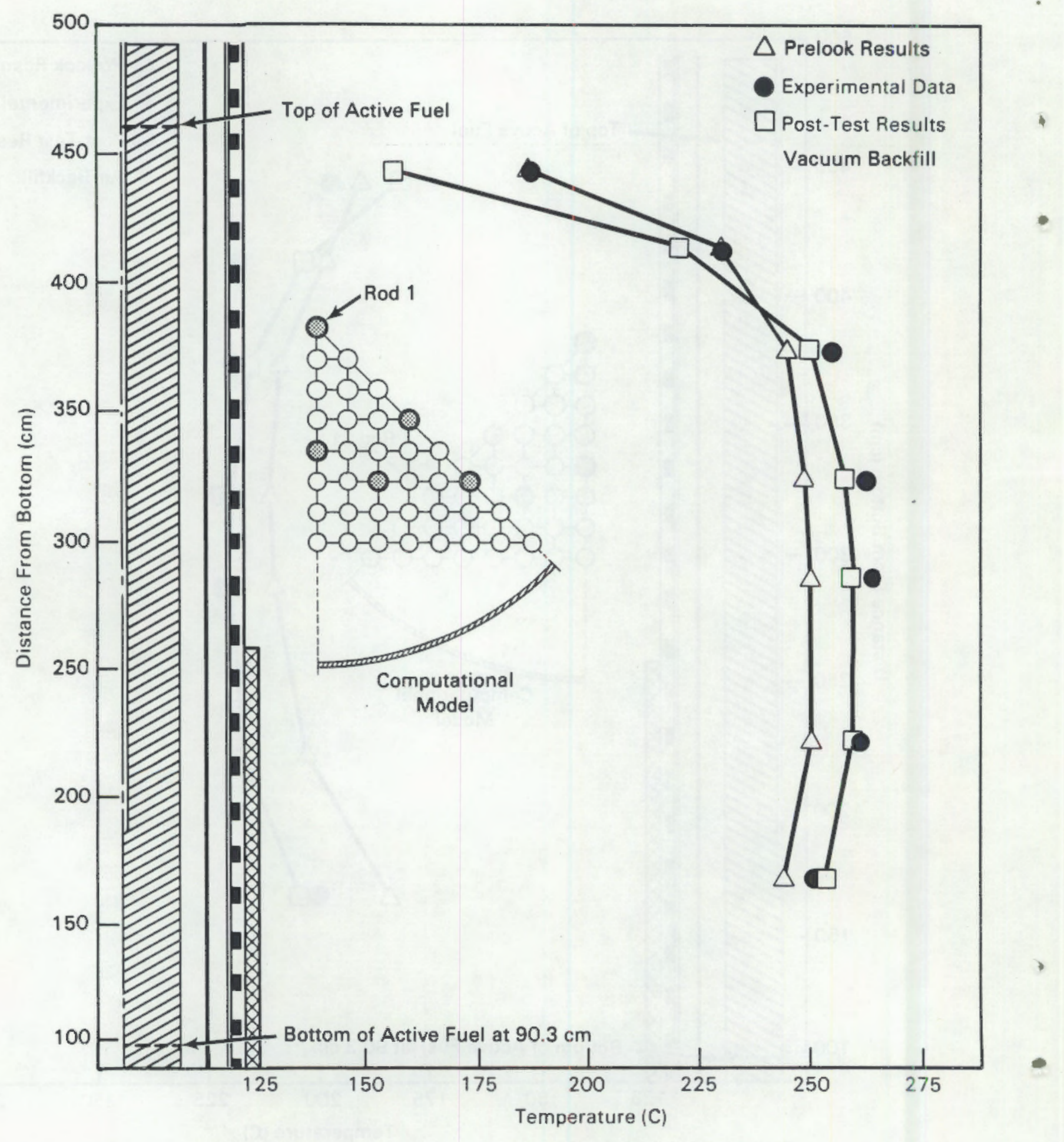

B. 12 


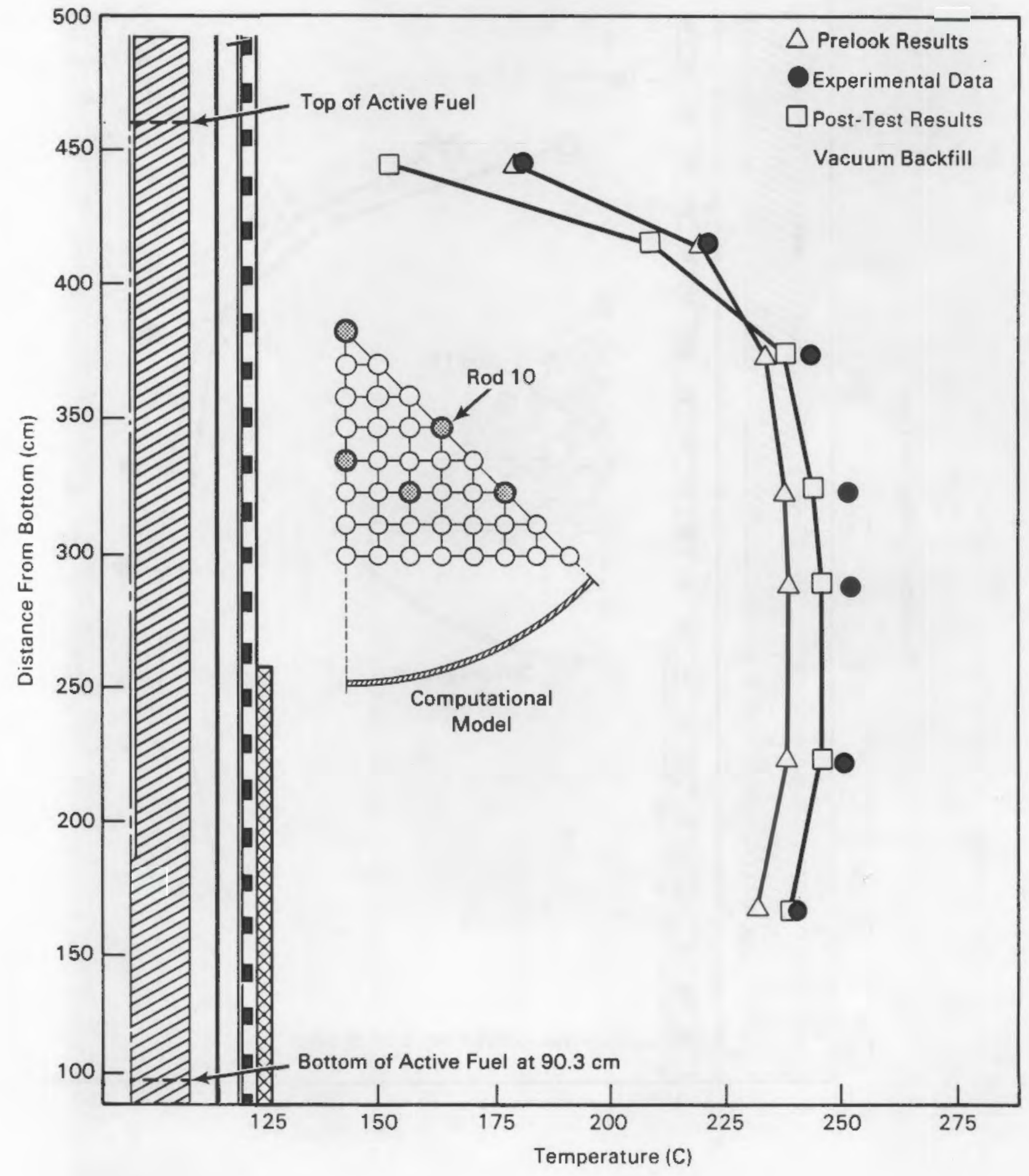

\section{B. 13}




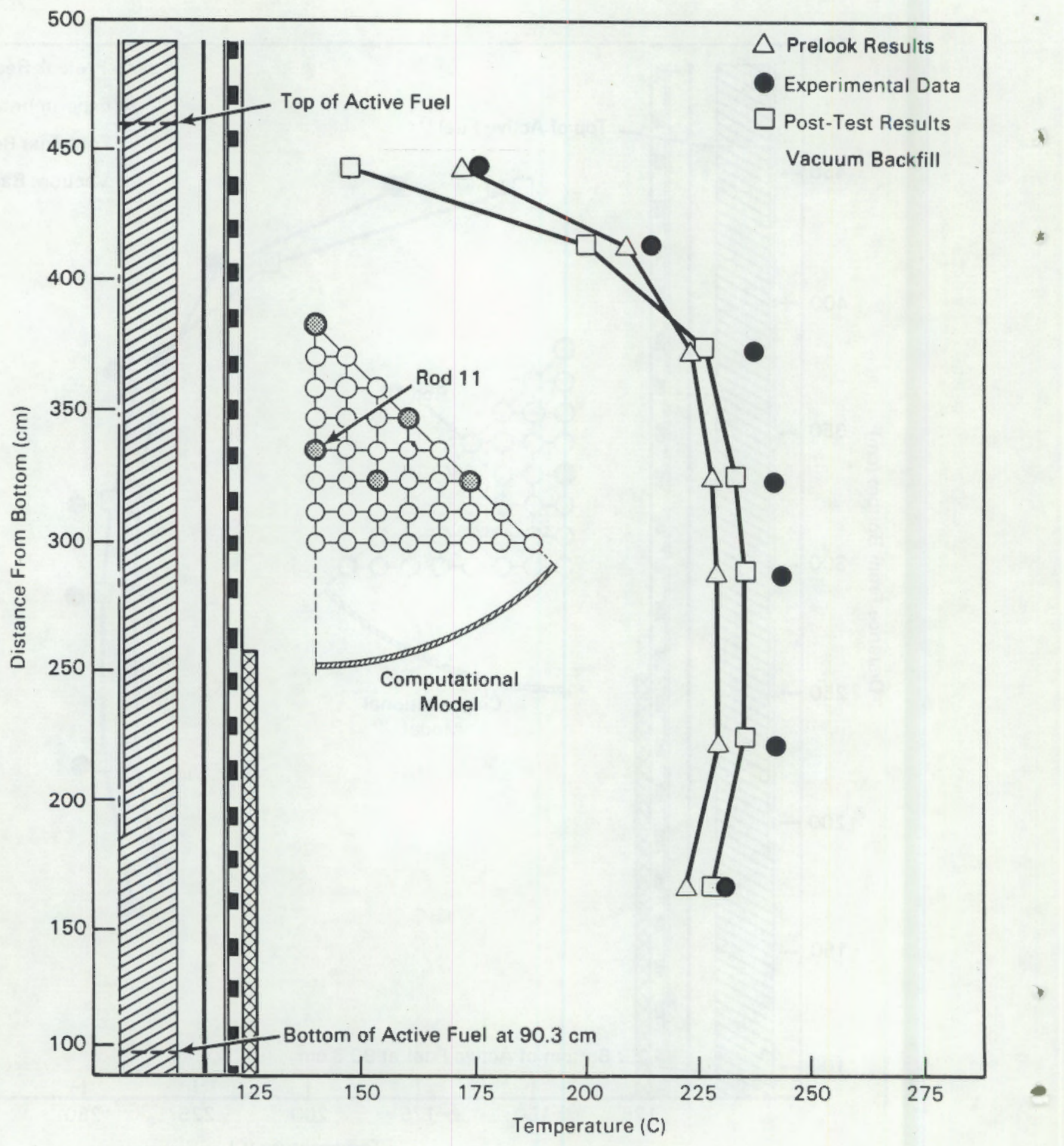

B. 14 


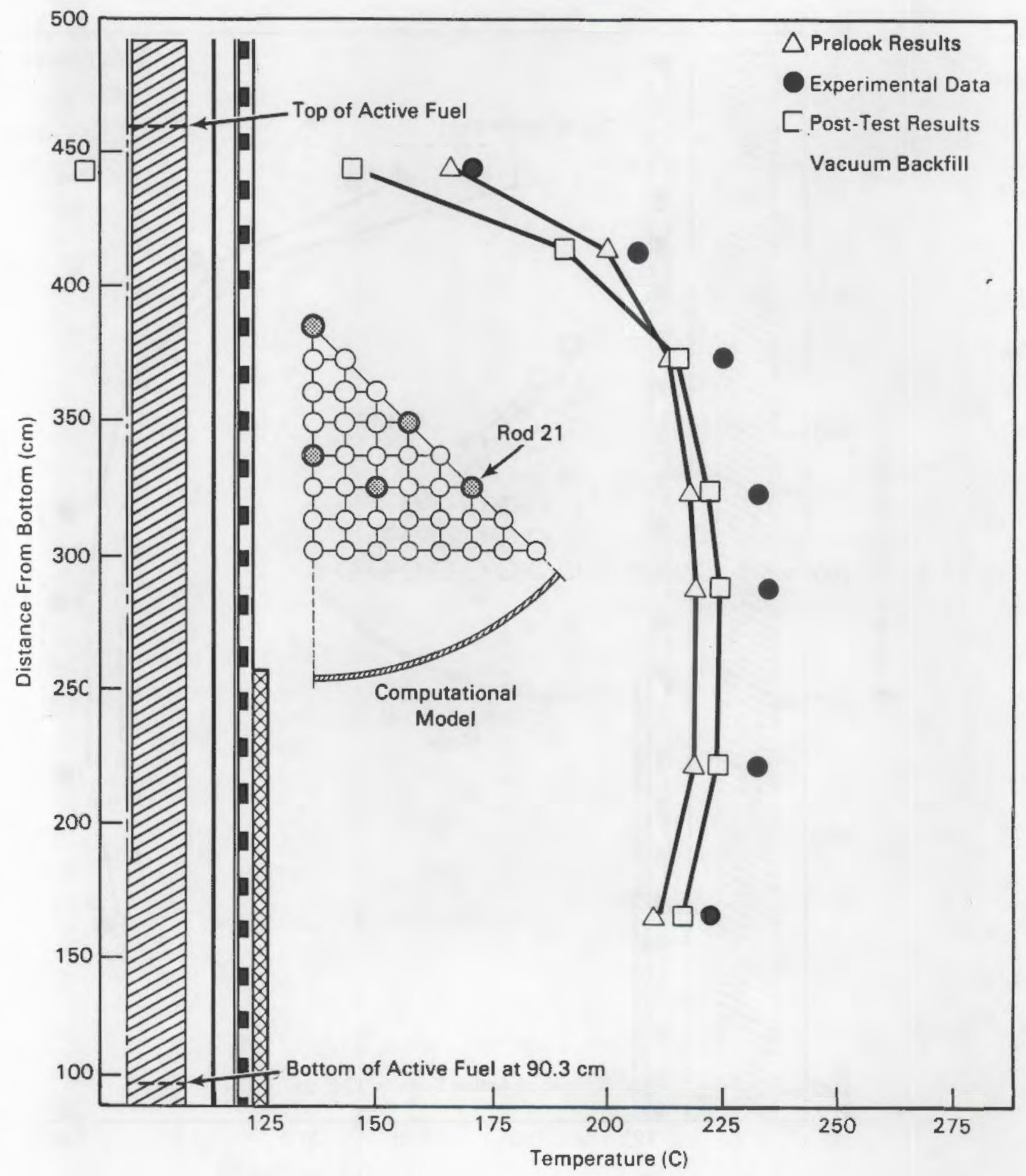

B. 15 


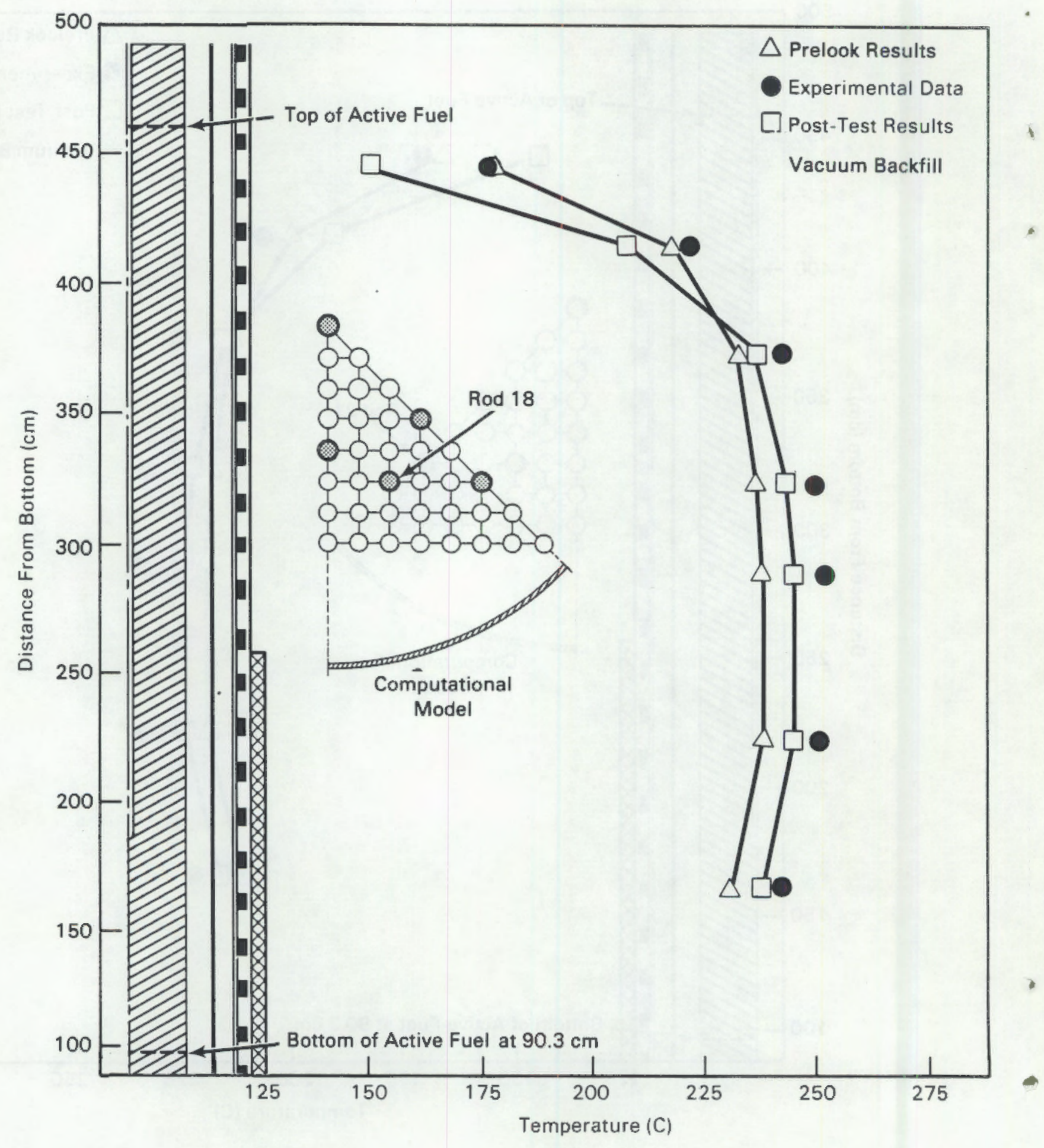

B. 16 . 


\author{
APPENDIX C \\ SAMPLE COBRA-SFS INPUT FOR THE ELECTRICALLY HEATED PWR \\ SINGLE ASSEMBLY SPENT FUEL TEST
}




\section{SAMPLE COBRA-SFS INPUT FOR THE ELECTRICALLY HEATED PWR}

\section{SINGLE ASSEMBLY SPENT FUEL TEST}

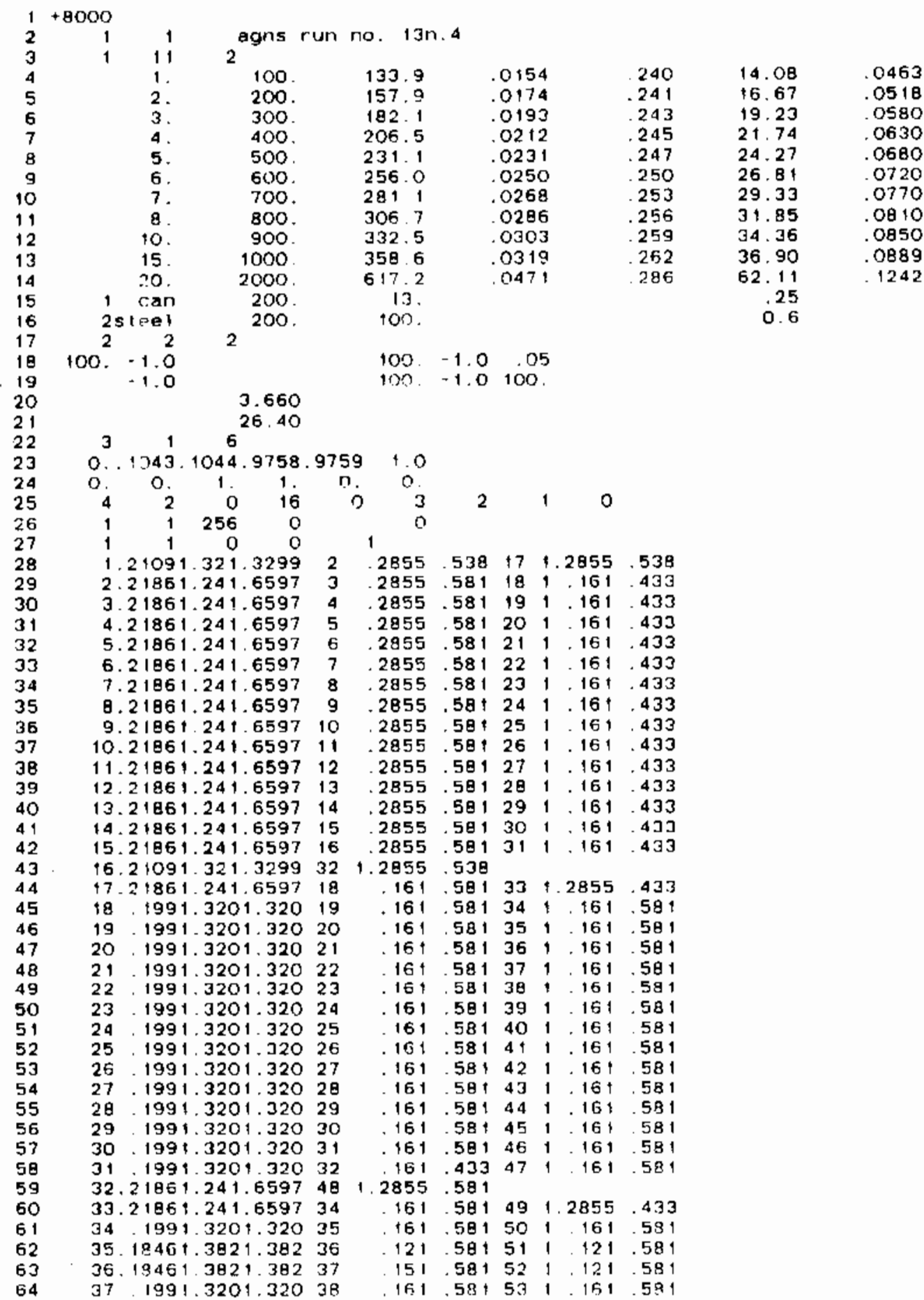




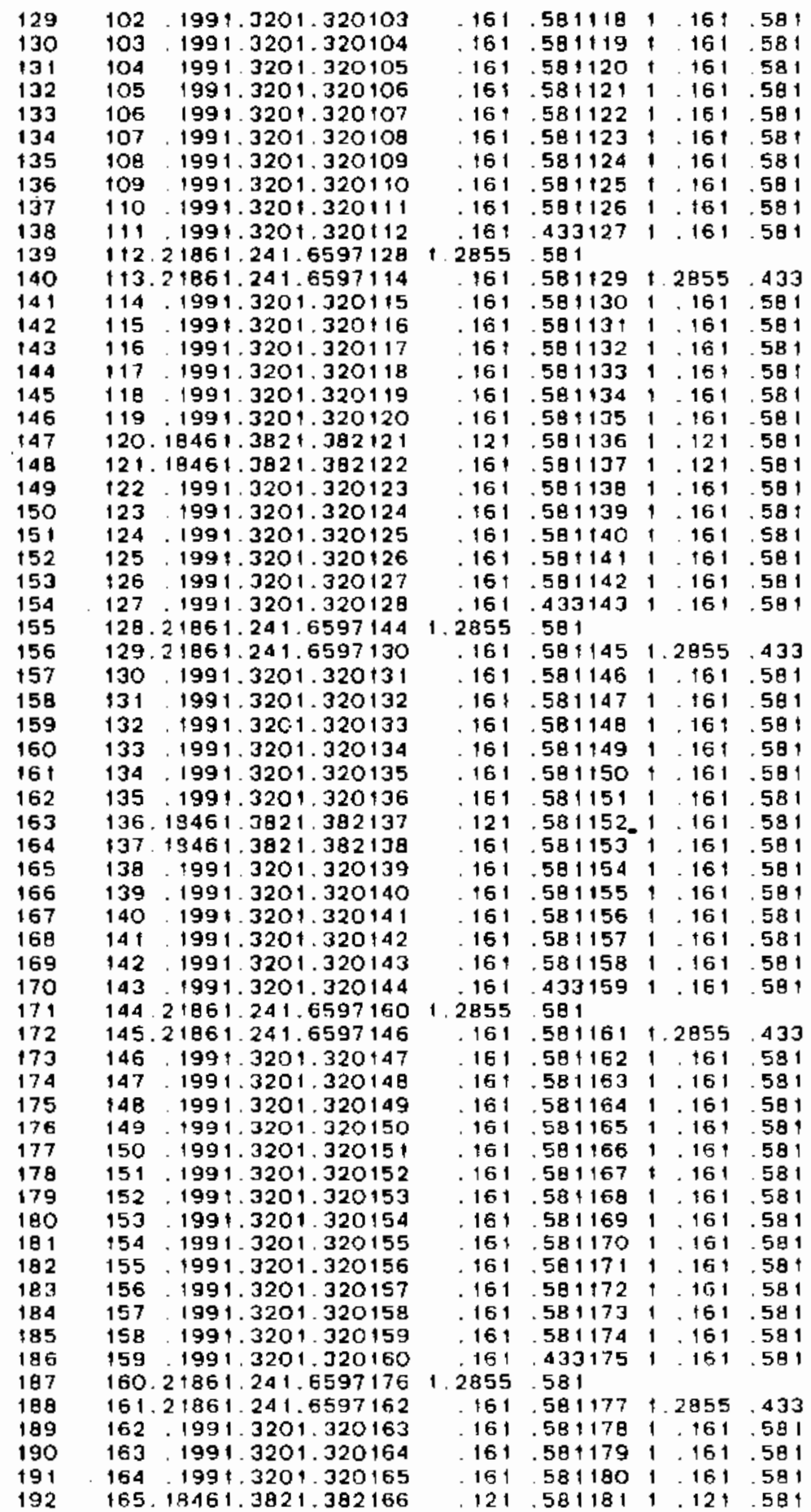




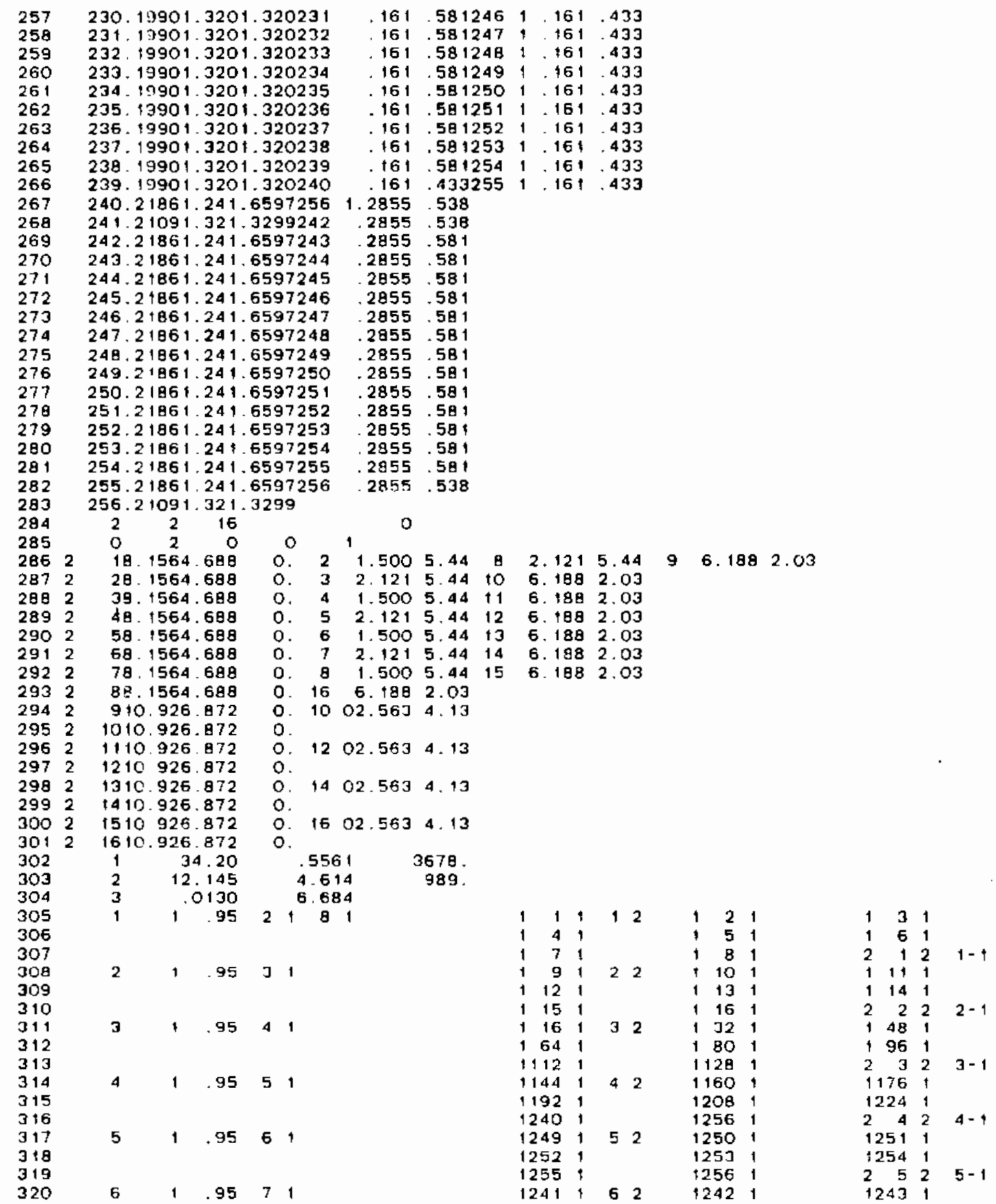




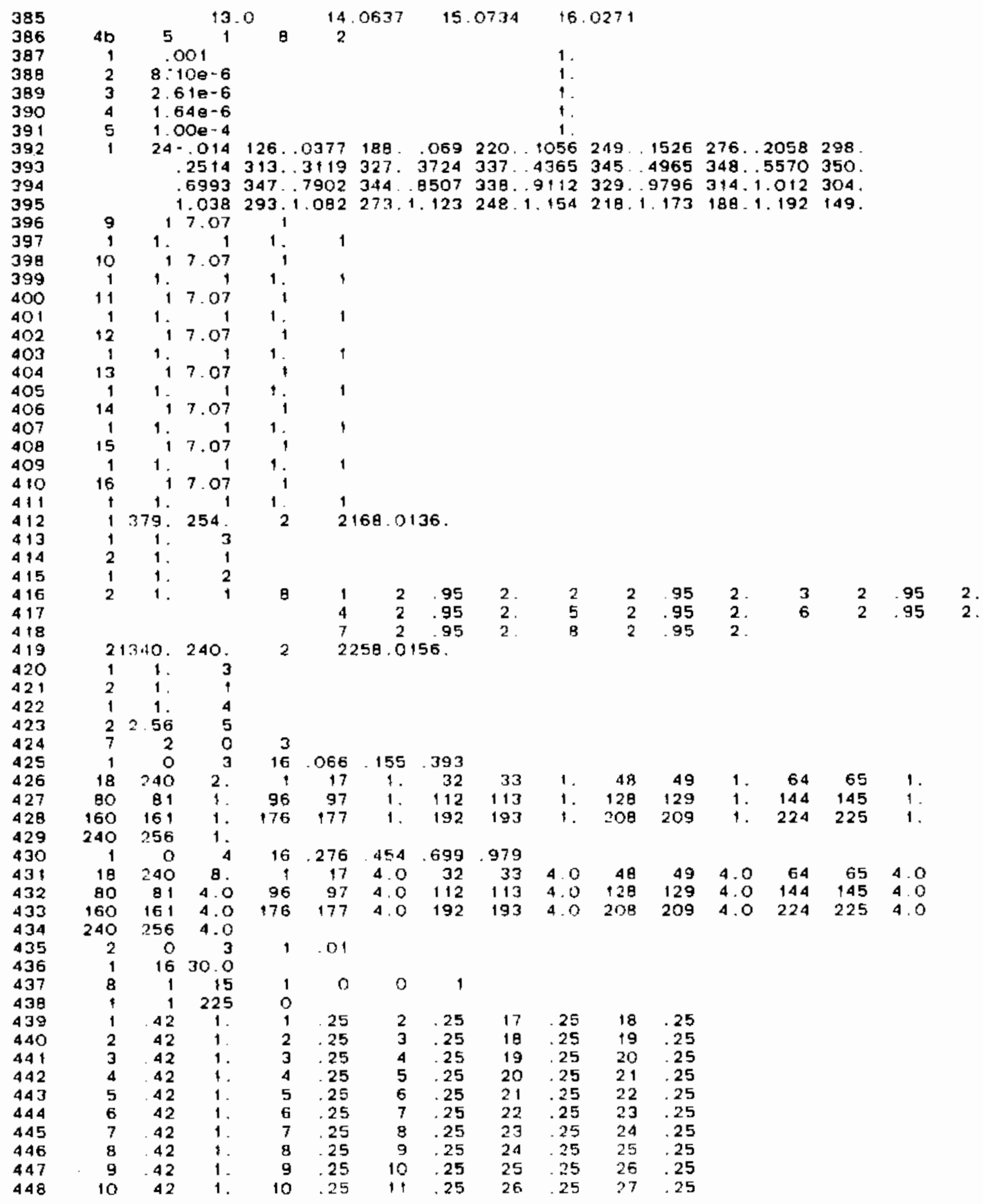




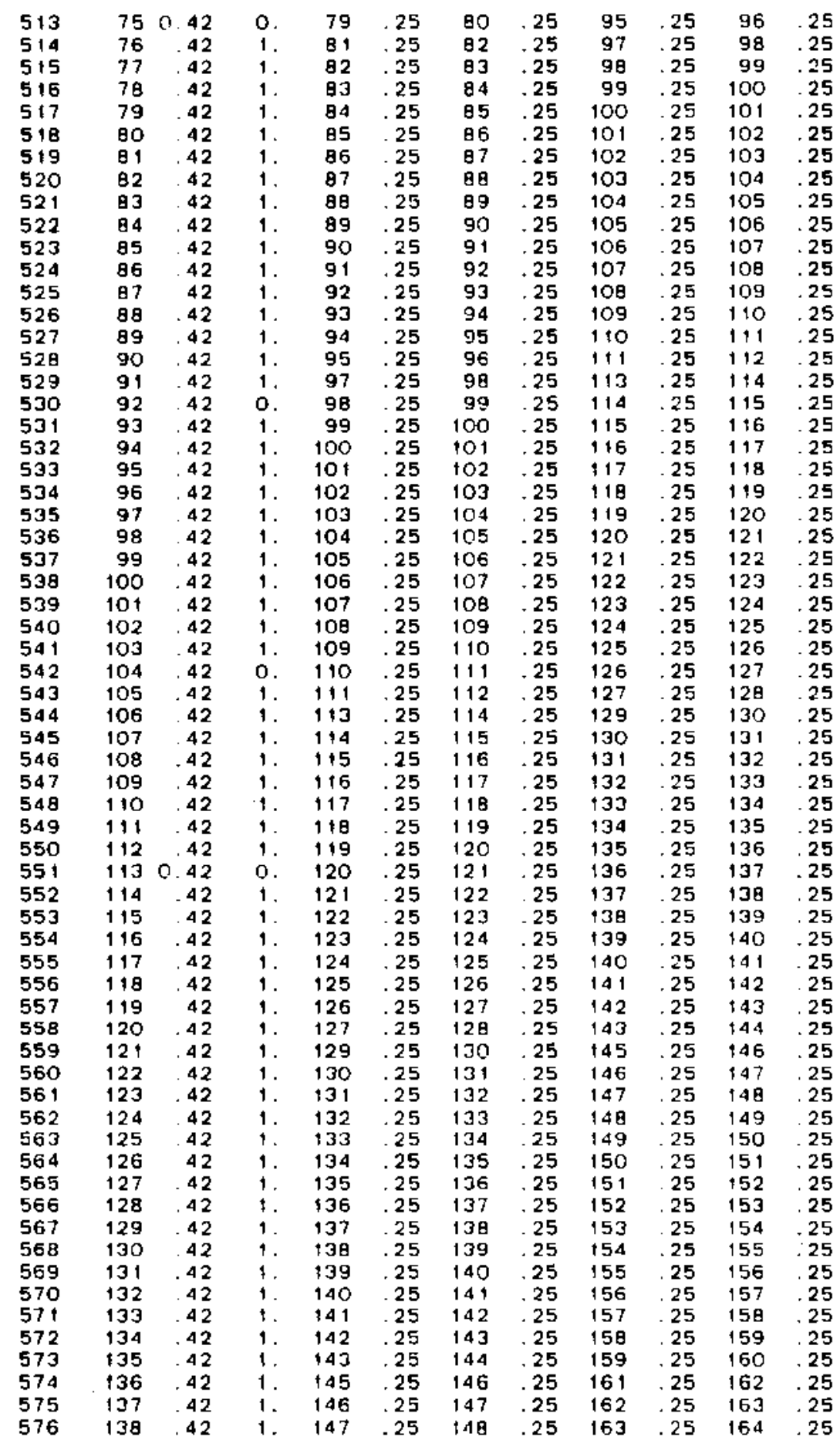




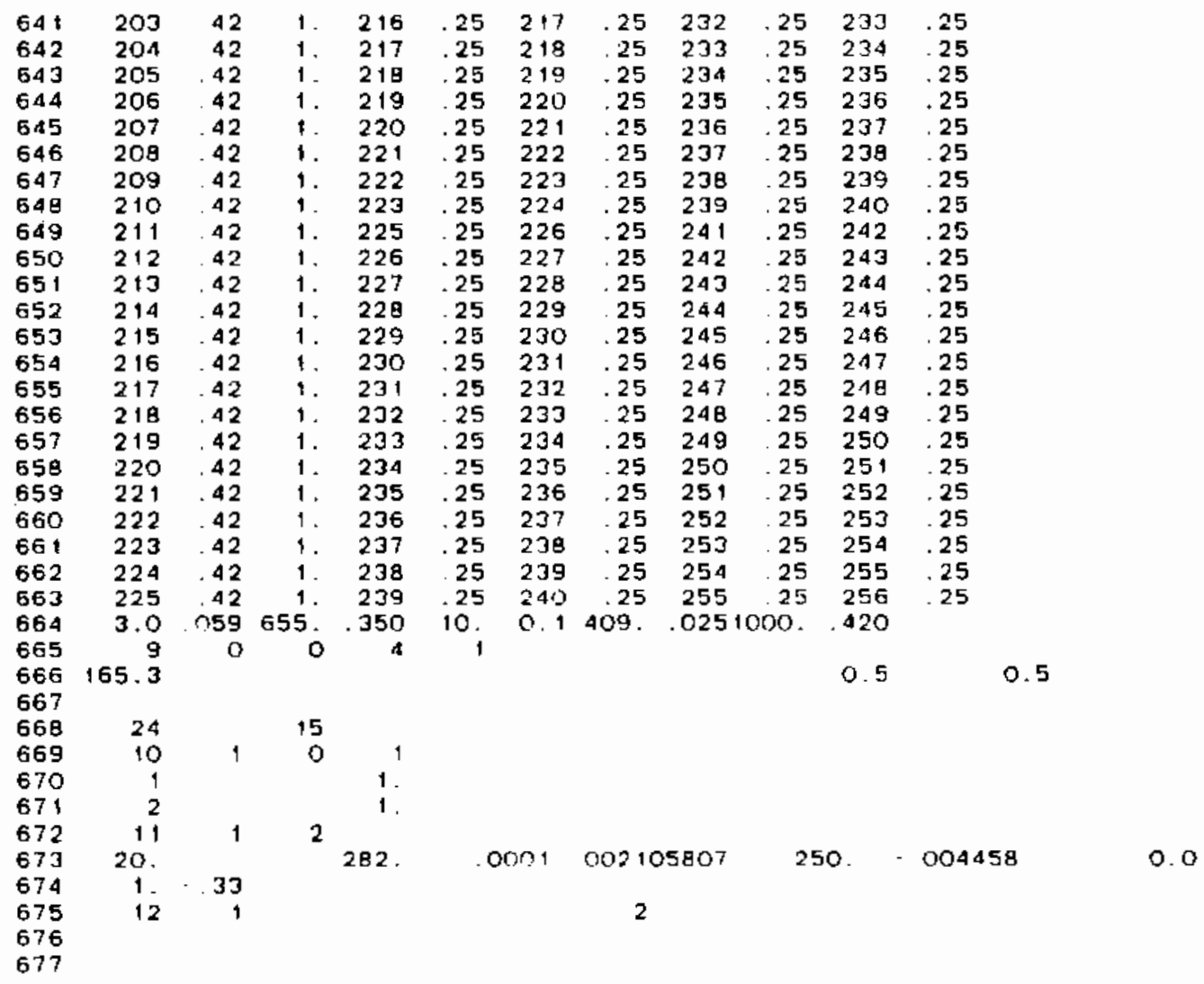


APPENDIX D

ELECTRICALLY HEATED PWR SINGLE ASSEMBLY SPENT FUEL TEST

PREDICTED AND EXPERIMENTAL AXIAL PROFILES 


\section{ELECTRICALLY HEATED PWR SINGLE ASSEMBLY SPENT FUEL TEST}

PREDICTED AND EXPERIMENTAL AXIAL PROFILES

Prelook predicted axial temperature profiles for the entire 18-run test matrix are presented on pages D.2 through D.19 along with the experimental data for four radial positions in the cask ( $\operatorname{rod} 9 \mathrm{H}$, Rod $1 \mathrm{~A}$, fuel tube, and cask boundary). Similar profiles showing the post-test predicted results and data are provided on pages Figures D.20 through D.23 for the four post-test simulations performed. 


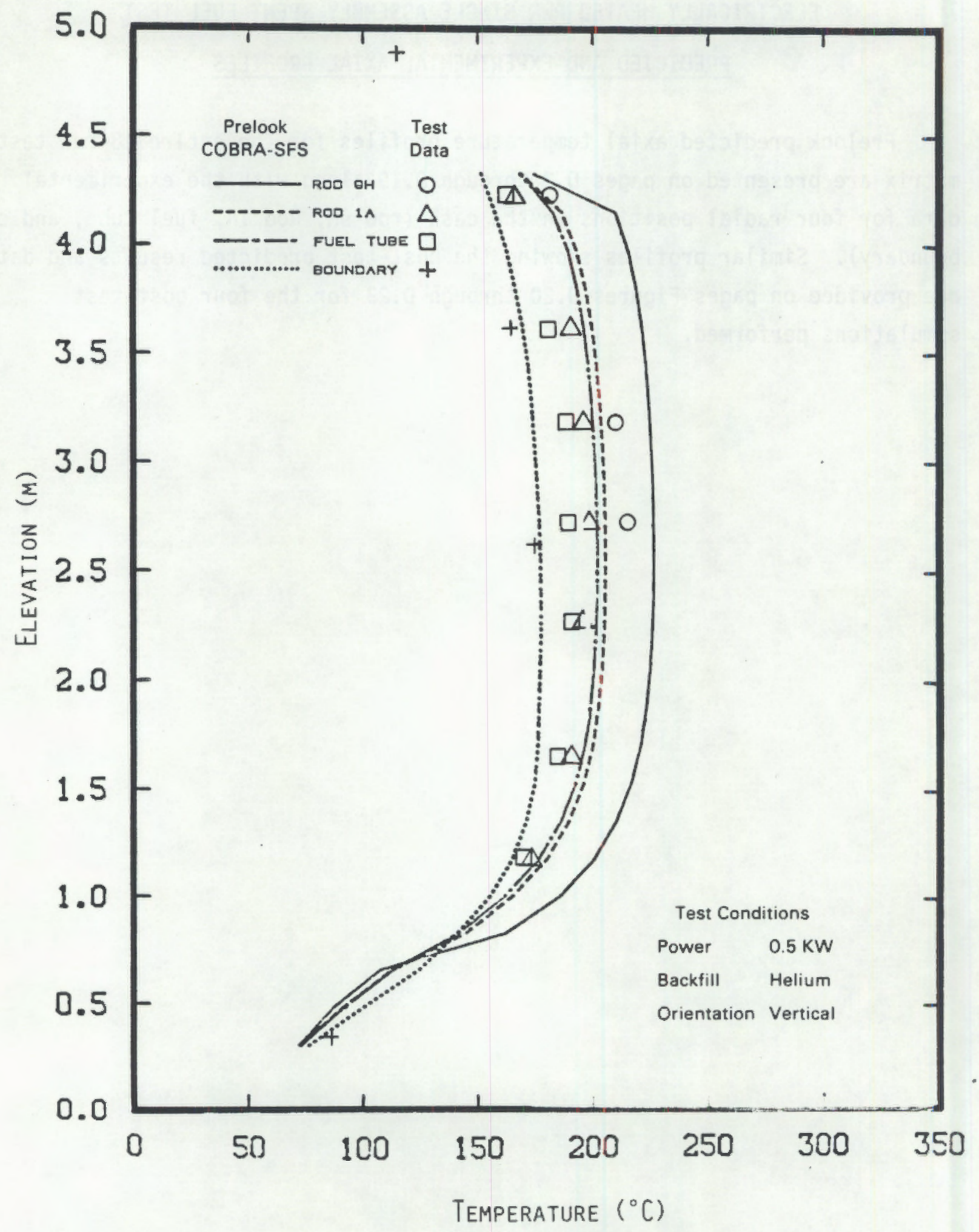

D. 2 


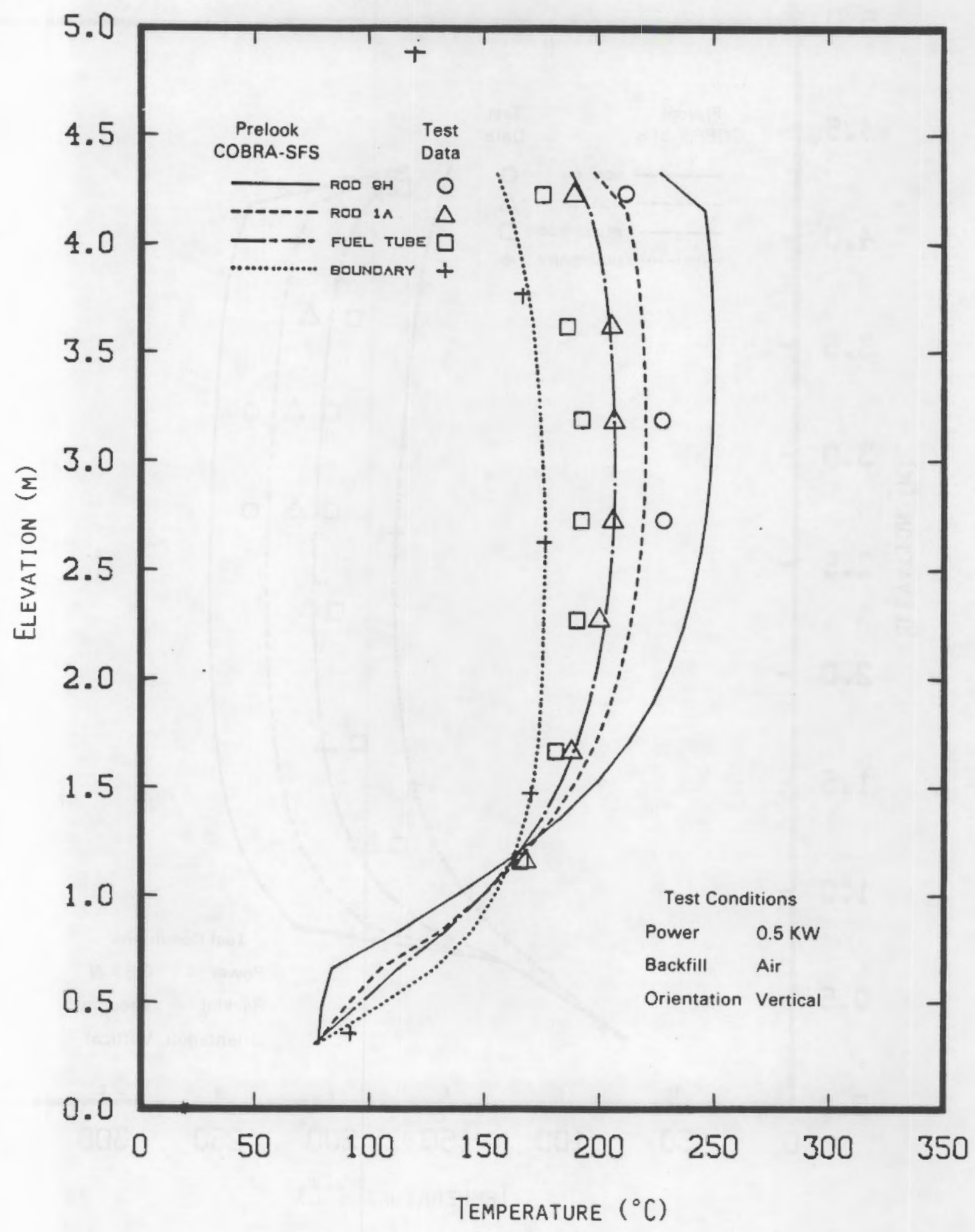

D. 3 


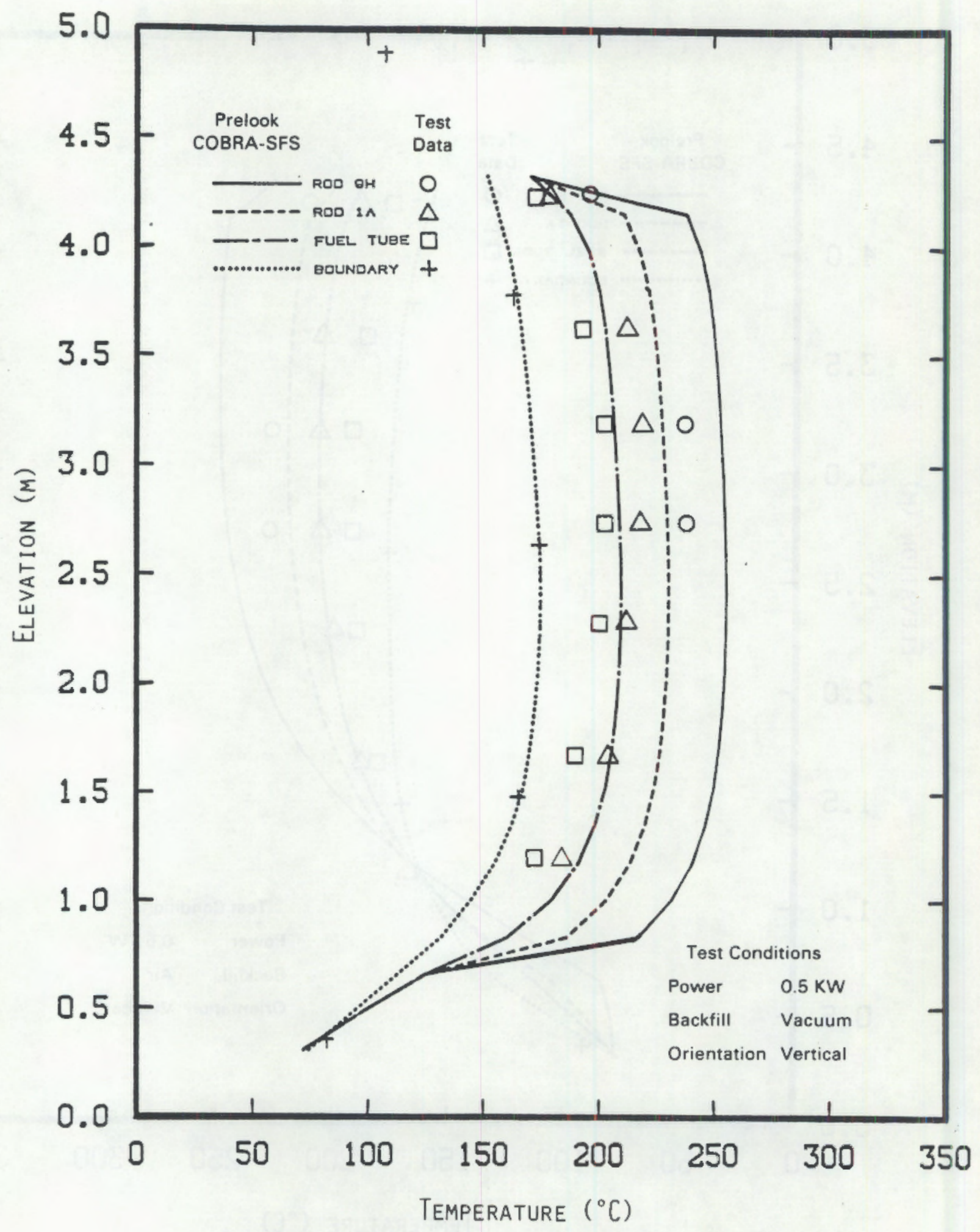

D. 4 


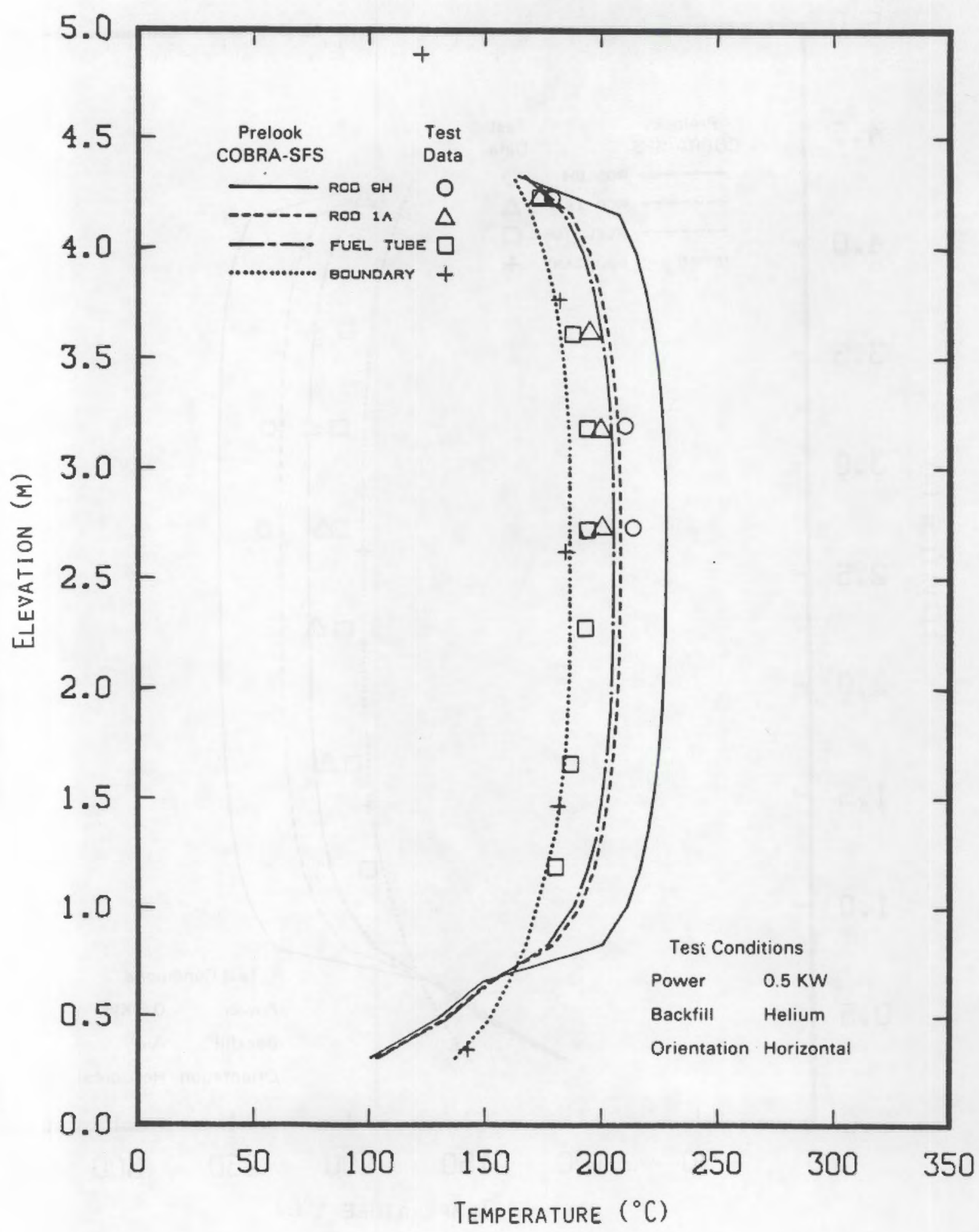

D. 5 


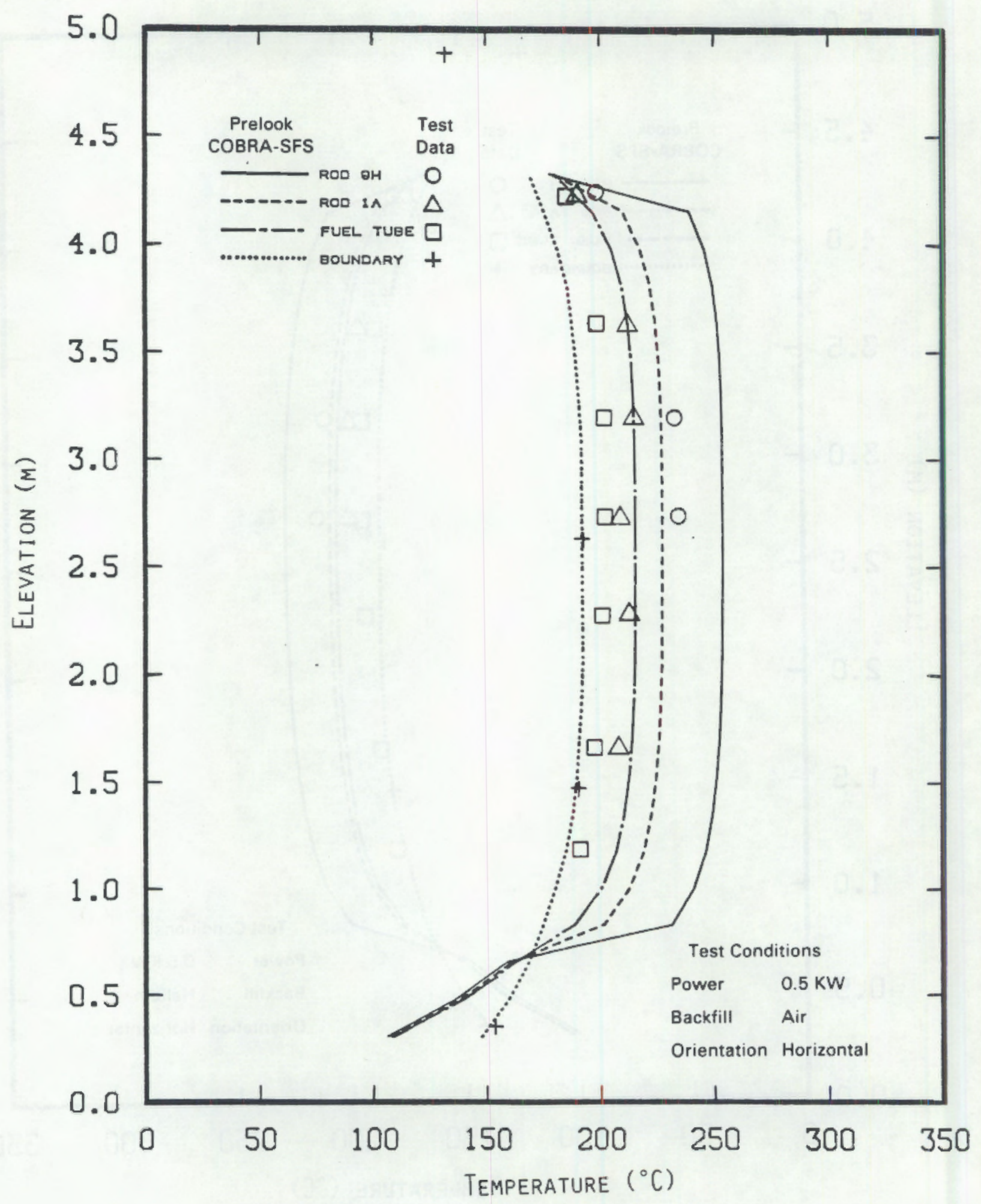

0.6 


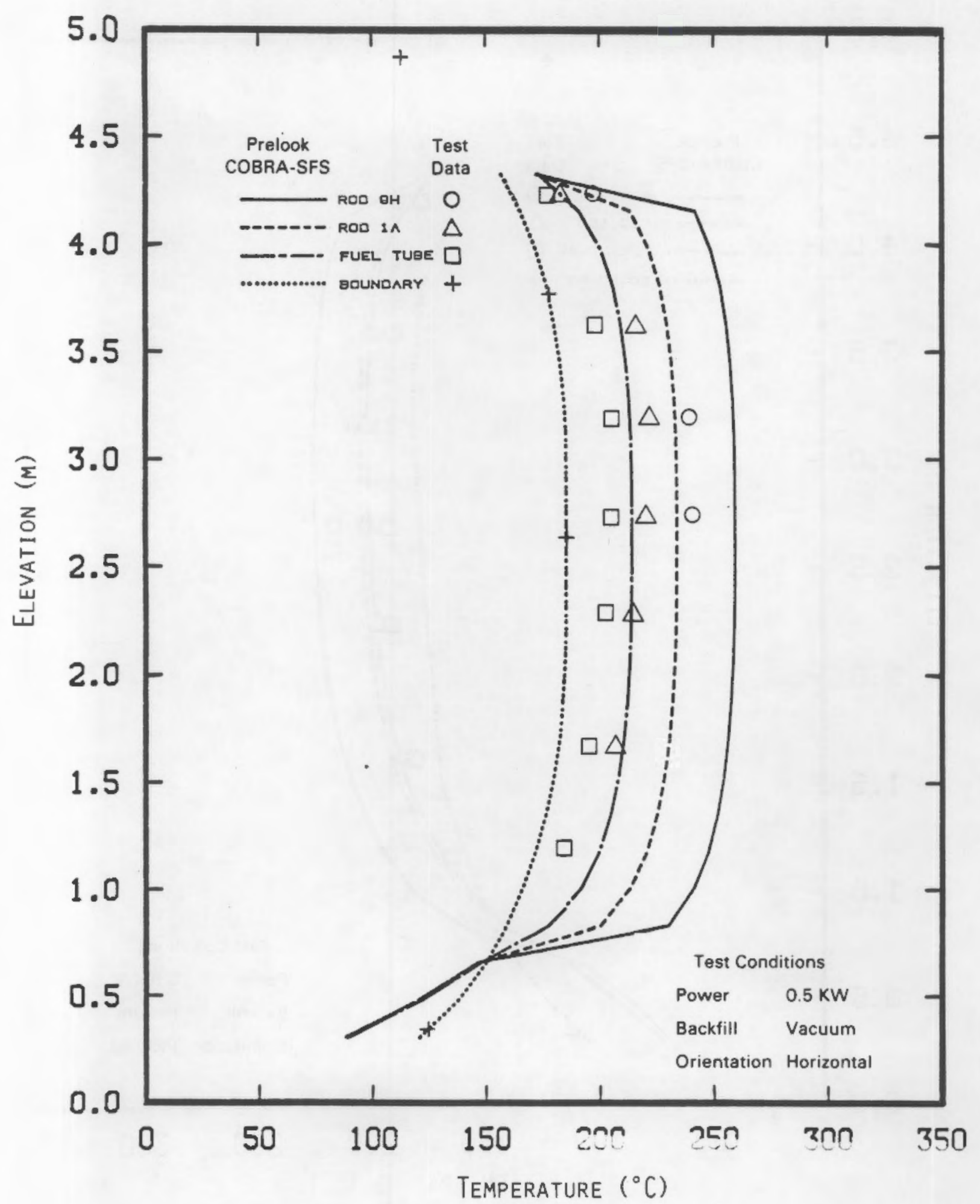

D. 7 


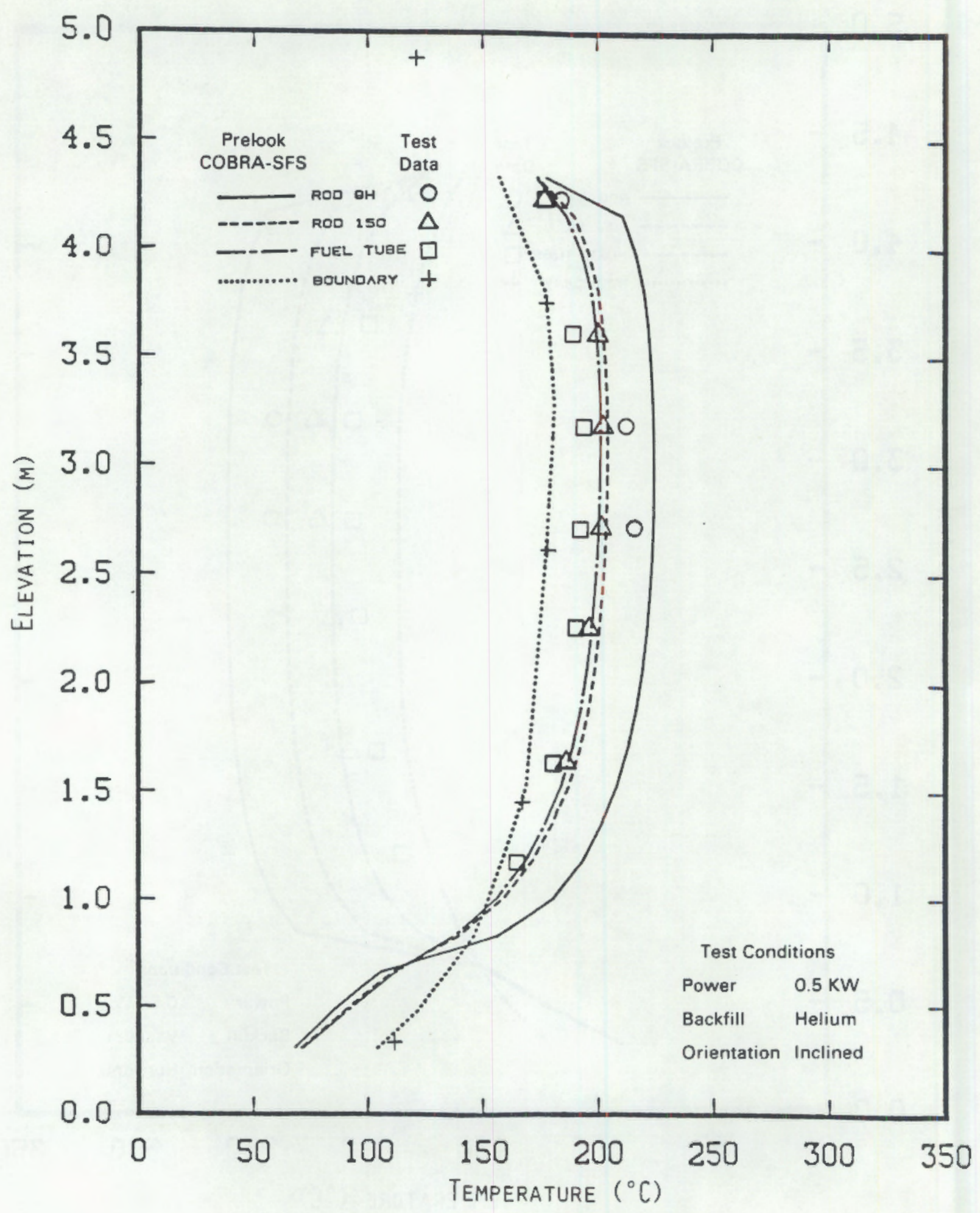

D. 8 


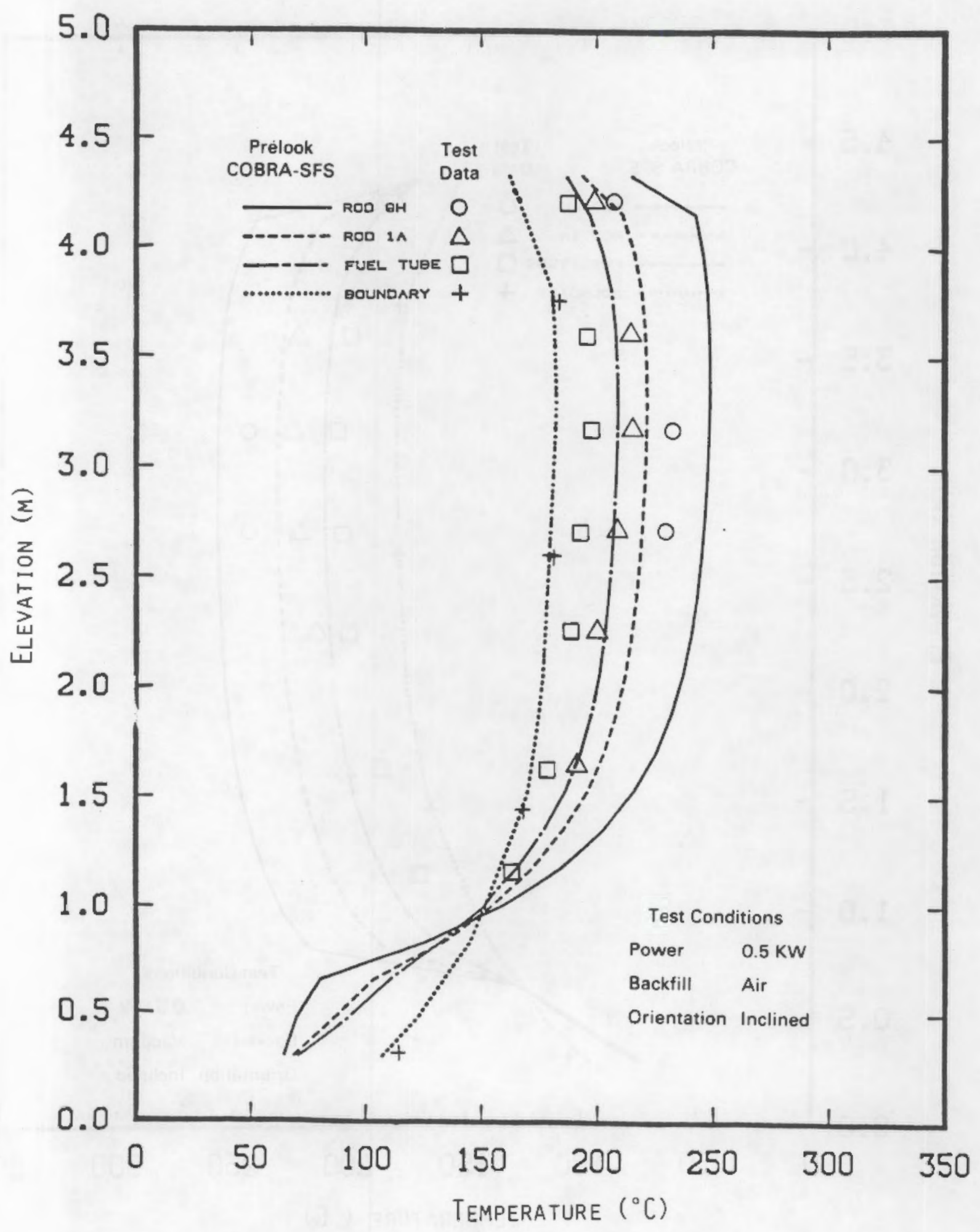

D. 9 


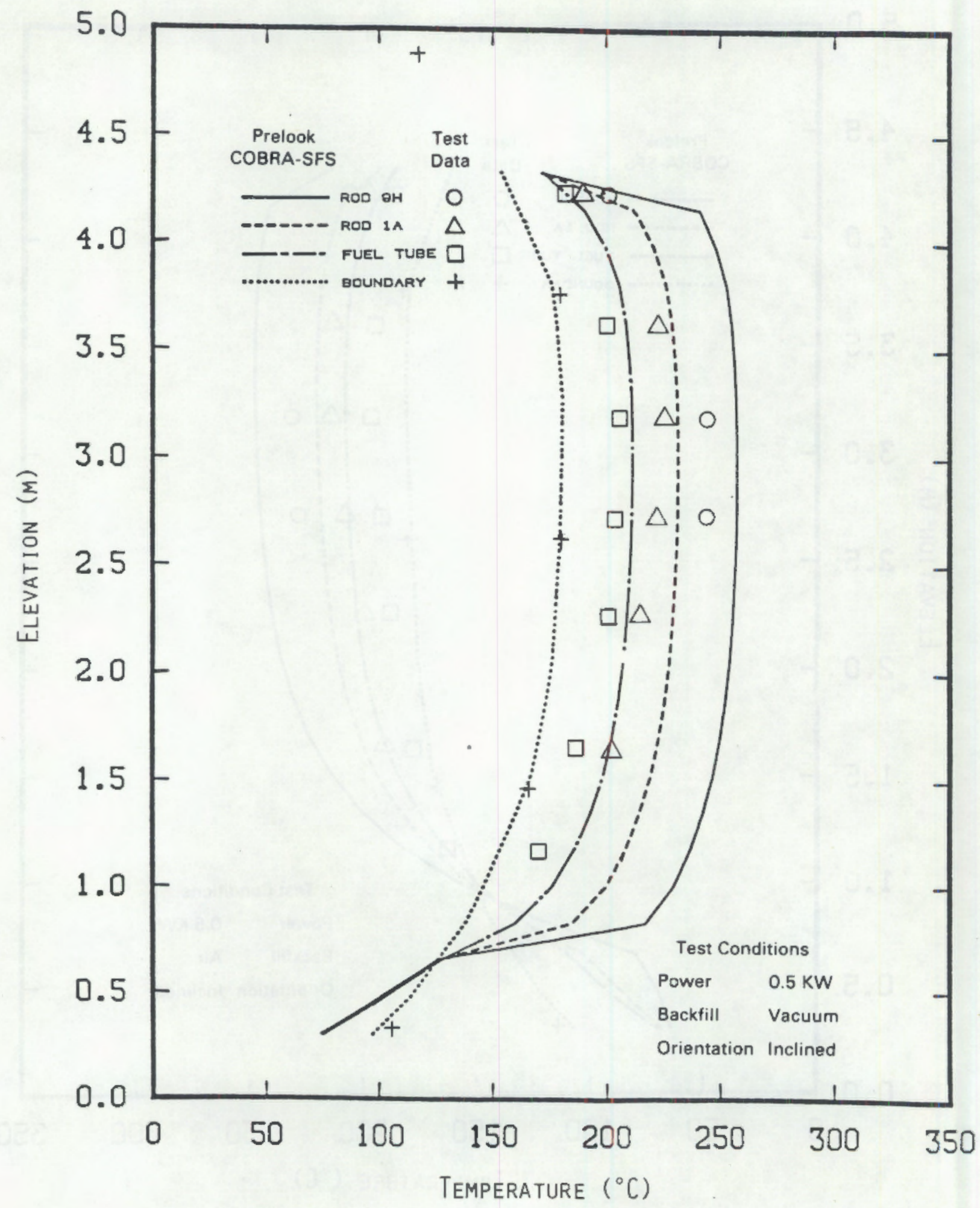

D. 10 


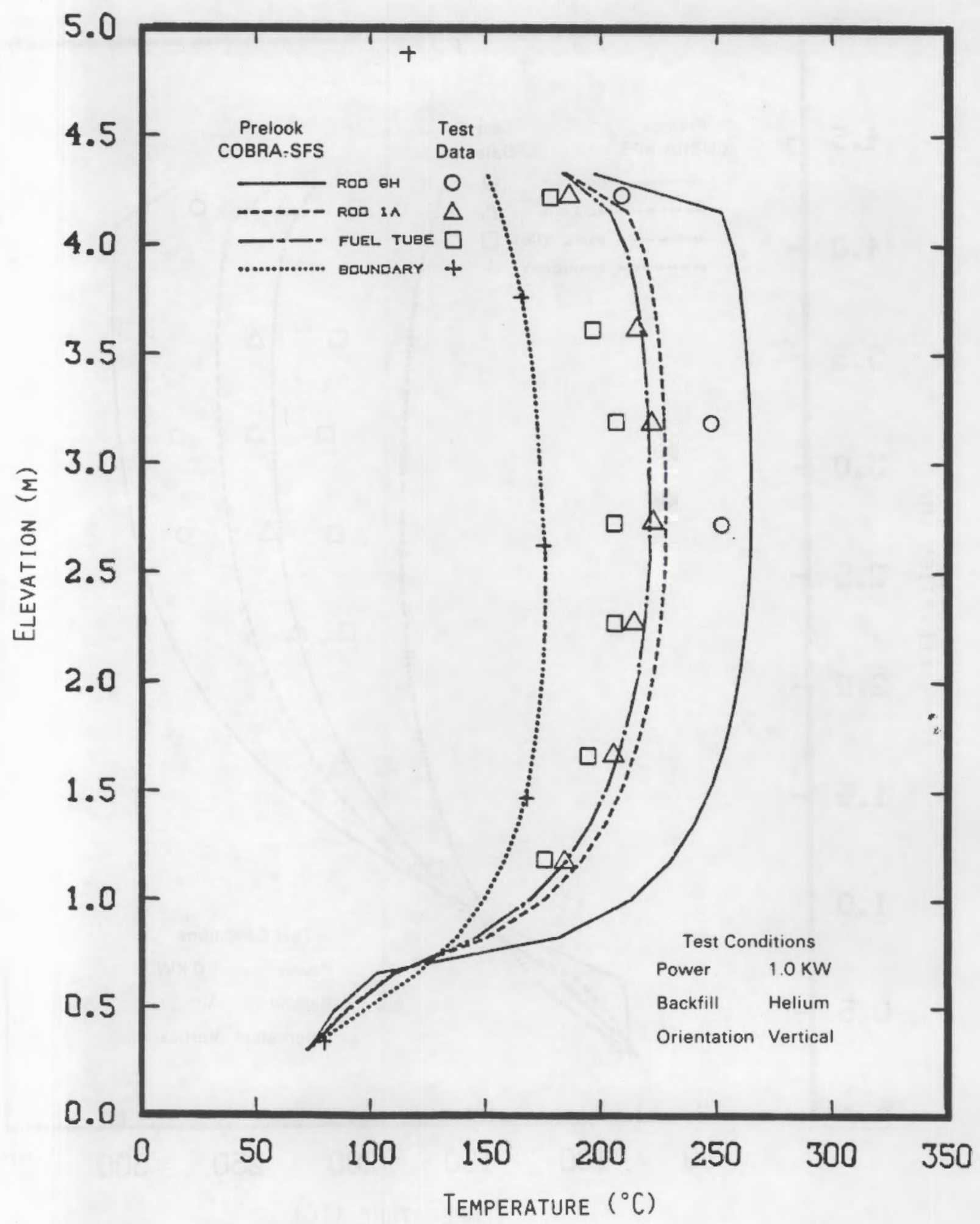

D.11 


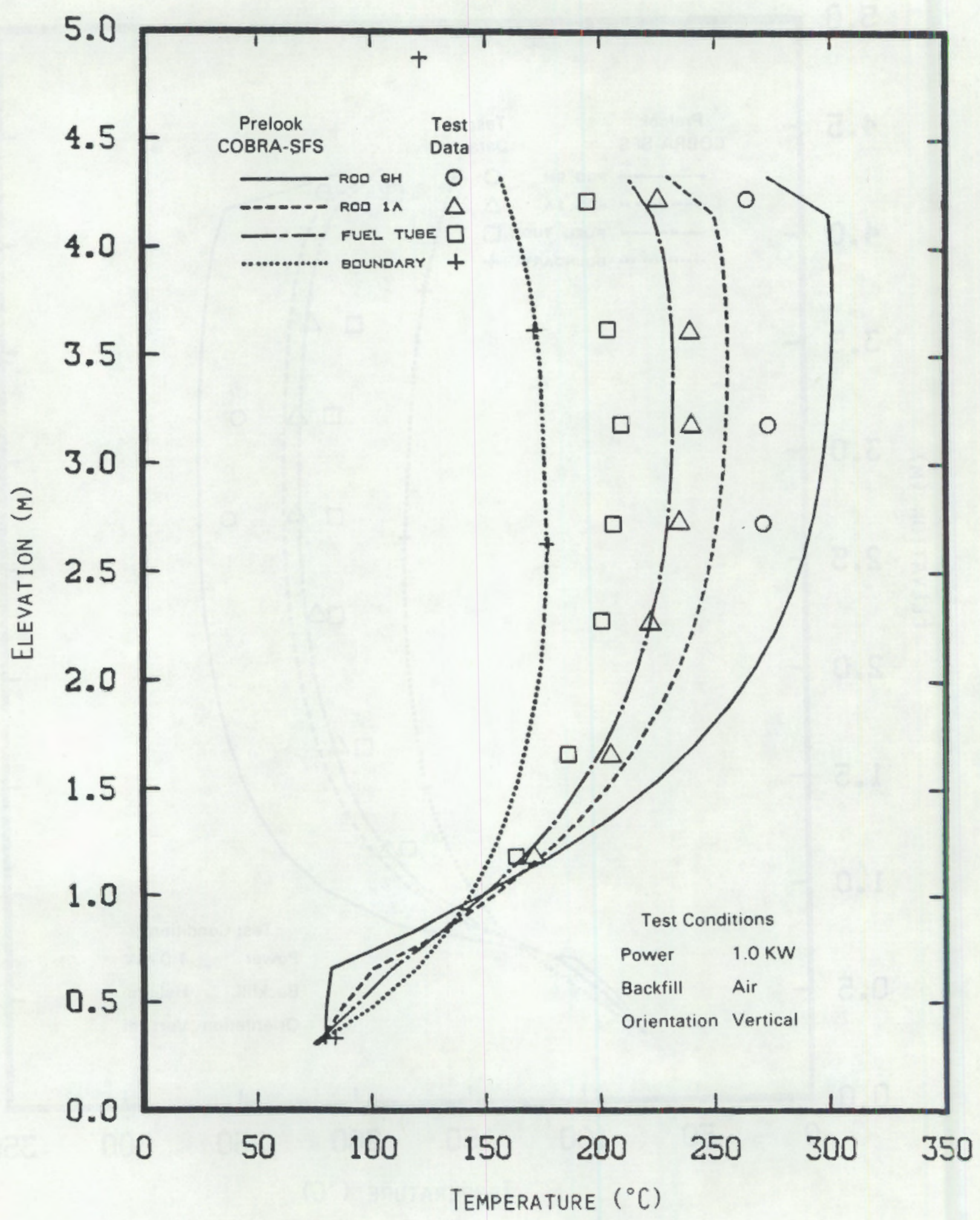




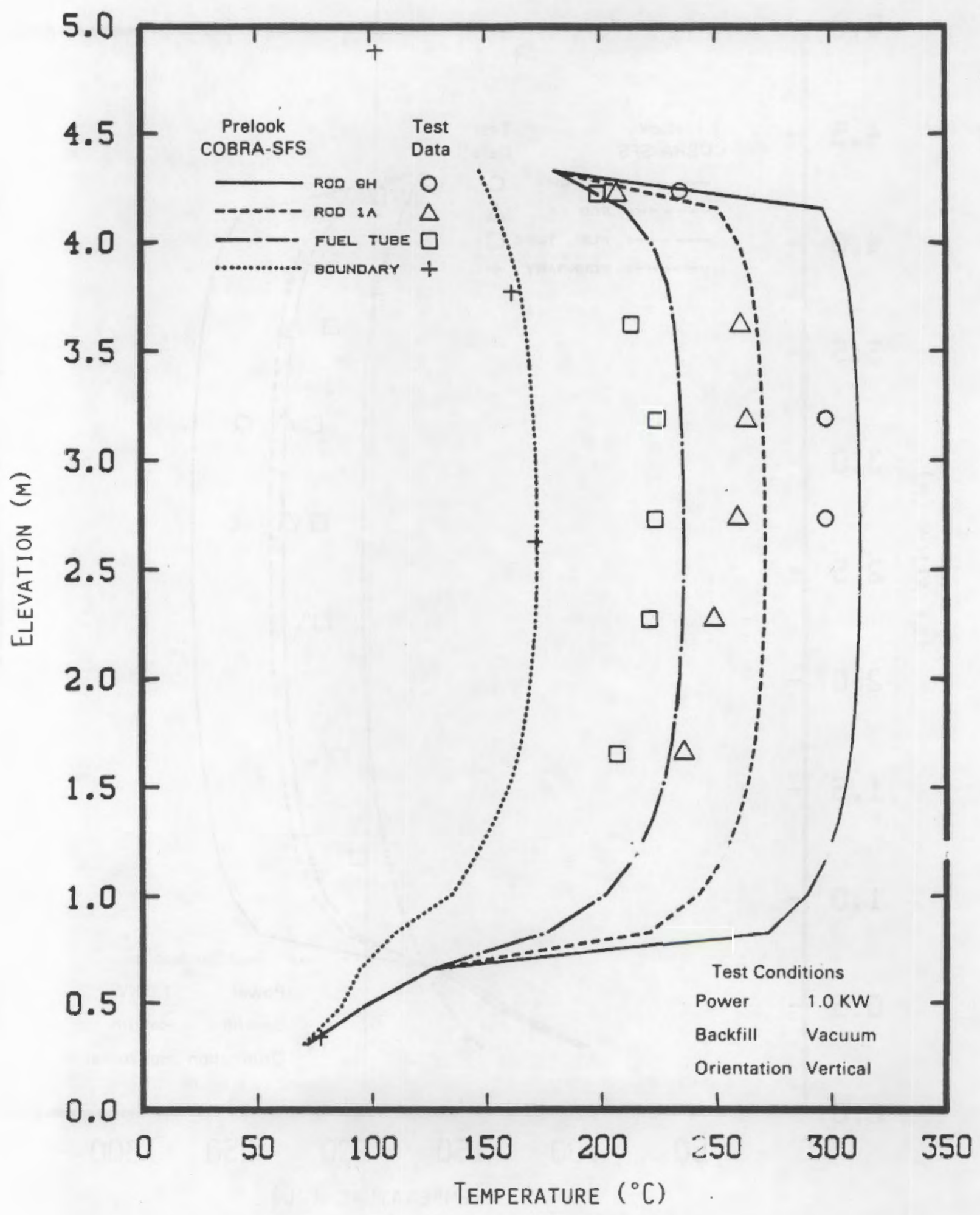

D. 13 


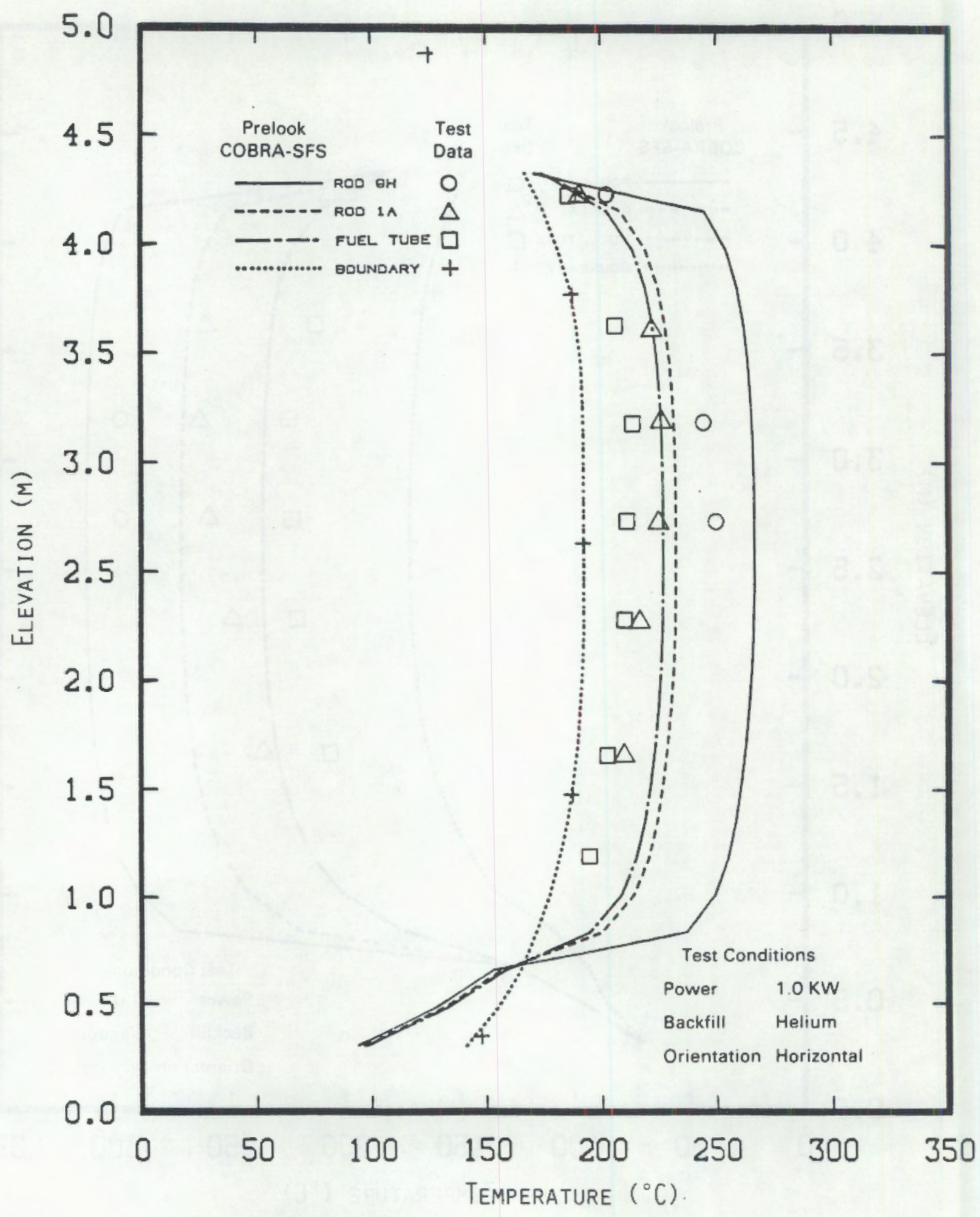

D. 14 


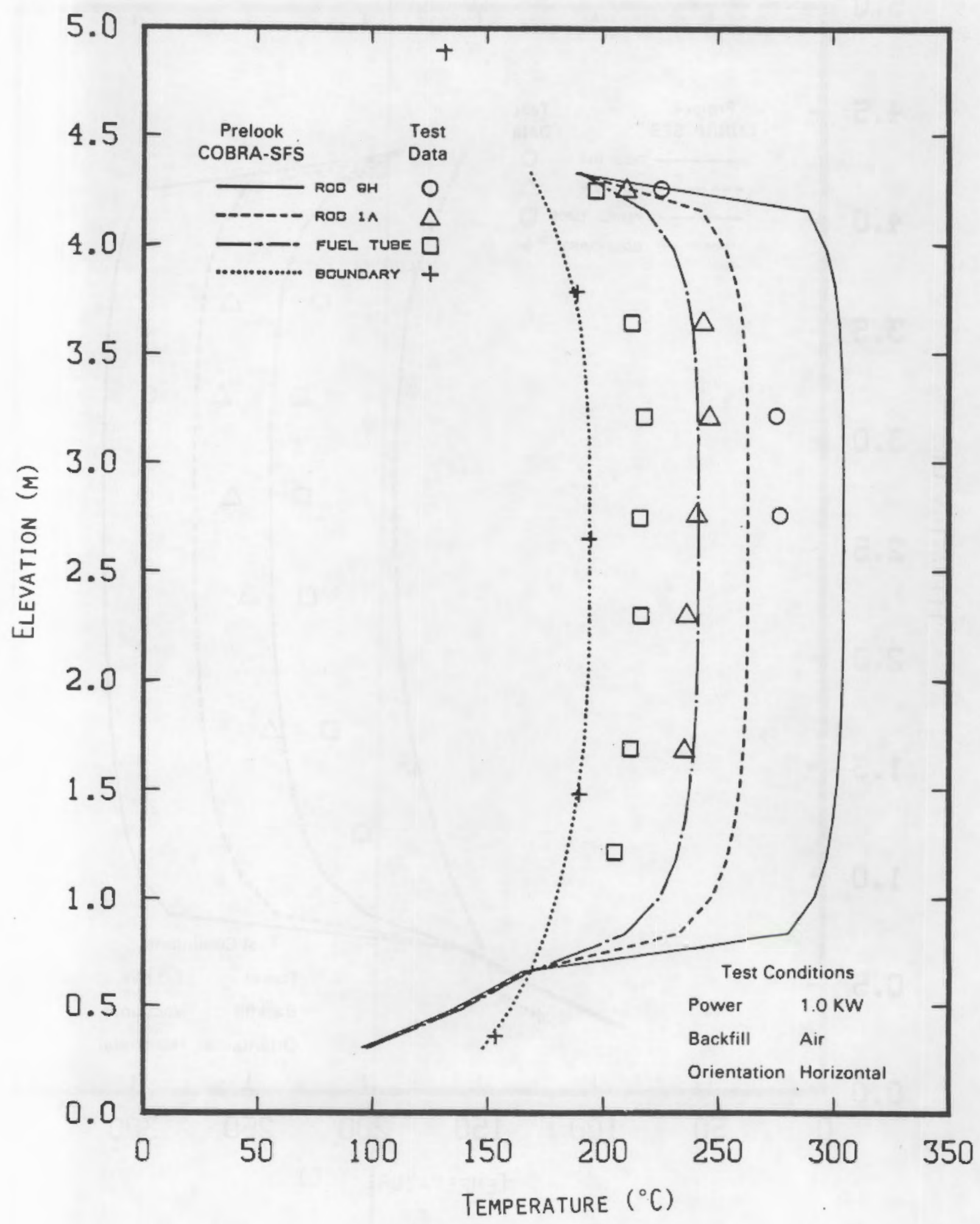

D. 15 


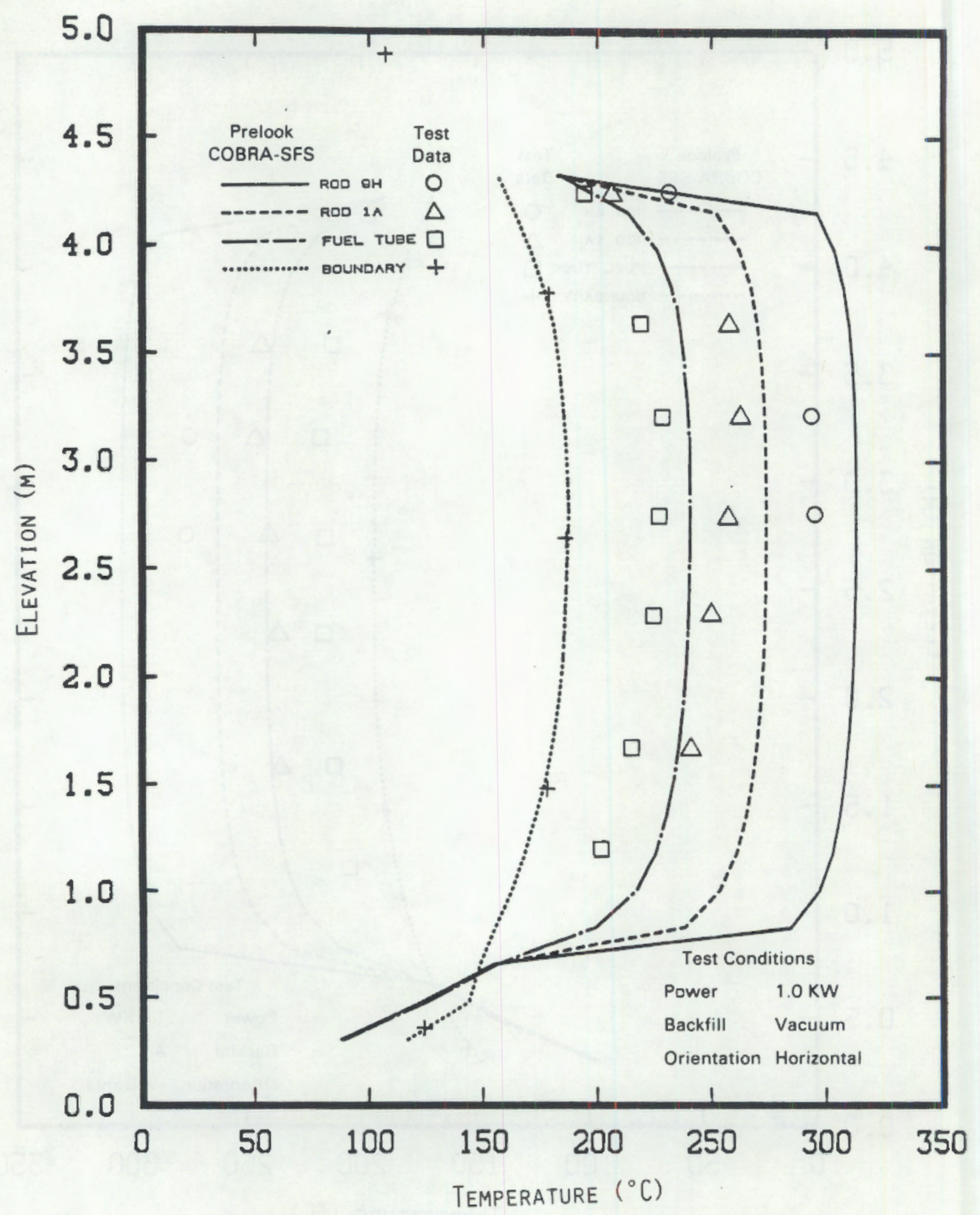




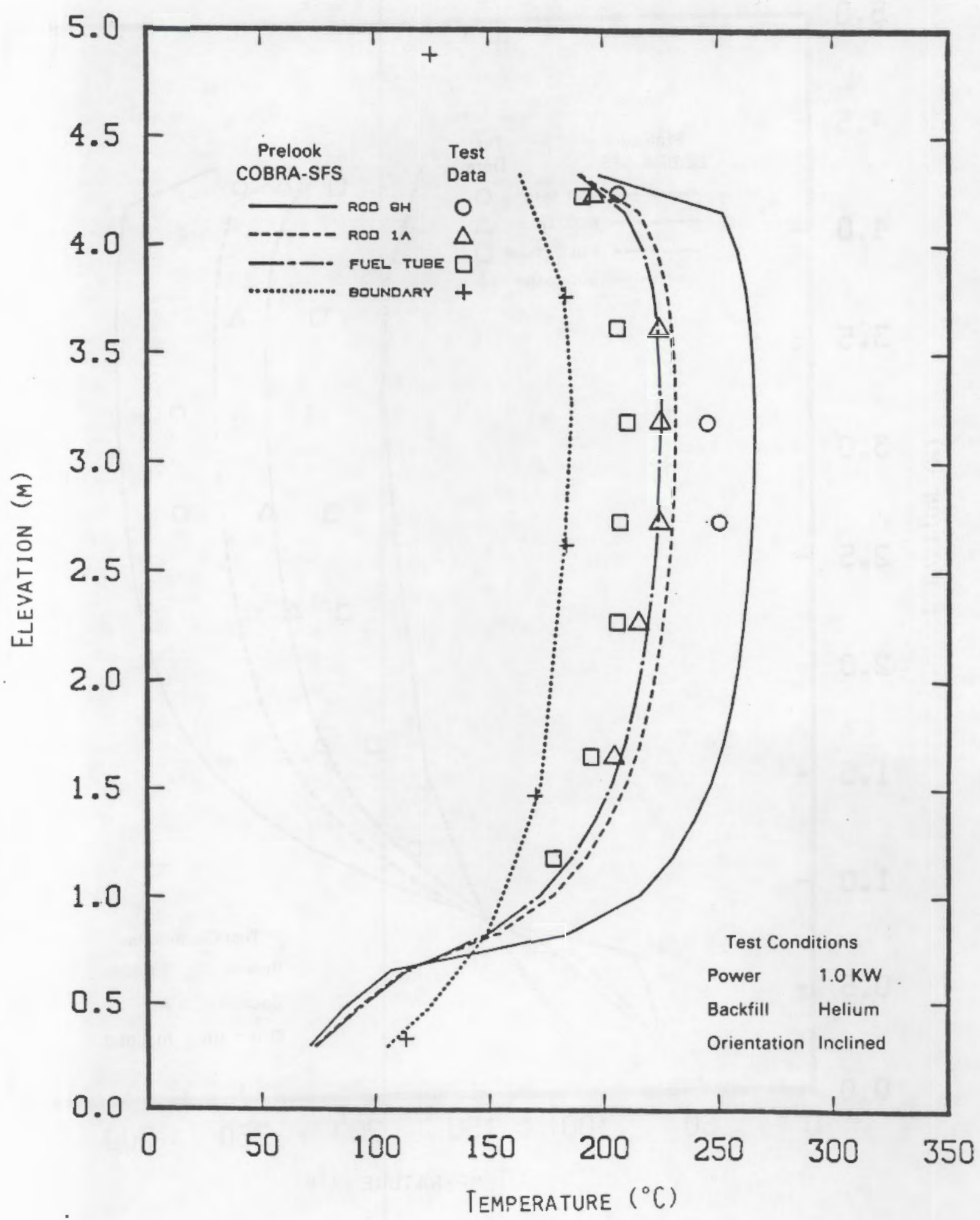

D. 17 


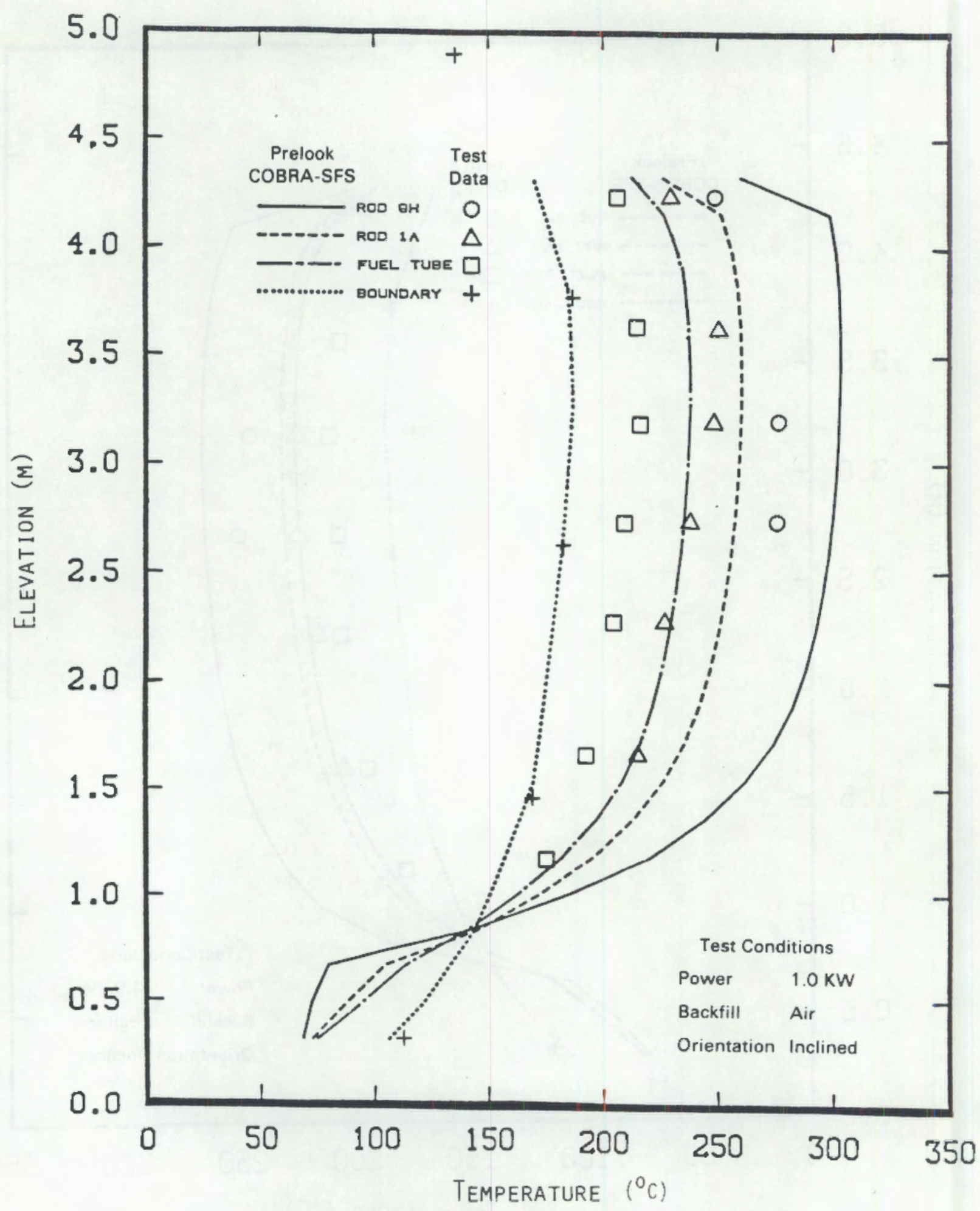




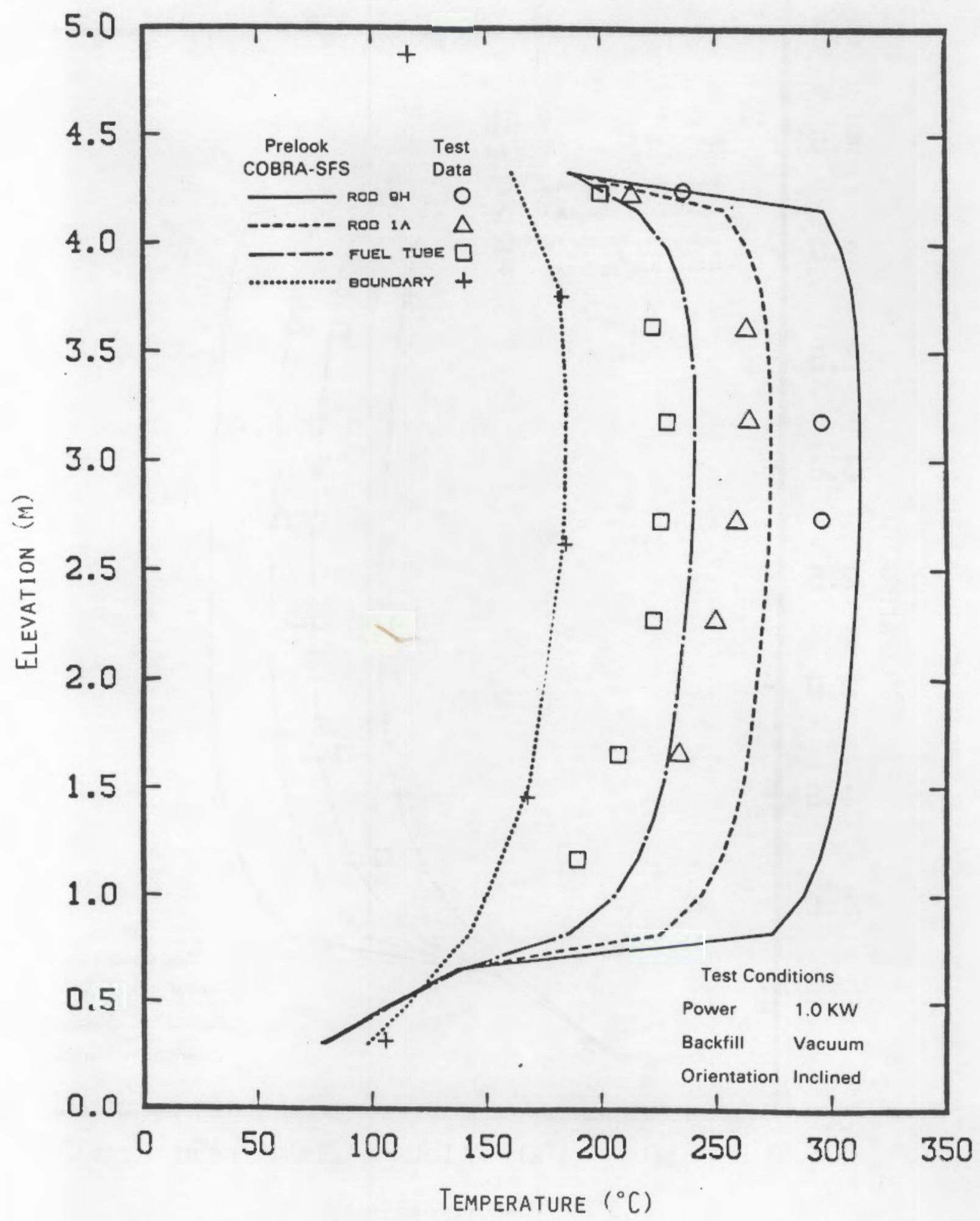

D. 19 


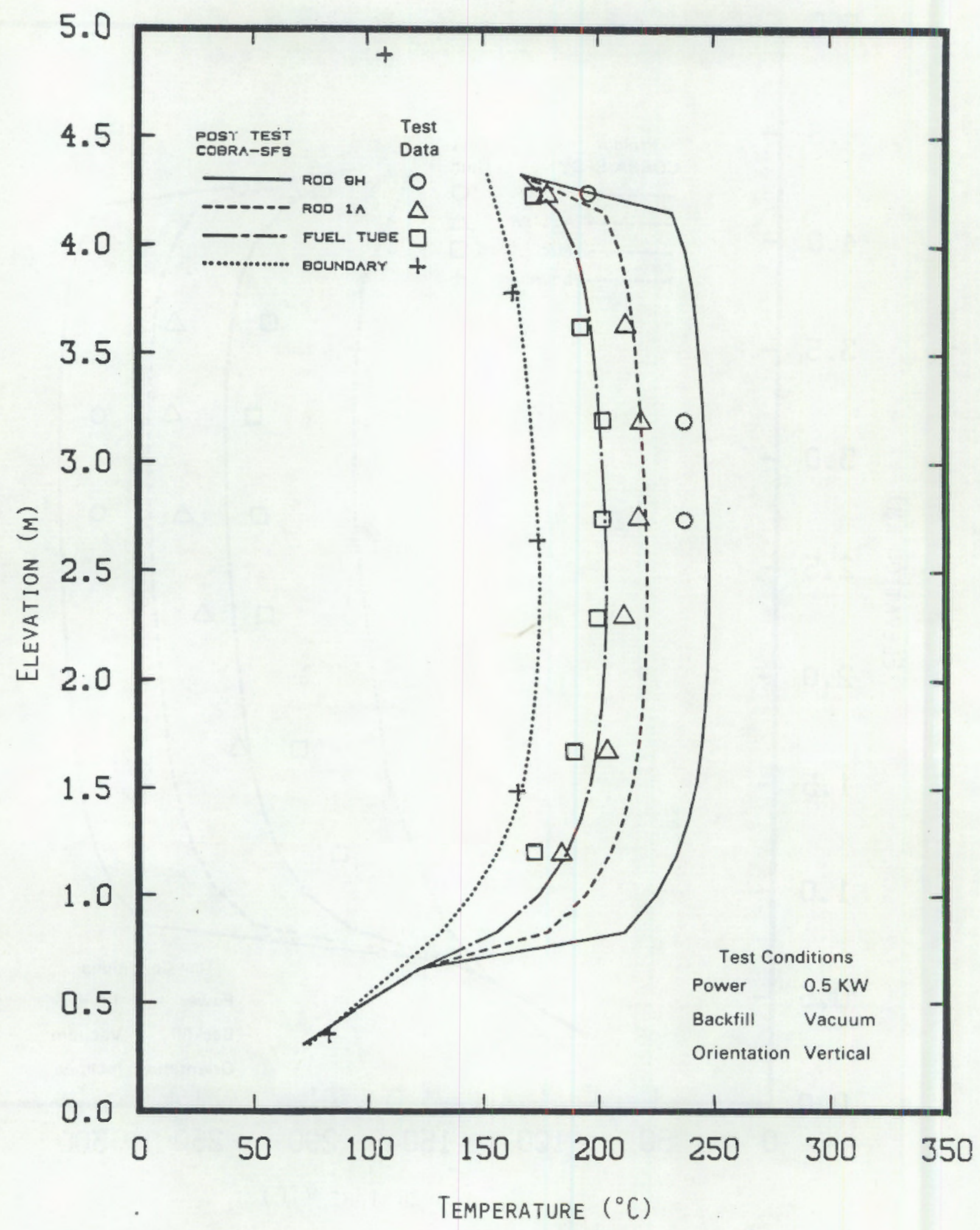

0.20 


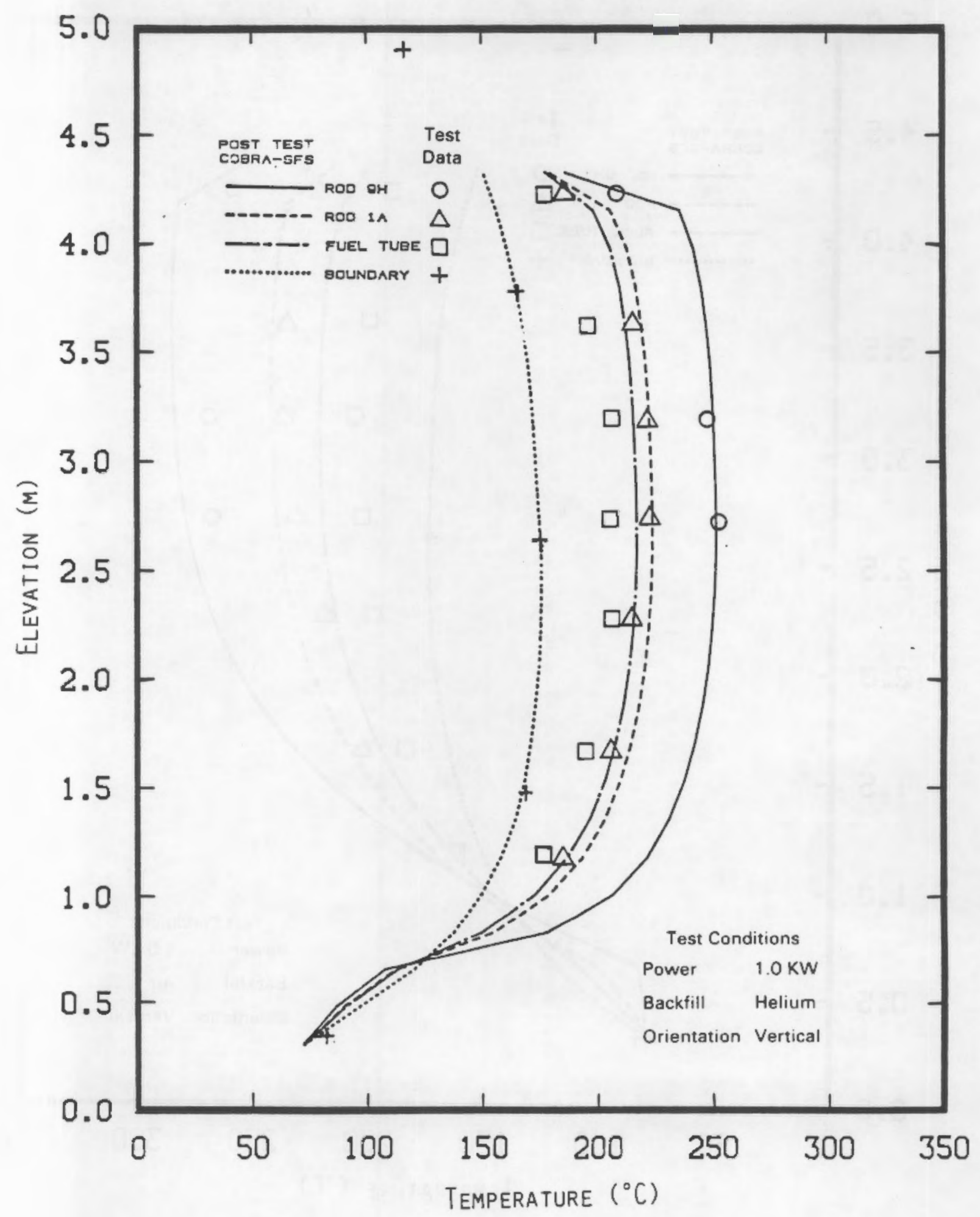

D.2.1 


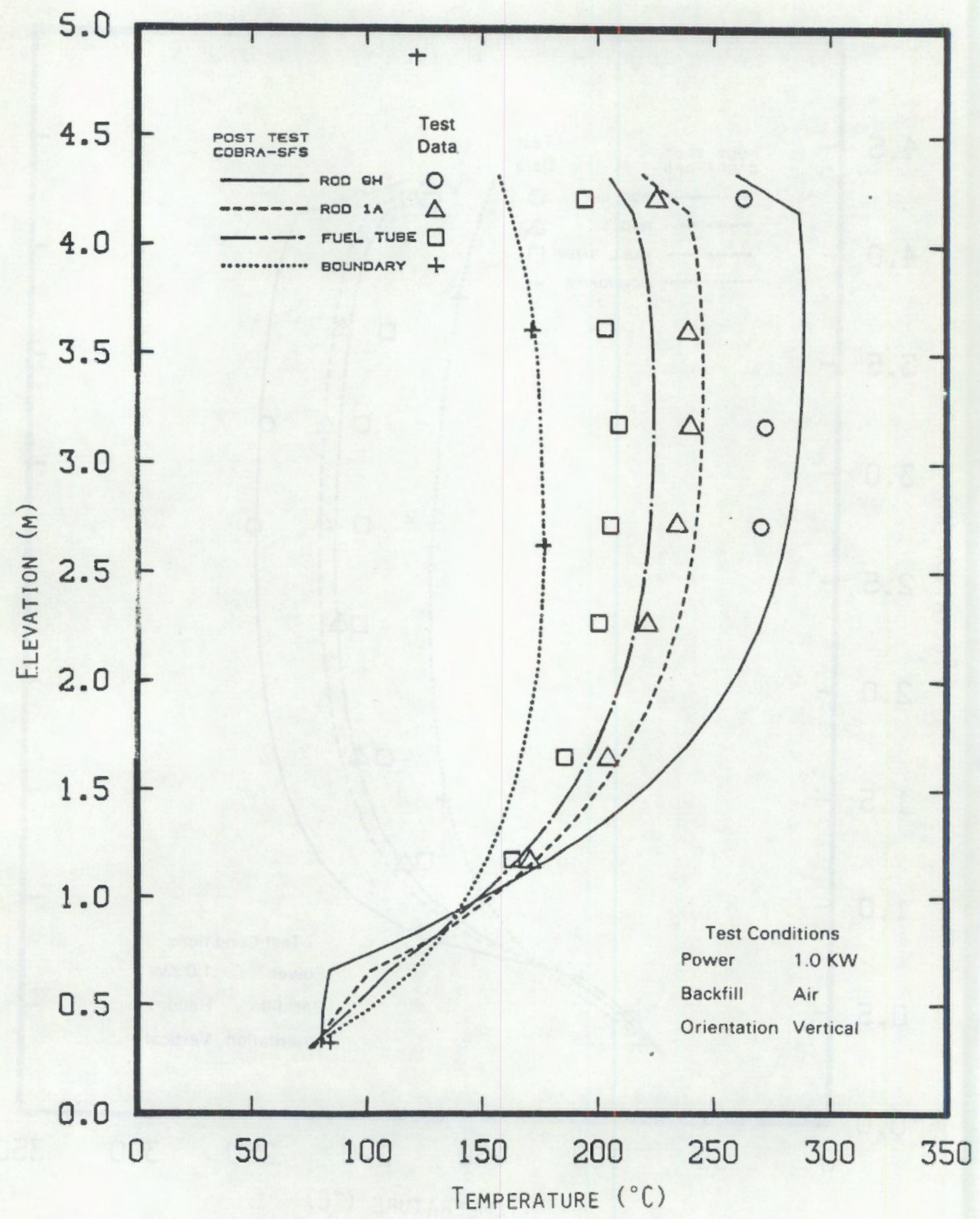

D.22 


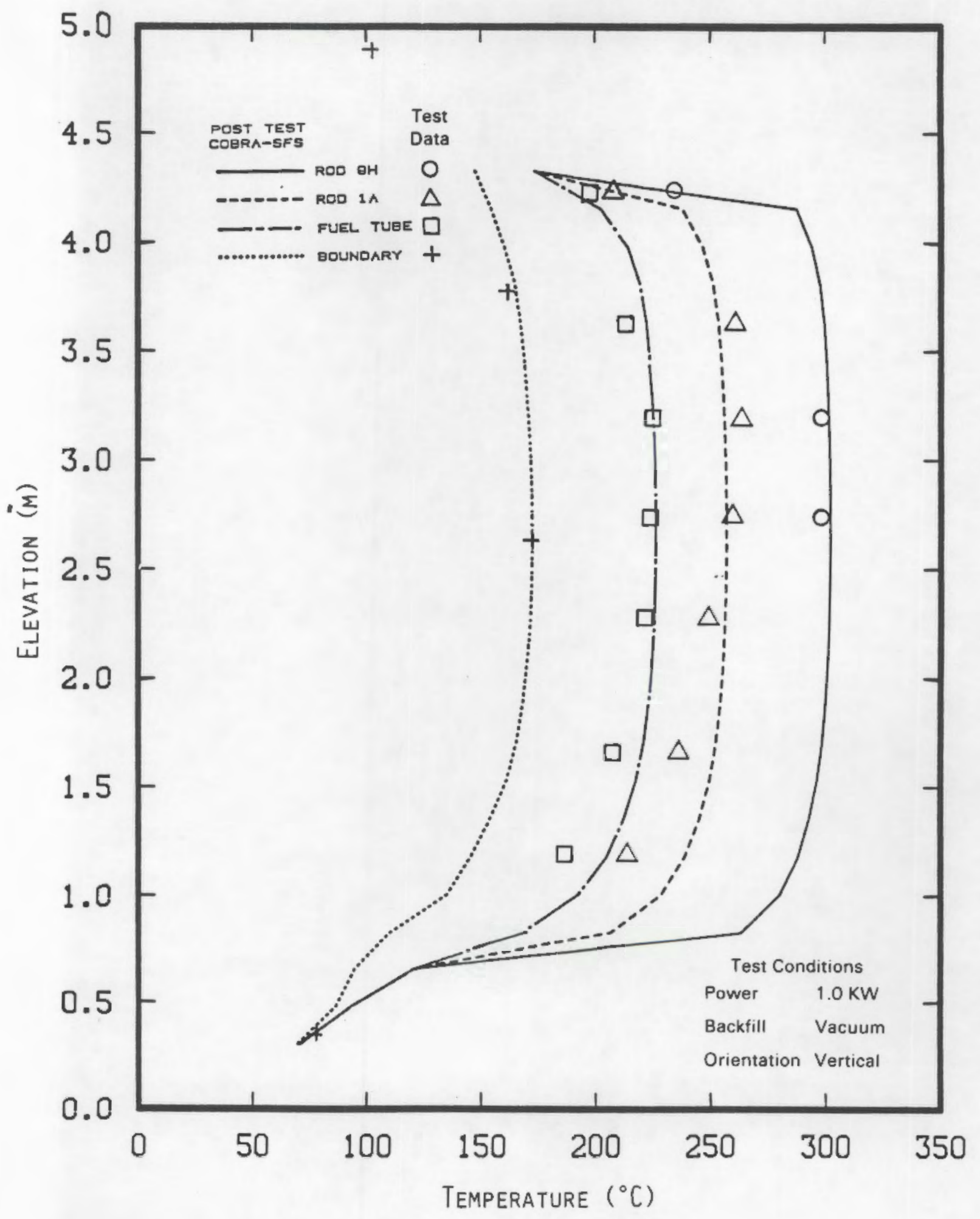





\section{DISTRIBUTION}

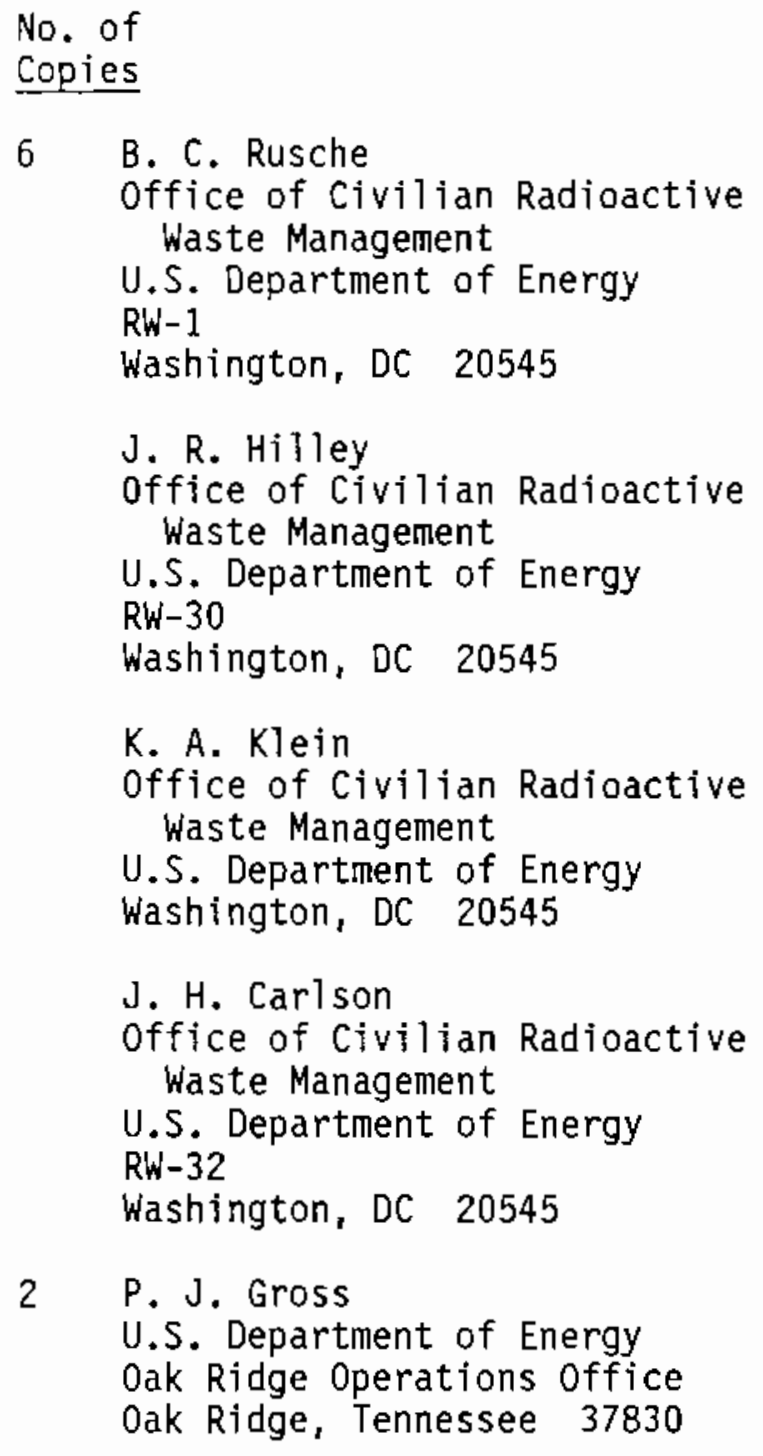

No. of

Copies

30 DOE Technical Information Center

U. W. Voss

Golder Associates

2950 Northup Way

Bellevue, WA 98004

W. D. Woods

The Ralph M. Parsons Company

100 West Walnut St.

Pasadena, CA 91124

\section{ONSITE}

3 DOE Richland Operations office

R. B. Goranson

R. D. Izatt (2)

48 Pacific Northwest Laboratory

J. M. Bates

G. H. Beeman

J. L. Braitman

J. M. Creer

J. F. Fletcher

R. M. Gale

R. J. Hall

R. E. Heineman (5)

D. S. Jackson

W. S. Kelly

D. K. Kreid (5)

M. R. Kreiter

R. C. Liikala

N. J. Lombardo (10) 
P. N. McDuffie

J. L. McEIroy

T. E. Michener

D. F. Newman

D. R. Payson

D. R. Rector

D. J. Silviera

R. I. Smith

C. L. Wheeler

M. K. White

Publishing Coordination (2)

Technical Information (5) 